\title{
VIBRATION STUDY OF THE APS STORAGE RING VACUUM-CHAMBER/GIRDER ASSEMBLY
}

by

\author{
J.A. Jendrzejczyk, M.W. Wambsganss, and R.K. Smith \\ Materials and Components Technology Division \\ Argonne National Laboratory
}

\section{BACKGROUND}

A vibration study of the APS magnet support assemblies was reported by Wambsganss et al. [1]. Test and analytical results were obtained relating to the vibration of the APS storage ring section 3 girder on its jack screw supports, with and without the magnets masses simulated. The study did not include the storage ring vacuum chamber which is supported from the girder by one stiff and two flexible-in-the-axial-direction supports. However, in the study of Ref. 1 attention was called to the possibility of coupling between the girder and vacuum chamber subsystems that could lead to magnification of the girder motion. Since the beam position monitors (BPMs) are attached to the vacuum chamber, motion of the vacuum chamber with respect to the positron beam can compromise the operation of the feedback control system.

\section{OBJECTIVES}

The overall objective of this study is to obtain insights into the dynamic coupling between the storage ring vacuum chamber and girder, and an assessment of the potential for unacceptable vibration amplitudes that would require redesign of the vacuum chamber supports.

Specific objectives include determination of the vibrational characteristics (natural frequencies and modes) of the coupled vacuum-chamber/girder system, measurement of response amplitudes to forced excitation and ambient floor motion, and calculation of magnification factors associated with the various coupled vibration modes. 


\section{DISCLAIMER}

This report was prepared as an account of work sponsored by an agency of the United States Government. Neither the United States Government nor any agency thereof, nor any of their employees, makes any warranty, express or implied, or assumes any legal liability or responsibility for the accuracy, completeness, or usefulness of any information, apparatus, product, or process disclosed, or represents that its use would not infringe privately owned rights. Reference herein to any specific commercial product, process, or service by trade name, tradenark, manufacturer, or otherwise does not necessarily constitute or imply its endorsement, recommendation, or favoring by the United States Government or any agency thereof. The views and opinions of authors expressed herein do not necessarily state or reflect those of the United States Government or any agency thereof. 


\section{APPROACH}

Ideally one would like to have the magnet masses simulated in the test. The magnets represent the majority of the weight of the system and will affect the magnitude and distribution of the overall mass and mass moment of inertia. Additionally, coupling can result from the dynamic subsystems associated with individual magnets on their jack screw supports.

In the study of Ref. 1, the magnets were simulated using concrete shielding blocks. However, with the vacuum chamber in place, it is not possible to simulate the magnets using concrete blocks. Therefore, the subject testing was performed without the magnets simulated. The effects of the magnets on system natural frequencies and modes were determined from the results of Ref. 1. As to be expected, the major effect was to lower the natural frequencies associated with the various modes. The additional mass also provides effective vibration isolation. Therefore, as discussed later, it may be possible to consider the results of subject tests without the magnets to be conservative.

\section{TEST DESCRIPTION}

Test article. The test article is shown schematically in Fig. 1. The girder is a prototype of the storage ring section 3 girder and the vacuum chamber is a prototype of the section 3 vacuum chamber. The jack screw support arrangement is that designated configuration $\mathrm{A}$ in Ref. 1 . The turnbuckles between the girder and jack screw positioning frame were tight, however, the jack screws were not bolted to the floor. The test article was supported off the floor of the Bldg. 362 highbay. Basic dimensions and the location of the girder and vacuum chamber supports relative to the end of the girder are given on Fig. 1.

Excitation methods and response measurements. Two excitation methods were employed: (1) force excitation using an electrodynamic exciter and (2) floor motion in response to ambient ground motion. Tests were performed with the exciter mounted on the girder in the proximity of the middle support for the vacuum chamber and on the floor near the middle jack screw support. Locations of the vibration exciter are given in Fig. 1. Three different excitation levels designated $0.6,0.4$, and 0.1 were applied. Response was measured using accelerometers mounted on the vacuum chamber, girder, and floor. The accelerometer signals were electronically double-integrated to obtain ciisplacements.

Motion of the vacuum chamber is of interest only as it affects the BPMs. There are three BPMs located on the section 3 vacuum chamber. Two are located 
near the end supports for the vacuum chamber. The third is located approximately 16 in. from the middle vacuum chamber support. Of the three, it was felt that the BPM near the middle support is in a location having the greatest potential for magnification of girder motion. Therefore, an accelerometer triplet (chree accelerometers oriented in three orthogonal directions) was position at this BPM location. The three orthogonal orientations of the accelerometer triplet correspond to in-plane (z-direction), out-of-plane (y-direction), and axial ( $x$ direction) motion of the vacuum-chamber/girder system.

The accelerometer triplet mounted on the girder was located over the middle jack screw. The rationale for selecting this location is that floor motion will be transmitted through the jack screws. The accelerometer triplet mounted on the floor was located close to the middle jack screw and the vibration exciter. Again, the rationale is that the floor motion is transmitted to the vacuum chamber and girder through the jack screws.

Test matrix. A series of test was planned and performed to accomplish the objectives of the study. A description of each of the tests in the series follows.

Test 1 -

Excitation: force excitation of girder in three orthogonal directions; three force levels; random motion over frequency range $0-150 \mathrm{~Hz}$

Measurements: displacement of vacuum chamber in three orthogonal directions at middle BPM location; displacement of girder in three orthogonal directions (the accelerometer locations are given in Fig. 1 and are the same for all the tests involving the measurement of vacuum chamber and/or girder motion)

Test 2 -

Excitation: force excitation of floor in three orthogonal directions; three force levels; random motion over frequency range $0-150 \mathrm{~Hz}$

Measurements: displacement of vacuum chamber in three orthogonal directions at middle BPM location; displacement of girder in three orthogonal directions

Test 3 -

Excitation: ambient floor motion in three orthogonal directions 
Measurements: displacement of vacuum chamber in three orthogonal directions at middle BPM location; displacement of girder in three orthogonal directions

Test 4 -

Excitation: force excitation of floor in three orthogonal directions; three force levels; random motion over frequency range $0-150 \mathrm{~Hz}$

Measurements: displacement of vacuum chamber in three orthogonal directions at middle BPM location; displacement of floor in three orthogonal directions (the accelerometer location on the floor is given in Fig. 1 and is the same for all floor motion measurements)

Test 5 -

Excitation: ambient floor motion in three orthogonal directions

Measurements: displacement of vacuum chamber in three orthogonal directions at middle BPM location; displacement of floor in three orthogonal directions

Test 6 -

Excitation: force excitation of girder in three orthogonal direction; sinusoidal excitation at frequencies corresponding to identified natural frequencies of the system

Measurements: displacement of vacuum chamber in three orthogonal directions at middle BPM location; displacement of girder in three orthogonal directions

Test 7 -

Excitation: force excitation of central power supply chassis in three orthogonal direction; three force levels; random motion over frequency range $0-150 \mathrm{~Hz}$

Measurements: displacement of vacuum chamber in three orthogonal directions at middle BPM location; displacement of girder in three orthogonal directions 


\section{RESULTS AND DISCUSSION}

Dynamic characteristics. The test data were analyzed with the objectives of determining the coupled mode frequencies of the vacuum-chamber/girder system and, as possible, identifying the associated mode shapes. Towards this end, (a) power spectral density plots (Appendix A) and related response data (Appendix B) from Tests 1, 3-5, and 7 were studied and dominant frequency peaks were identified, and (b) a "sine sweep" was performed to identify response peaks, as well as related mode shapes from phase information. In the performance of the sine sweep, natural frequencies are identified from response peaks, the exciter frequency is fixed at an identified system frequency, and a hand-held accelerometer is moved around on the structure while monitoring and recording in a notebook the changes in phase relative to a fixed accelerometer.

The natural frequencies determined from analysis of the power spectral density curves are given in Tables 1 and 2 . Table 1 was developed from information obtained from the power spectral density data; in Table 1, the number listed corresponds to the number of the test in which a particular frequency was dominant (Test 2 data was not reduced). In particular, the frequency peaks and the particular tests in which they were evidenced for each combination of excitation direction, measurement direction, and accelerometer location, are documented. As expected, certain modes are more easily excited than others and, consequently, not all modes are excited for each excitation-measurement combination. Table 2 presents natural frequency data obtained from power spectral density data and provides comments relative to the various modes as determined, among other ways, from the sine sweep tests.

As readily observed from the results given in Tables 1 and 2 , the vacuumchamber/girder/power-supply-chassis system has a large number of relatively complex modes in the frequency range $5-130 \mathrm{~Hz}$.

In an attempt to gain further insights into the dynamic behavior of the coupled vacuum-chamber/girder system, in Table 3 the maximum values of the measured RMS displacement for each mode and each of the various measurement orientations/locations are listed as obtained from Test 1 data. As expected, in all cases the maximum value occurs for the maximum excitation level of 0.6 . The excitation direction associated with each maximum value is also given and the maximum response among the maximums for a given mode are also highlighted.

From the results in Table 3 one can conclude that the 8.8 and $9.5 \mathrm{~Hz}$ modes are dominantly out-of-plane (y-direction) modes; the $12.9,15.8$, and $23.7 \mathrm{~Hz}$ modes are dominantly axial (x-direction) modes; and the 45.9, 108.1, 116.9, and $126 \mathrm{~Hz}$. 
modes are dominantly in-plane (z-direction) modes. These results are in agreement with the observations made on Table 2. One can also observe from the relative magnitudes of the RMS displacements that the lower modes are more readily excited to a higher value of displacement than the higher modes (recall that the excitation level is the same for all cases); this also is as expected.

With regard to coupling between the vacuum chamber and girder, the strongest coupling occurred at frequencies of 12.9 and $23.7 \mathrm{~Hz}$ in the axial (x) direction. As illustrated in Fig. 2, the $12.9 \mathrm{~Hz}$ mode is predominantly an in-phase mode, while the $23.7 \mathrm{~Hz}$ mode is predominantly an out-of-phase mode.

Magnification factors. The vacuum chamber is coupled to the girder through its three supports. A primary motivation for the study was provided by the concern over possible magnification of girder motion resulting in large amplitude response of the vacuum chamber. To investigate this, transfer functions were calculated corresponding to the various modes identified from the PSD data. In particular, transfer functions between two measurement points were calculating by dividing RMS amplitude at one point (the "output" - typically vacuum chamber or girder motion) by that at the other (the "input" - typically girder or floor motion). In this way, transfer functions were calculated for each test run and measurement orientation. The results, together with the measured RMS displacement values, are given in Appendix B for the various modes of Tests 1 and 4.

It should be noted that if the system behaves linearly, as one might expect for the very small motions involved, the transfer function (magnification factor) between a given measurement pair should be the same regardless of the excitation direction and excitation level. For the most part, as shown by the results in Appendix $B$, this is the case as the calculated transfer functions are essentially constant for a given measurement pair. This result is important, not only because it confirms the linearity of the system, but also because it provides confidence in the data and the accuracy of the displacement measurements. There are a few cases in which deviation from a constant value is significant. In many cases this can be attributed to the small amplitude levels being measured and inaccuracies that are in inherent in the basic measurement and compounded in the division of one small number by another.

The calculated transfer functions were averaged for each measurement pair and, in Tables 4 and 5, the averaged transfer function (i.e., magnification factor) between the girder and vacuum chamber (Table 3) and floor and vacuum chamber (Table 5) are summarized. In consideration of the data presented in Tables 4 and 5 , the primary interest is in identifying magnification factors greater than one. 
When analyzing the results given in Table 4, it must be remembered that the transfer function (magnification factor) is between two points, in this case the girder motion at the base of the middle vacuum chamber support and the motion of the vacuum chamber at the middle BPM position. A transfer function between any other two points will obviously be different (greater or less) than the reported transfer function. Only a few magnification factors greater than one were measured and of those none would be termed "high" (say, greater than 10). Several of the magnification factors are in the neighborhood of one, implying that the vacuum chamber is effectively moving with the girder as one would expect for many of the "girder-dominated" rigid body modes.

From the results given in Table 5, one observes that there is no magnification of floor motion at the middle BPM position on the vacuum chamber. Some magnification factors are close to one, implying that the vacuum chamber is following the motion of the floor. However, it is significant that the majority of the magnification factors are significantly less than one, suggesting that the system acts as a filter effectively attenuating floor motion.

Response amplitudes. While knowledge of the system's natural frequencies, modes, and transfer functions are important in understanding the overall dynamic behavior of the system, the bottom line is whether or not the vibration of the magnets and/or vacuum chamber exceed the established vibration criteria. Recognizing that the subject test article is not prototypic, since the magnets and bellows at the ends of the vacuum chamber are not included, and also that the site is not prototypic, measured response amplitudes can, nevertheless, provide useful insights.

In Tests 2 and 4 , the floor was force excited with the electrodynamic shaker at three excitation levels, and in Tests 3 and 5, response to ambient floor motion was measured. Wideband $(5-250 \mathrm{~Hz})$ RMS displacement amplitudes from Test 4 (floor and vacuum chamber motion) are given in Table 6 . It can readily be observed that the measured response does not vary significantly with excitation level or direction, indicating that the shaker is not sufficiently powerful enough to excite the floor slab. As a consequence, the measured response can be assumed to be equivalent to the ambient floor excitation. Since the response is independent of excitation level and direction, as the vibration exciter is not effective, an averaged value was computed for each measurement location/direction and reported in Table 6.

In Table 7, RMS displacements (girder and vacuum chamber motion) in response to ambient floor motion in Test 3 are given for two different time periods and three different bandwidths: $5-250 \mathrm{~Hz}, 10-250 \mathrm{~Hz}$, and $15-250 \mathrm{~Hz}$. The different bandwidths were selected because the vibration criteria have a lower frequency 
bound (in the $10-20 \mathrm{~Hz}$ range) dependent on the dynamic characteristics of the positron beam feedback control system. Similar data are given in Table 8 from Test 5 (floor and vacuum chamber motion), but for only one time period.

Several observations can be made from the data given in Tables 6 -8:

- The RMS displacement varies with the time of measurement. As shown on Table 5, 4:30 pm is a "noisier" time than 9:30 am. It can be speculated that this may be due to the increase in traffic that occurs at the $4: 30 \mathrm{pm}$ closing time for a particular group of employees.

- Overall girder or floor motion is not magnified when transmitted to the vacuum chamber. Vacuum chamber motion in all cases is consistently less than girder or floor motion.

- The majority of the energy is in the low frequency range. As the lower bound on the analysis frequency range is increased from 5 to 10 to $15 \mathrm{~Hz}$, the overall RMS response amplitudes decrease.

- The measured values of floor motion are of the same order of magnitude as the measurements made in Bldg. 335 and at the IPNS facility. However, a direct comparison with the measurements made in Bldg. 335 [1] shows that the ambient floor motion in Bldg. 362 is higher by a factor of about 2, suggesting a noisier site.

- The RMS displacements measured on the girder and vacuum chamber are on the order of the APS storage ring criteria for allowable vibration of the quadrupole magnets as given in Table 9.

Transients. In the course of performing the steady-state measurements it was observed from monitoring the oscilloscope screen with displacement time signals displayed that a transient was experienced whenever a vehicle would drive over the railroad tracks and potholes in the road behind the Bldg. 362 highbay. Typical time histories illustrating this type of transient response are given in Fig. 3; additional examples are given in Appendix C. In general, a given transient is seen at all three measurement stations (floor, girder, and vacuum chamber).

As can be determined from Fig. 3, peak-to-peak amplitudes as high as 1.5 $\mu \mathrm{m}$ were measured on the girder and vacuum chamber as the result of transients associated with vehicular traffic. This re-enforces the importance of maintaining smooth road surfaces in the vicinity of the APS experimental hall and, as necessary, restricting vehicular traffic. 


\section{SUIMMARY AND CONCLUDING REMARKS}

A vibration study of the APS storage ring vacuum-chamber/support assembly was performed. The objectives of the study were to obtain insights into the dynamic coupling between the vacuum chamber and the girder on which it is mounted, and to assess the potential for unacceptable vibration amplitudes that would require redesign of the vacuum chamber supports.

While the vacuum chamber, ion pump, and girder were prototypic in the tests, it is significant that the magnets and the bellows-attachments at the ends of the vacuum chamber were not included in the simulation, also the girder supports were not bolted to the floor. Nevertheless, with these facts recognized, it is felt that the test program provided the necessary data to meet the stated objectives. From a structural dynamics standpoint the system is very complex, with the study further made difficult by the massiveness of the components, coupled with the very small vibration levels being measured (on the order of tenths of a micron or less).

The test measurements were made with pairs of accelerometer triplets, each triplet oriented to measure response in three orthogonal directions corresponding to the out-of-plane (y), in-plane (z), and axial (x) directions relative to the vacuum-chamber/girder assembly. For all test runs, an accelerometer triplet was mounted on the vacuum chamber at the location of the middle BPM; the other accelerometer triplet was either mounted on top of the girder in the plane of the middle vacuum chamber support or on the floor near the middle girder jack screw support. When utilized, forced excitation was provided by an electrodynamic exciter.

The vibrational characteristics (coupled modes and frequencies) were determined from measured response to both forced excitation of the girder and ambient floor motion. Magnification factors between vacuum chamber and girder, and between vacuum chamber and floor, motions were calculated from measured response at identified system natural frequencies. Response of the vacuum chamber and girder to ambient floor motion was also measured along with floor motion.

A relatively large number of vibration modes were identified in the frequer.cy range 0 to $150 \mathrm{~Hz}$. Several of the low frequency modes (e.g., 8.8 and 9.5 $\mathrm{Hz}$ ) were associated with rigid body motion of the girder. Two coupled vacuumchamber/girder axial modes were determined: an in-phase mode at $12.9 \mathrm{~Hz}$ and an out-of-phase mode at $23.7 \mathrm{~Hz}$. In-plane and out-of-plane bending modes of the vacuum chamber occurred at frequencies of $45.9 \mathrm{~Hz}$ and $126 \mathrm{~Hz}$, respectively. Coupling with the ion pump resulted in modes at frequencies of 86.7 and $108.1 \mathrm{~Hz}$. 
The first in-plane bending mode of the girder occurred at $116.9 \mathrm{~Hz}$. Finally, several modes $(8.1,10.0$, and $17.8 \mathrm{~Hz}$ ) were associated with coupling with the power supply chassis. Among other things, the frequencies of the modes are of interest relative to the upper bound on the frequency range over which the feedback control system is operable; this upper-bound frequency is in the range of 10 to $20 \mathrm{~Hz}$.

Magnification factors between two points on the assembly were calculated for each of the dominant modes by dividing the RMS response amplitude at one measurement point (the "output" - typically vacuum chamber or girder motion) by that at the othor (the "input" - typically girder or floor motion). The fact that, for the most pari, the magnification factors were constant and independent of excitation level and direction confirms that the system is behaving linearly. Only a few of the magnification factors based on girder motion were greater than one and of those none would be termed high. Based on floor motion the majority of the magnification factors were significantly less than one, implying that the system acts as a filter effectively attenuating floor motion.

RMS displacement response to ambient floor motion was measured and reported for different time periods and three different frequency bandwidths. Results showed that ambient floor motion varies with the time of day at which measurements are made, and that the girder system responds to transients associated with vehicles driving over the railroad tracks behind the Bldg. 362 high bay. The dominant modes excited by the ambient floor motion were the 8.8 and $9.5 \mathrm{~Hz}$ modes which correspond to the out-of-plane rigid body modes of the girder. The RMS levels measured were of the same order of magnitude as similar measurements made at the IPNS facility and in Bldg. 335. Relative to the APS storage ring vibration criteria, the measured RMS displacements of the girder and vacuum chamber were, dependent on the frequency bandwidth over which the data were analyzed, very close to, or in excess of, the allowable limits for random excitation. However, one can argue that the subject tests are conservative for the following reasons: (1) The APS site will be quieter from the standpoint of ground motion; (2) The storage ring basemat (foundation) will be thicker and more massive than the Bldg. 362 high bay floor; and (3) The bellows attachment to adjacent vacuum chambers will contribute stiffness and damping to the vacuum chamber subsystem.

In conclusion, the strongest coupling between the vacuum chamber and girder subsystems occurred at frequencies of 12.9 and $23.7 \mathrm{~Hz}$ in the axial direction (positron beam direction). No large magnification factors were measured; if anything, floor and girder motion tended to be attenuated in transmission to the vacuum chamber. Based on these results there appears to be no need to redesign the vacuum chamber supports. Dependent on the frequency 
range chosen for analysis, RMS motion of the system in response to ambient floor motion was found to be close to, or to exceed, the vibration criteria based on the assumption of random vibration. However, it can be argued that the subject tests were conservative. If ic is felt to be necessary to reduce response to floor motion, consideration should be given to increasing the frequency of the out-of-plane rigid body modes at which the system tends to respond at. This can be accomplished by increasing the stiffness (or possibly reconfiguring the layout of) the girder jack screw supports. Measured transients, in response to vehicular traffic, reenforced the importance of maintaining smooth road surfaces in the vicinity of the APS experimental hall and, as necessary, restricting the speed of vehicular traffic.

\section{REFERENCES}

1. Wambsganss, M. W., Jendrzejczyk, J. A., and Chen, S. S., "Vibration Study of the APS Magnet Support Assemblies," APS/IN/VIB/90-3, November 1990. 


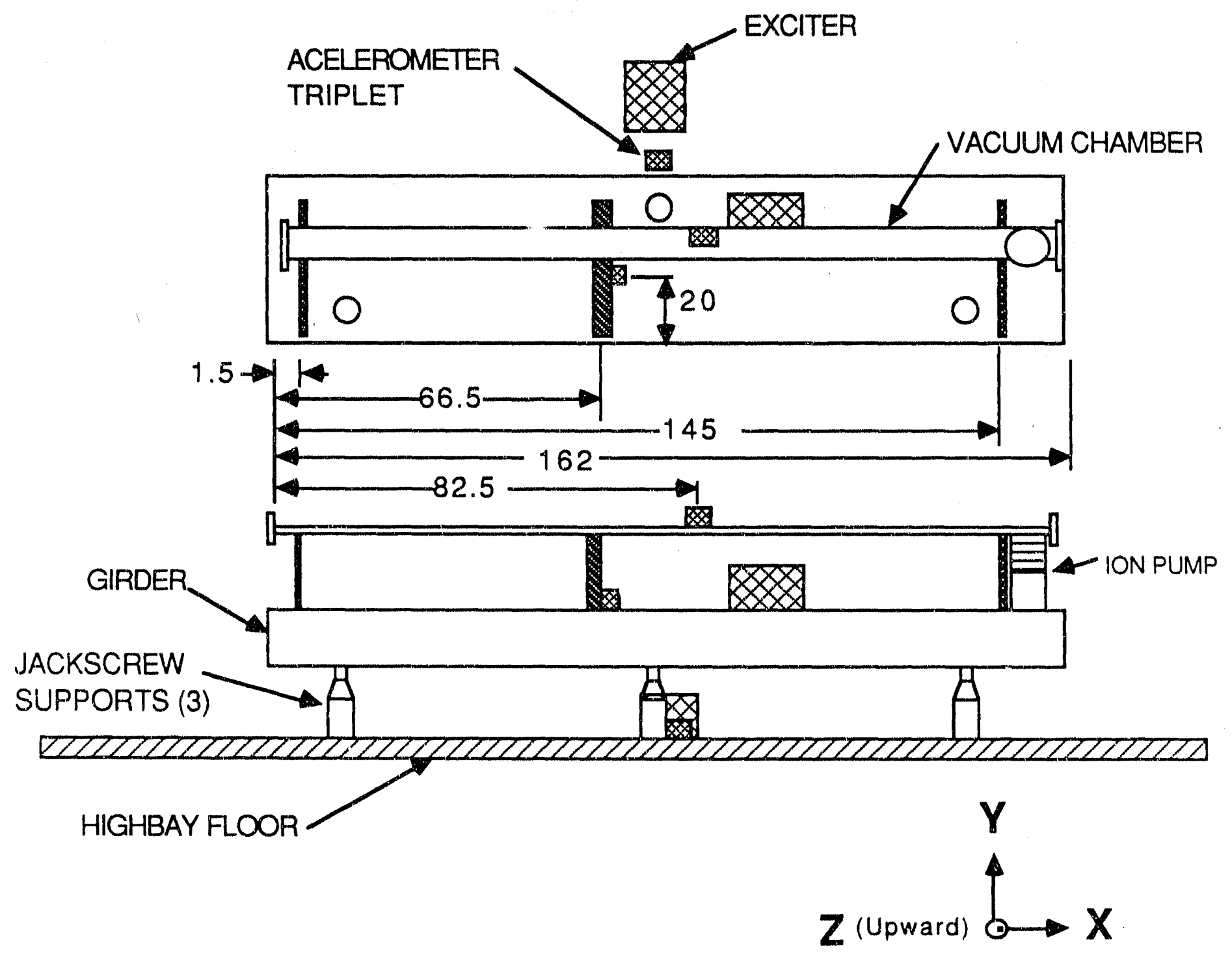

DIRECTIONS

(Plan View)

Fig 1. Schematic of test article(girder and vacuum chamber) showing locations of accelerometers and vibration exciter 


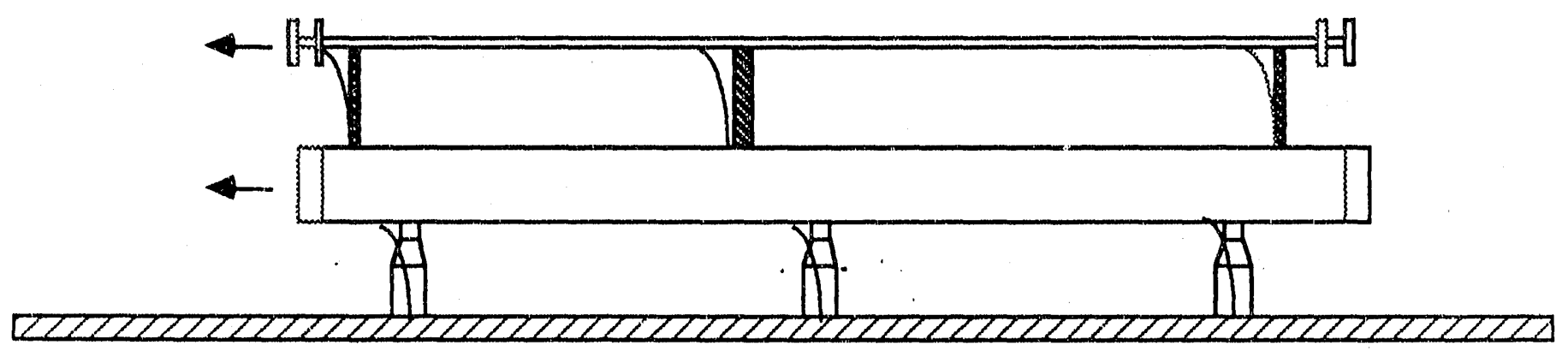

(a) in-phase mode, $f=12.9 \mathrm{~Hz}$

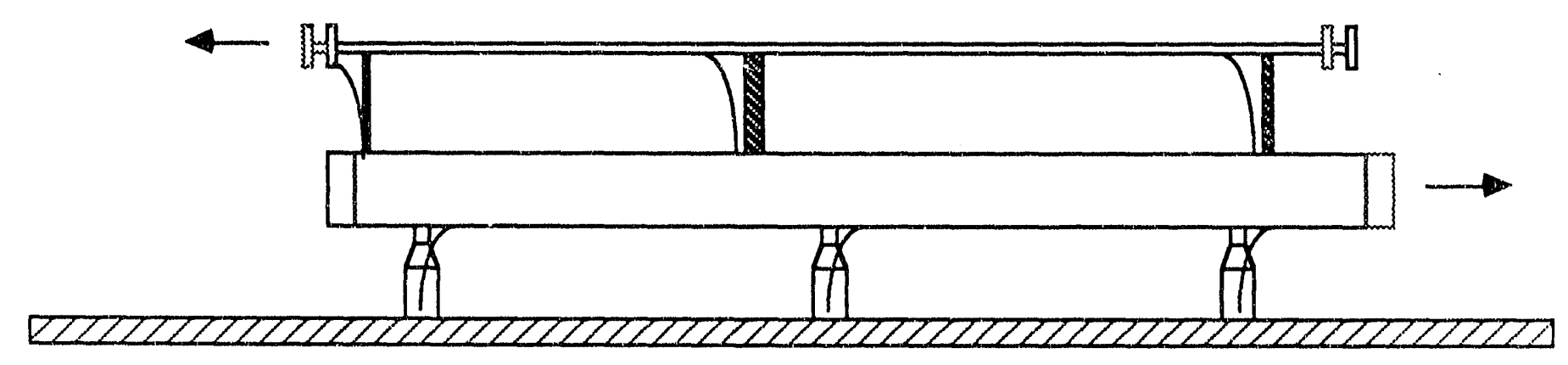

(b) out-of-phase mode, $f=23.7 \mathrm{~Hz}$

Fig. 2. Coupled modes of vacuum-chamber/girder system 

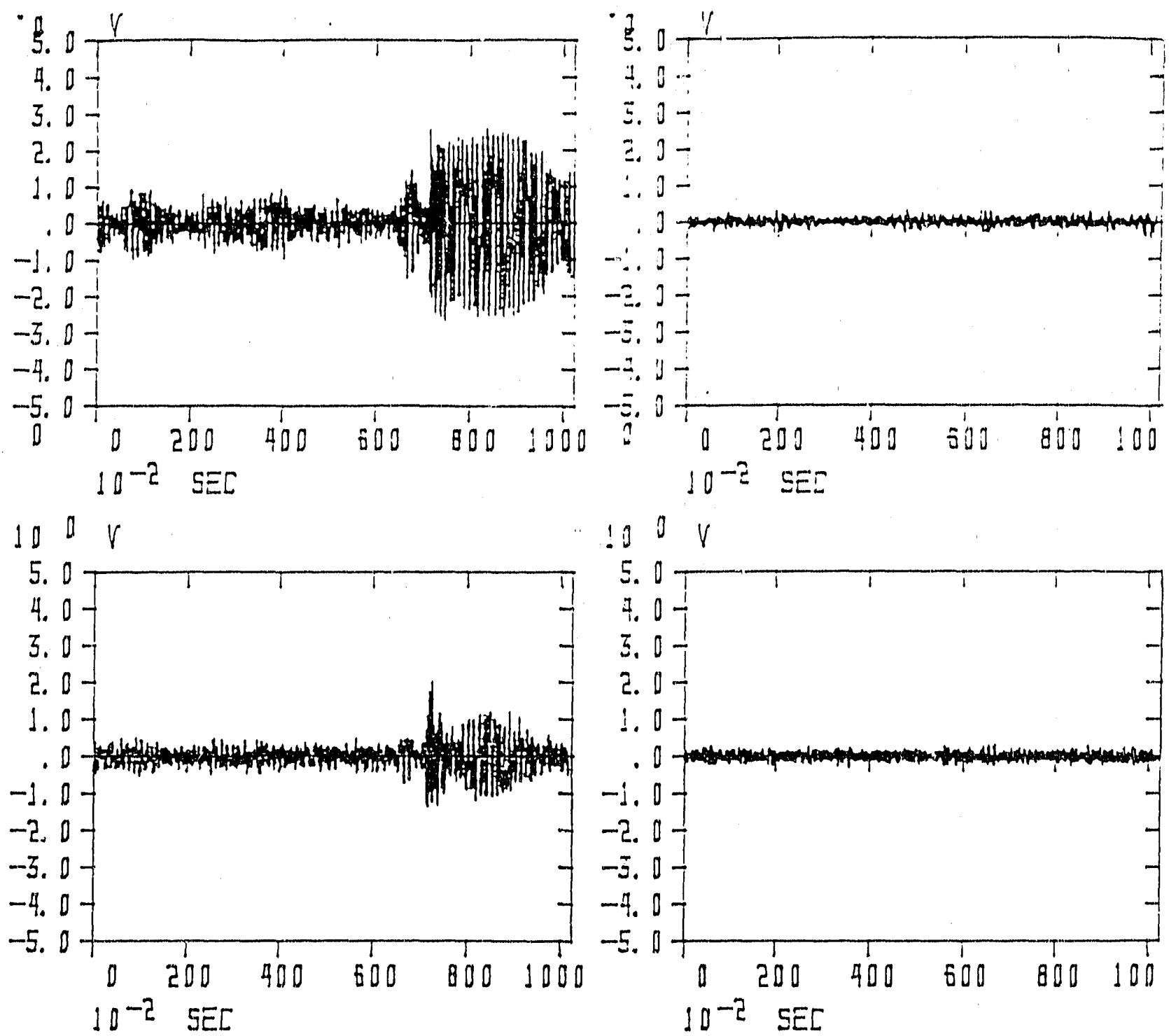

FLOOR

Y Measurement Direction

Primary Resp. Freq. $=9.5 \mathrm{~Hz}$

VACUUM CHAMEER

$Y$ Measurement Direcilon

Primary Resp. Freq. $=$ none

FLOOR

VACUUM CHAMBER

$Z$ Measurement Direction

$Z$ Direction Measurement

Primary Resp Freq. $=9.5 \mathrm{~Hz}$

Primary Resp. Freq. $=11.5 \mathrm{~Hz}$

1/24/91,11:25AM Data

0.3125 Microns $=1$ Volt

Fig. 3. Typical response of floor and vacuum chamber to vehicular traffic 


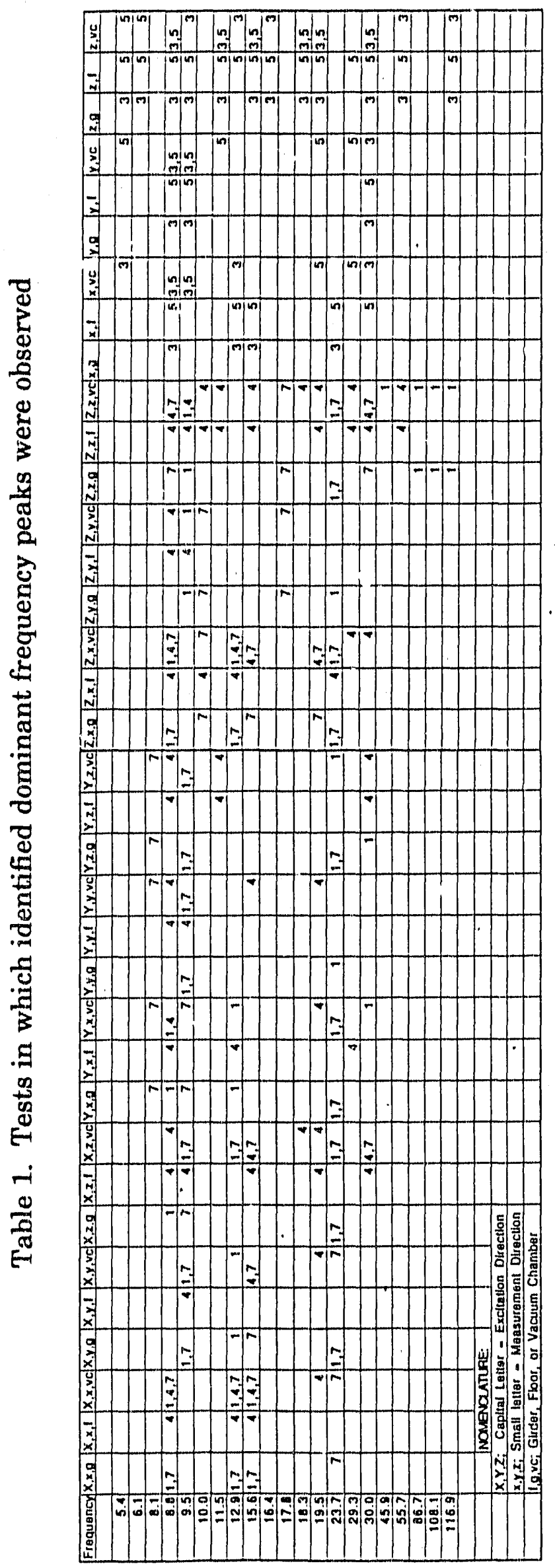


Table 2. Natural frequencies obtained from power spectral density datz

$f_{n}(H z)$

Comment

$5.4 \quad$ only excited by ambient floor motion (Tests 3 and 5)

6.1 only excited by ambient floor motion (Tests 3 and 5)

8.1 related to power supply chassis (Test 7)

8.8 out-of-plane rigid body mode - strong in $\mathrm{y} / \mathrm{x}$-directions

9.5 out-of-plane rigid body mode - strong in y-direction

10.0

11.5

associated with power supply chassis - strong in z-direction

12.9

associated with floor motion - strong in z-direction

in-phase coupled vacuum-chamber/girder axial mode strong in $\mathrm{x}$-direction)

15.6 axial ( $x$-direction) mode only excited by ambient floor motion - z-direction (in-plane rigid body mode?) related to power supply chassis (Test 7)

19.5 related to floor excitation - seen predominantly on vacuum chamber

23.7 out-of-phase coupled vacuum-chamber/girder axial mode strong in $\mathrm{x}$-direction)

29.3 related to floor excitation (Tests 3 and 4) rocking mode when viewed from end ( $\mathrm{x}$-direction) first in-plane (z-direction) bending mode of vacuum chamber related to floor excitation - z-direction (in-plane rigid body mode?)

86.7 coupled mode involving ion pump - z-direction coupled mode involving ion pump - z-direction first in-plane bending mode of girder - z-direction

126.7 


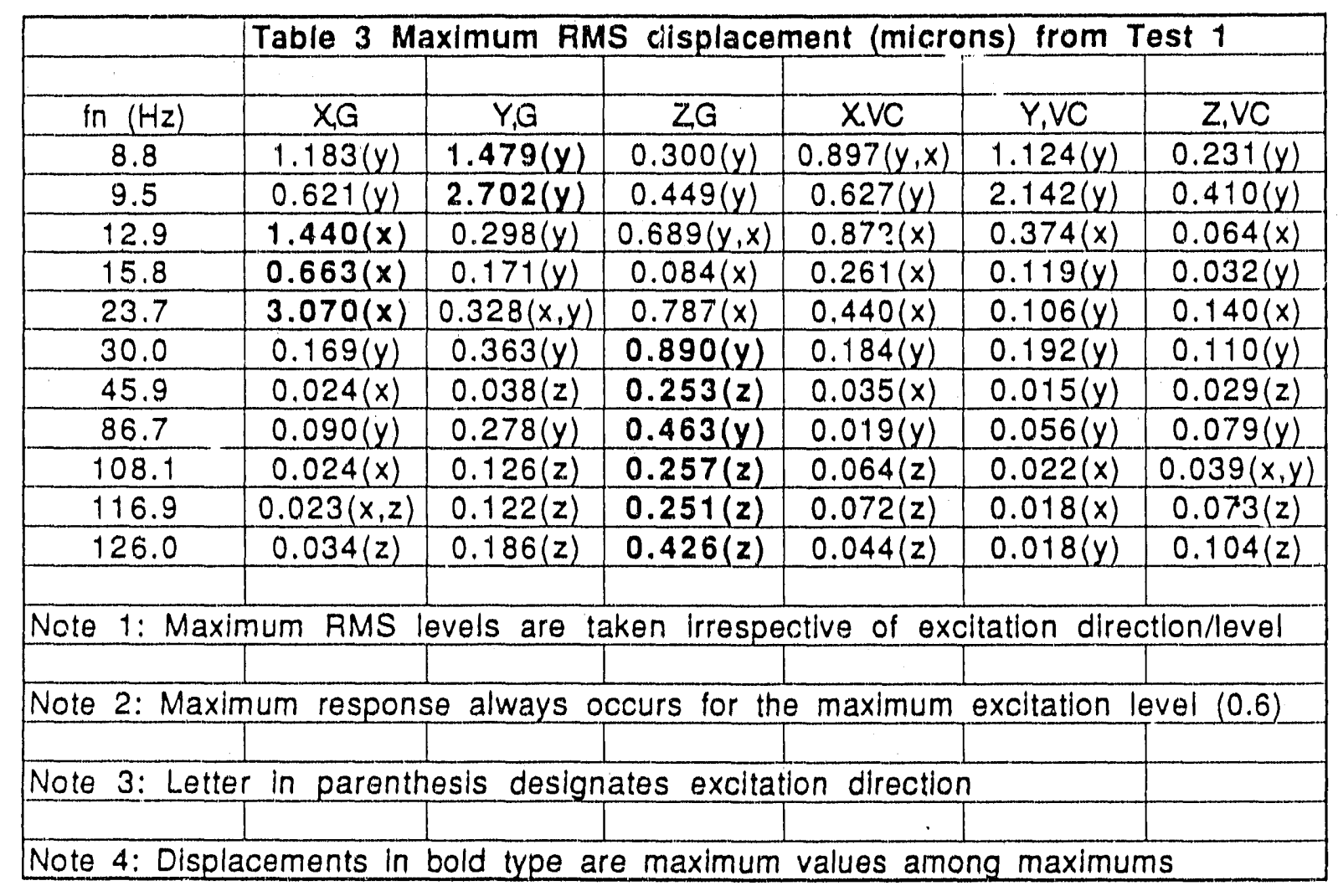


Table 4. Transfer function (magnification factor) between girder and vacuum chamber (vacuum-chamber/girder) - Test 1

$\begin{array}{rrrr}f_{\mathrm{n}}(\mathrm{Hz}) & \mathrm{T} F \mathrm{~T} & \mathrm{TFy} & \mathrm{TFz} \\ & & & \\ 8.8 & 0.75 & 0.72 & 0.52 \\ 9.5 & 0.95 & 0.79 & 0.91 \\ 12.9 & 0.60 & 2.23 & 0.81 \\ 15.6 & 0.42 & 0.82 & 0.68 \\ 23.7 & 0.14 & 0.29 & 0.18 \\ 30.0 & 1.11 & 0.60 & 0.39 \\ 45.9 & 0.75 & 0.39 & 0.12 \\ 86.7 & 0.24 & 0.23 & 0.16 \\ 108.1 & 1.98 & 0.38 & 0.32 \\ 116.9 & 3.18 & 0.43 & 0.44 \\ 126 & 1.23 & 0.30 & 0.31\end{array}$

Table 5. Transfer function (magnification factor) between floor and vacuum chamber (vacuum-chamber/floor) - Test 4

$\begin{array}{rccc}f_{\mathrm{n}}(\mathrm{Hz}) & \mathrm{TFx} & \mathrm{TFy} & \mathrm{TFz} \\ & & & \\ 8.8 & 0.15 & 0.16 & 0.48 \\ 9.5 & 0.16 & 0.05 & 0.26 \\ 12.9 & 0.10 & 0.49 & 0.95 \\ 15.6 & 0.25 & 0.65 & 0.91 \\ 29.3 & 0.99 & 0.44 & 0.41 \\ 30.0 & 0.24 & 0.23 & 0.32 \\ 49.5 & 0.81 & 0.20 & 0.11 \\ 58.3 & 0.67 & 0.15 & 0.21\end{array}$




\begin{tabular}{|c|c|c|c|c|c|c|c|}
\hline \multirow{2}{*}{ EXDir } & \multirow{2}{*}{ ExLeV } & \multicolumn{5}{|c|}{ Table 6 RMS displacement (microns) from Test 4} & \\
\hline & & $\# 1,(X, F)$ & $\# 2,(Y, F)$ & $\# 3,(Z, F)$ & $\# 4,(X, V C)$ & $\# 5,(Y, \vee C)$ & $\# 6,(Z, \vee C)$ \\
\hline & & mic. RMS & mic. RMS & mic. RMS & mlc. RMS & mic. RMS & mic. RMS \\
\hline$x$ & 0.6 & 0.0875 & 0.1519 & 0.0824 & 0.0330 & 0.0316 & 0.0371 \\
\hline$x$ & 0.4 & 0.0763 & 0.1231 & 0.0623 & 0.0288 & 0.0316 & 0.0311 \\
\hline$x$ & 0.1 & 0.0892 & 0.1310 & 0.0529 & 0.0305 & 0.0310 & 0.0291 \\
\hline$y$ & 0.6 & 0.0834 & 0.1137 & 0.0598 & 0.0313 & 0.0313 & 0.0318 \\
\hline$y$ & 0.4 & 0.0937 & 0.1264 & 0.0602 & 0.0313 & 0.0314 & 0.0338 \\
\hline$y$ & 0.1 & 0.1277 & 0.1373 & 0.0619 & 0.0307 & 0.0331 & 0.0407 \\
\hline$z$ & 0.6 & 0.0884 & 0.2019 & 0.0956 & 0.0324 & 0.0409 & 0.0621 \\
\hline$z$ & 0.4 & 0.1785 & 0.2879 & 0.0962 & 0.0395 & 0.0396 & 0.0574 \\
\hline$z$ & 0.1 & 0.0920 & 0.1445 & 0.0620 & 0.0316 & 0.0315 & 0.0358 \\
\hline & $A \vee G$ & 0.1019 & 0.1575 & 0.0704 & 0.0321 & 0.0335 & 0.0399 \\
\hline
\end{tabular}




\begin{tabular}{|c|c|c|c|c|c|c|}
\hline \multicolumn{6}{|c|}{ Table 7 RMS displacement (microns) in response to ambient floor motion } \\
\hline Transducer: & $\# 1,(X, G)$ & $\# 2,(Y, G)$ & $\# 3,(Z, G)$ & $\# 4,(X, V C)$ & $\# 5,(Y, V C)$ & $\# 6,(Z, V C)$ \\
\hline & & & & & & \\
\hline Date,TIme & Frequency range: $5-250 \mathrm{~Hz}$ & & & \\
\hline & & & & & & \\
\hline $1 / 23,4: 30 \mathrm{pm}$ & 0.1036 & 0.1634 & 0.0744 & 0.0769 & 0.1397 & 0.0492 \\
\hline $1 / 24,9: 30 \mathrm{am}$ & 0.0793 & 0.1306 & 0.0599 & 0.0609 & 0.1066 & 0.0395 \\
\hline & & & & & & \\
\hline & Frequency range: 10-250 $\mathrm{Hz}$ & & & \\
\hline $1 / 23,4: 30 \mathrm{pm}$ & 0.0703 & 0.0548 & 0.0514 & 0.0404 & 0.0421 & 0.0380 \\
\hline $1 / 24,9: 30 \mathrm{am}$ & 0.0496 & 0.0435 & 0.0486 & 0.0301 & 0.0303 & 0.0327 \\
\hline & & & & & & \\
\hline & Frequency range: 15.250 $\mathrm{Hz}$ & & & \\
\hline & & & & & & \\
\hline $1 / 23,4: 30 \mathrm{pm}$ & 0.0374 & 0.0359 & 0.0446 & 0.0191 & 0.0141 & 0.0273 \\
\hline $1 / 24,9: 30 \mathrm{am}$ & 0.0277 & 0.0280 & 0.0436 & 0.0158 & 0.0113 & 0.0250 \\
\hline
\end{tabular}

\begin{tabular}{|c|c|c|c|c|c|c|}
\hline \multicolumn{2}{|c|}{ Table 8 RMS displacement (microns) in response to ambient floor motion } \\
\hline Transducer: & $\# 1,(X, F)$ & $\# 2,(Y, F)$ & $\# 3,(Z, F)$ & $\# 4,(X, V C)$ & $\# 5,(Y, V C)$ & $\# 6,(Z, V C)$ \\
\hline & & & & & & \\
\hline Date, Time & Frequency range: $5-250 \mathrm{~Hz}$ & & & \\
\hline $1 / 24,11: 25 \mathrm{am}$ & 0.0766 & 0.1150 & 0.0533 & 0.0298 & 0.0315 & 0.0292 \\
\hline & & & & & & \\
\hline & Frequency range: $10-250 \mathrm{~Hz}$ & & & \\
\hline $1 / 24,11: 25 \mathrm{am}$ & 0.0434 & 0.0367 & 0.0402 & 0.0112 & 0.0124 & 0.0251 \\
\hline & & & & & & \\
\hline & Frequency range: $15-250 \mathrm{~Hz}$ & & & \\
\hline & & & & & & \\
\hline $1 / 24,11: 25 \mathrm{am}$ & 0.0251 & 0.0248 & 0.0348 & 0.0079 & 0.0079 & 0.0163 \\
\hline & & & & & & \\
\hline & & & & & & \\
\hline
\end{tabular}


Table 9. Vibration criteria: allowable vibration amplitudes $(\mu \mathrm{m})$

$\begin{array}{lcc}\text { Peak } & \text { RMS } & \text { RMS } \\ \text { (Sinusoidal) } & \text { (Random) }\end{array}$

$\begin{array}{llll}\text { Vertical: } & 0.12 & 0.085 & 0.04 \\ \text { Horizontal: } & 0.34 & 0.24 & 0.11\end{array}$


APPENDIX A - Power Spectral Density Plots 

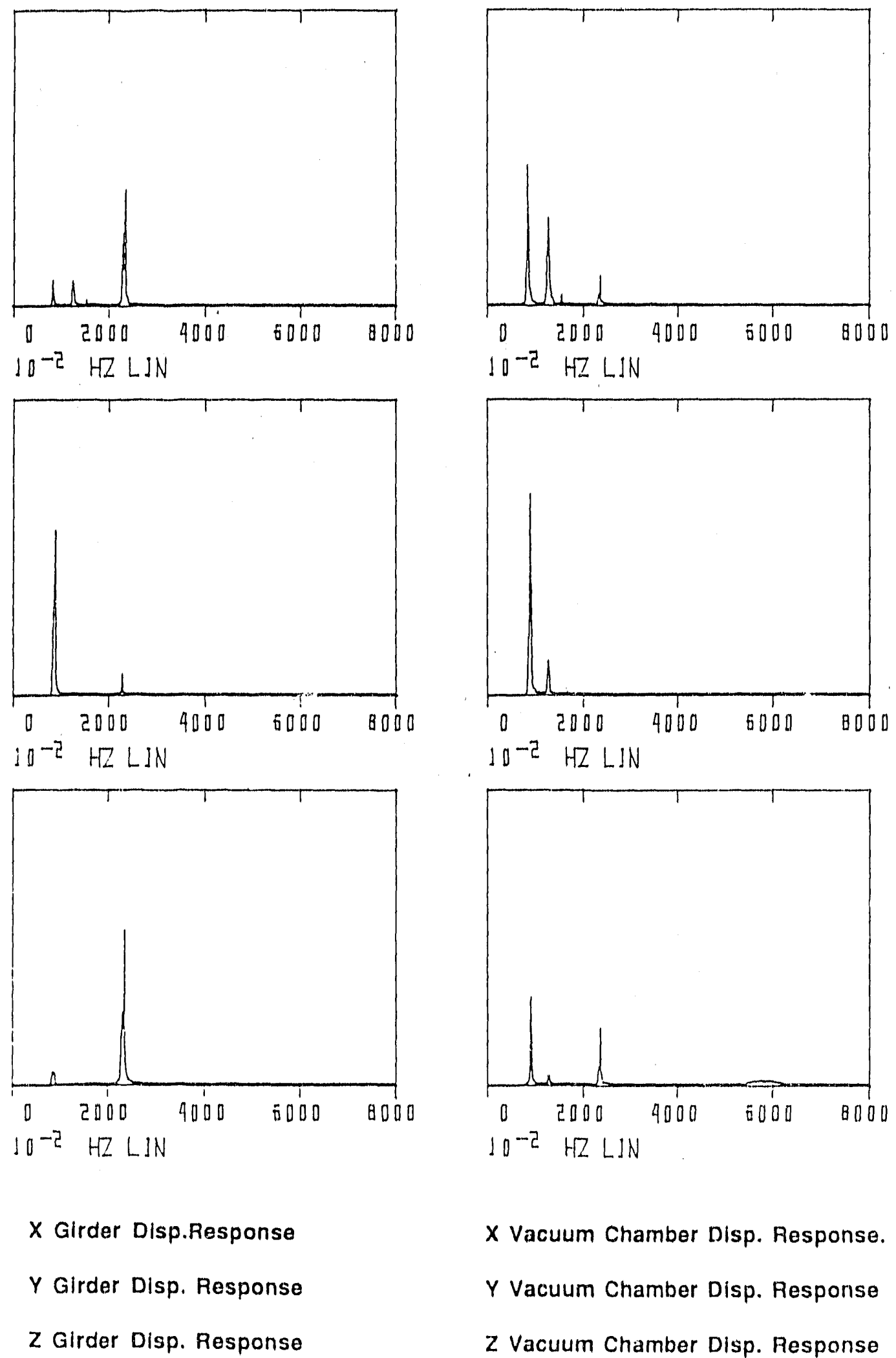

X Vacuum Chamber Disp. Response.

Y Vacuum Chamber Disp. Response

$Z$ Vacuum Chamber Disp. Response

TEST 1 

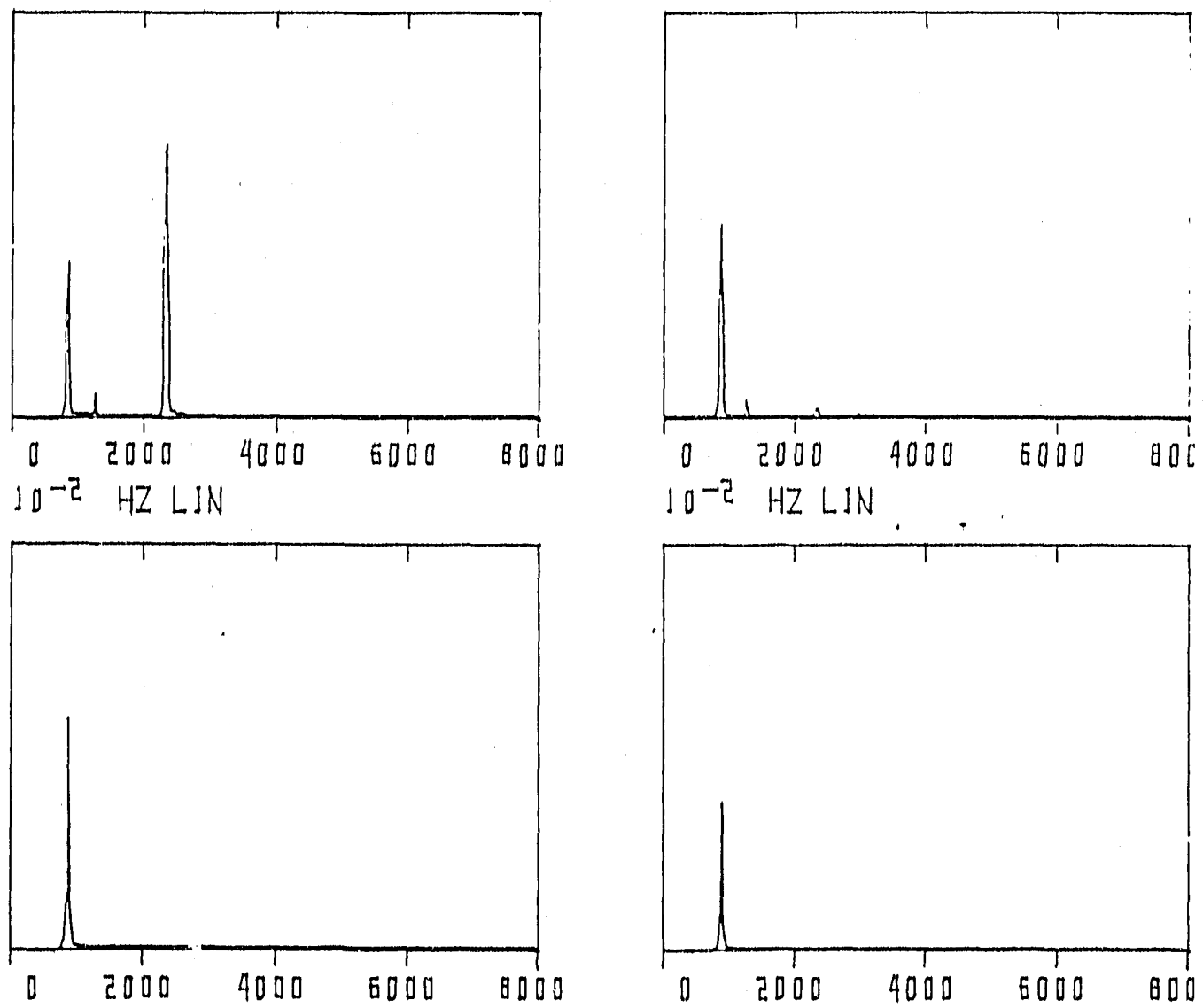

$10^{-2} \quad H Z L I N$
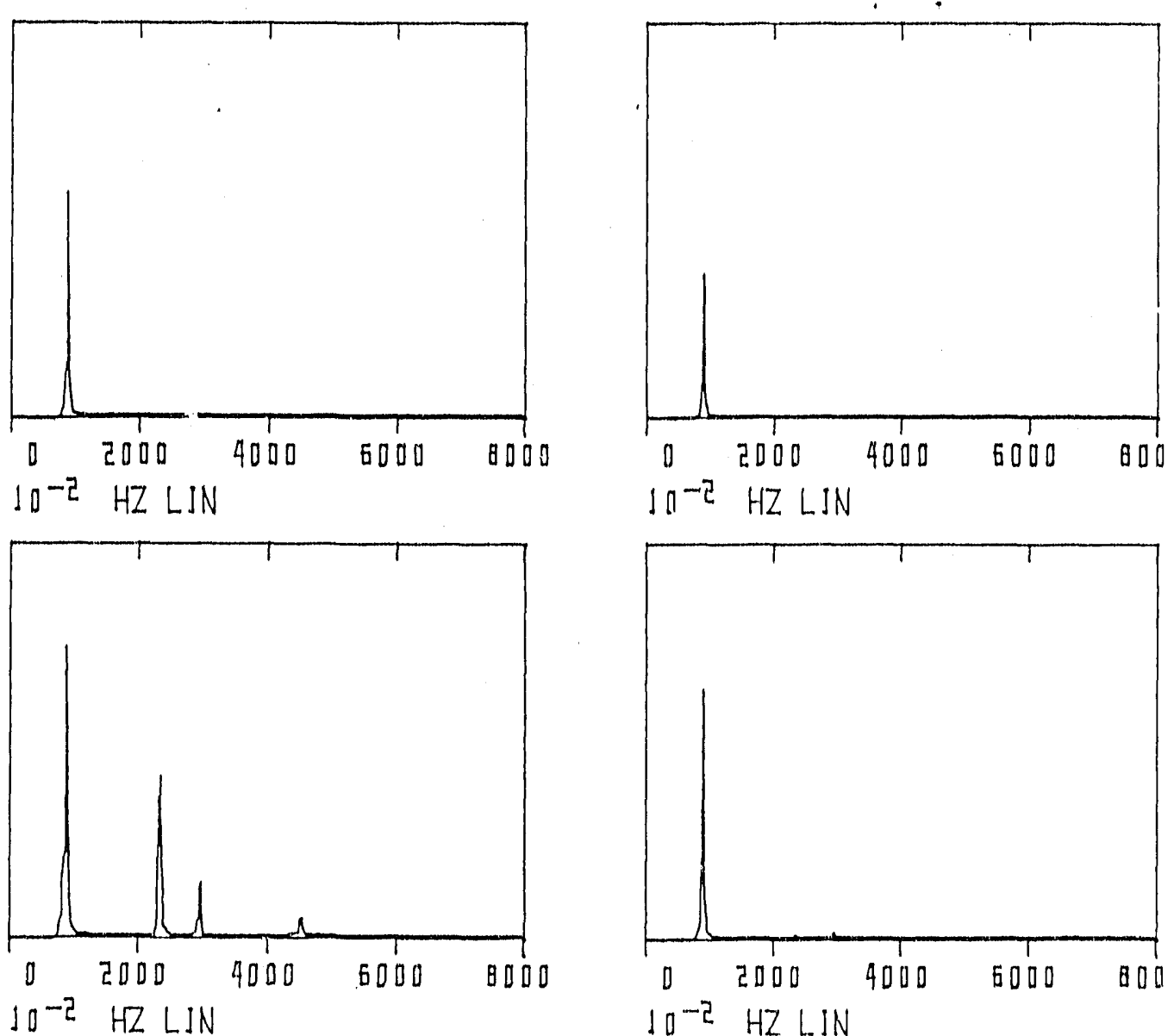

$10^{-2} \quad H Z L J N$

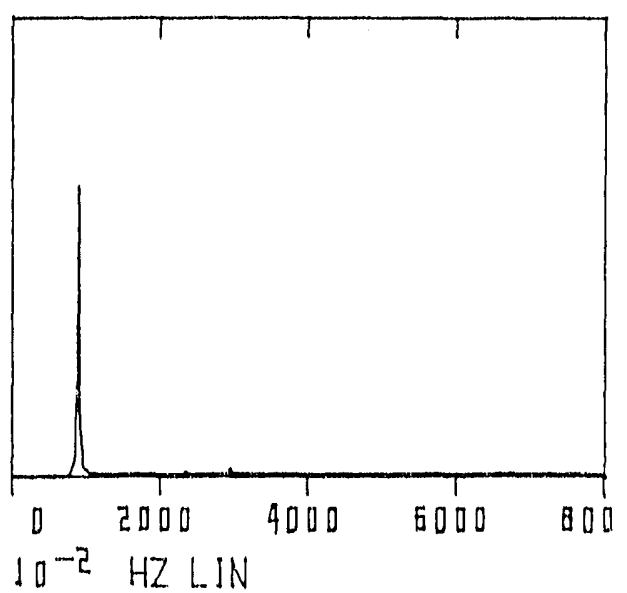

\footnotetext{
$X$ Girder Disp.Response

Y Girder Disp. Response

Z Girder Disp. Response
}

X Vacuum Chamber Disp. Response.

Y Vacuum Chamber Disp. Response

$Z$ Vacuum Chamber Disp. Response

TEST 1

$Y$ Direction Excitation

Excitation Level $=0.6$ 

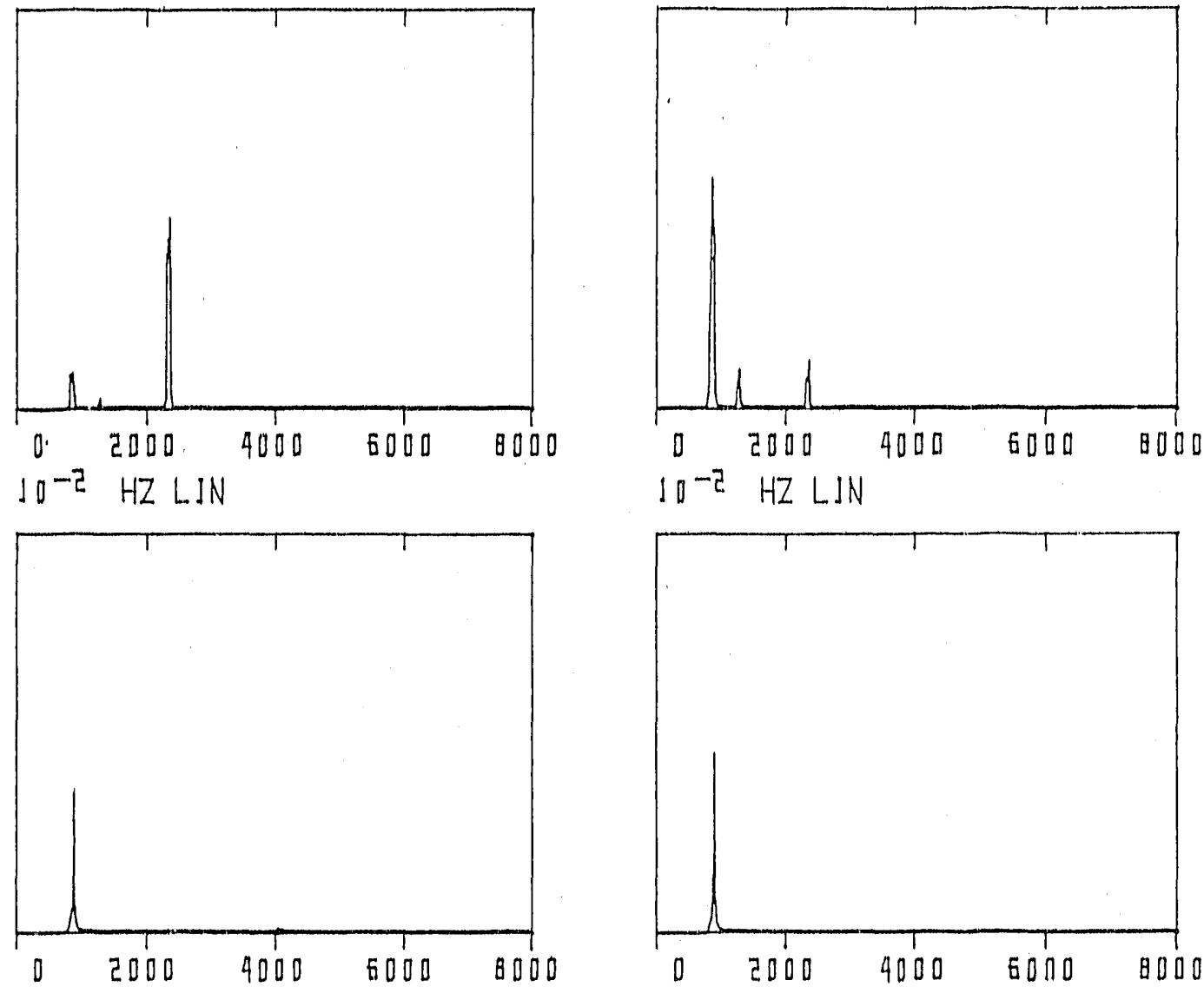

$10^{-2} \quad H Z L I N$

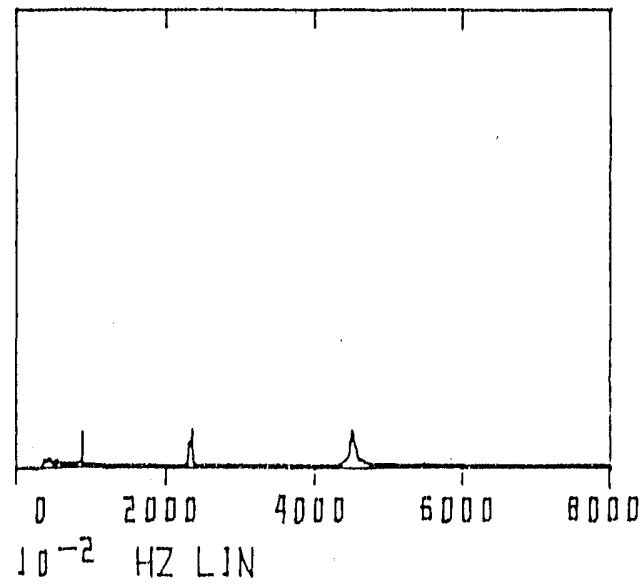

$10^{-2} \quad H I L I N$

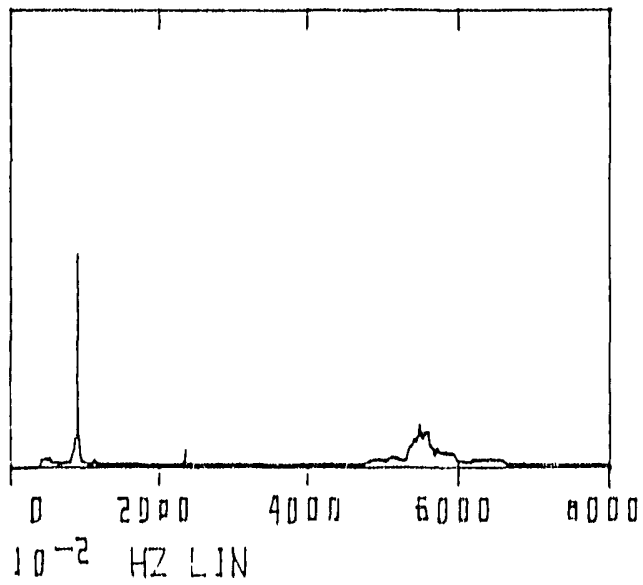

X Girder Disp.Response

X Vacuum Chamber Disp. Response.

Y Girder Disp. Response

Y Vacuum Chamber Disp. Response

Z Girder Disp. Response

Z Vacuum Chamber Disp. Response 

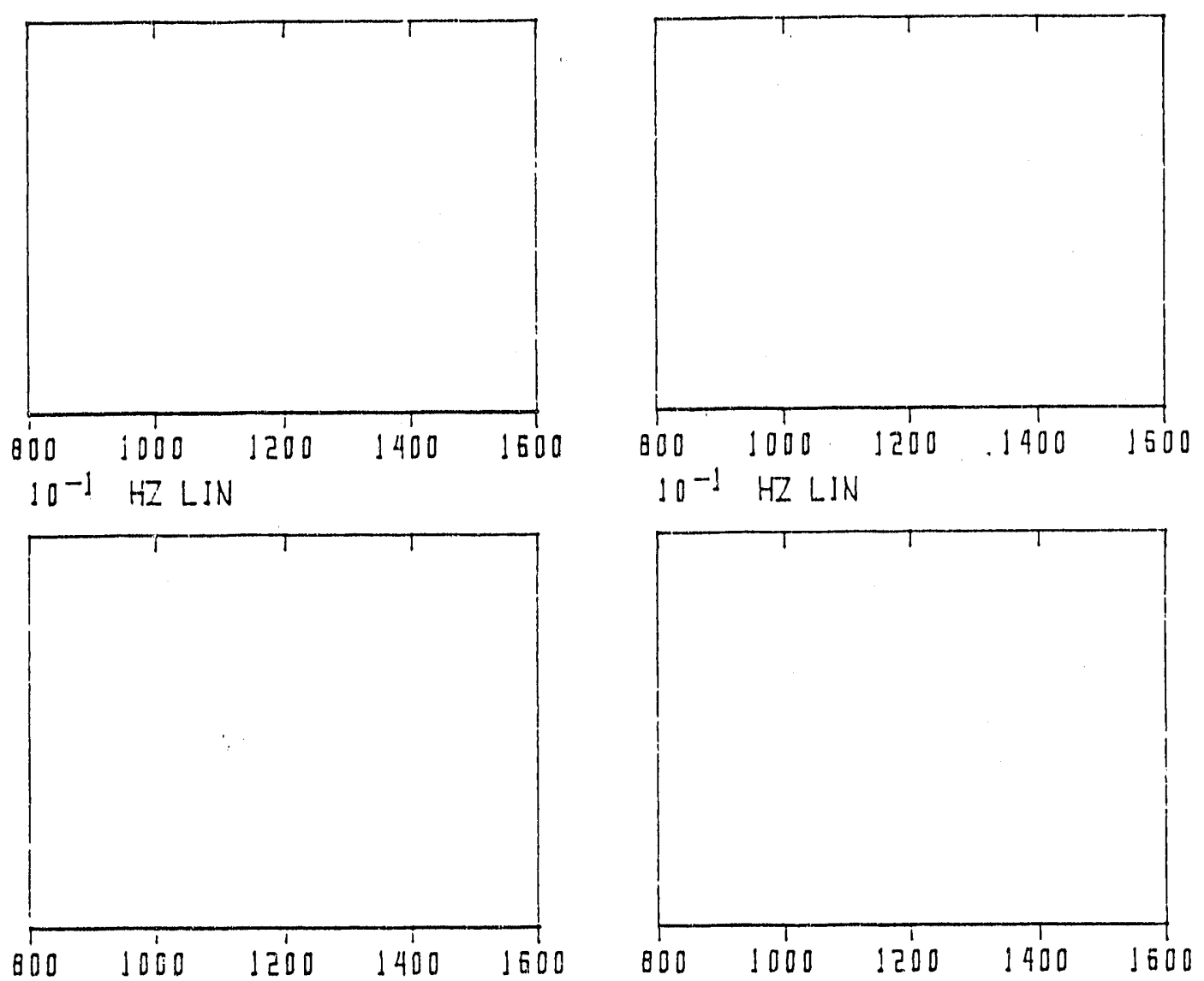

$10^{-\mathrm{j}} H Z: I N$

$10^{-1} \quad H Z \operatorname{LIN}$
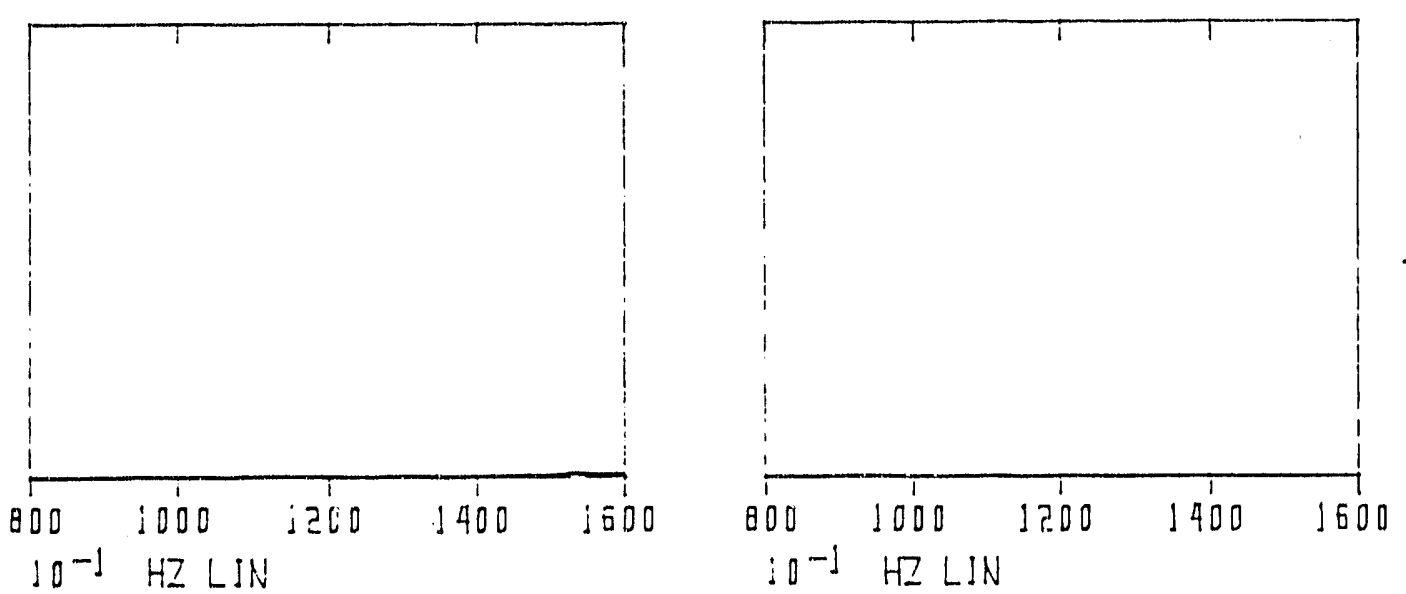

$X$ Girder Disp.Response

Y Girder Disp. Response

$Z$ Girder Disp. Response
X Vacuum Chamber Disp. Response.

Y Vacuum Chamber Disp. Response

$Z$ Vacuum Chamber Disp. Response

TEST 1

$\ddot{x}$ Üirection Excitatiouii

Excitation Level $=0.6$ 

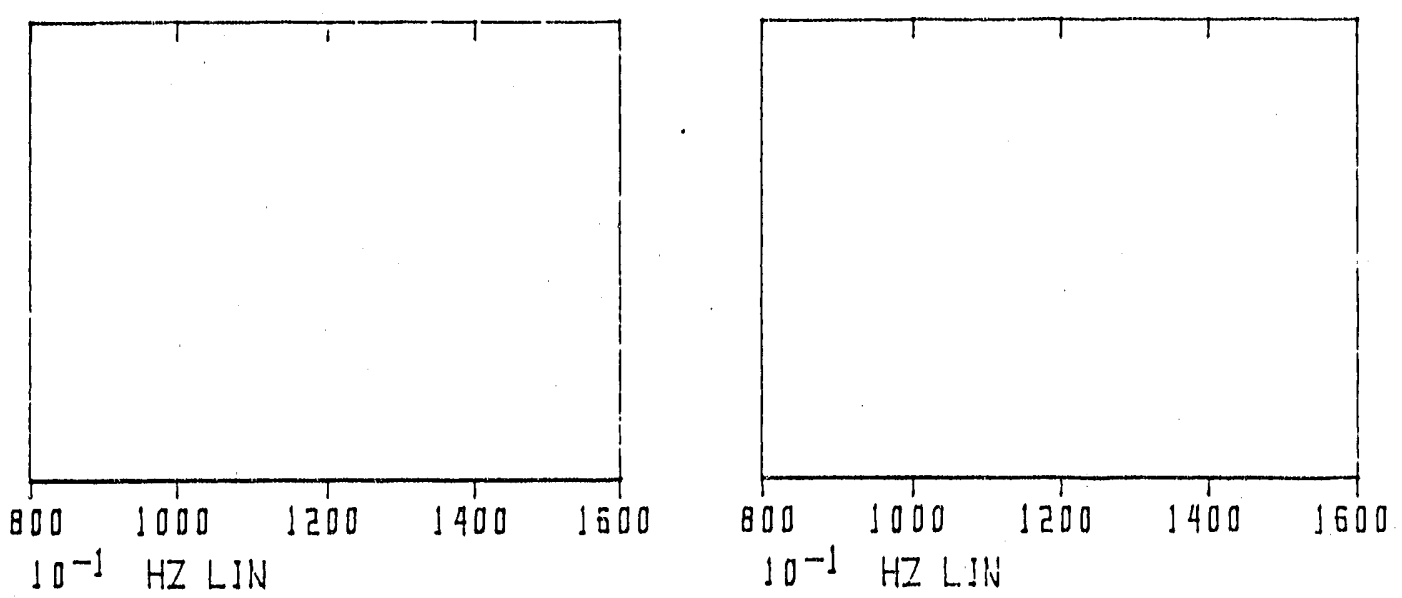

$10^{-1} \quad H Z \operatorname{LIN}$
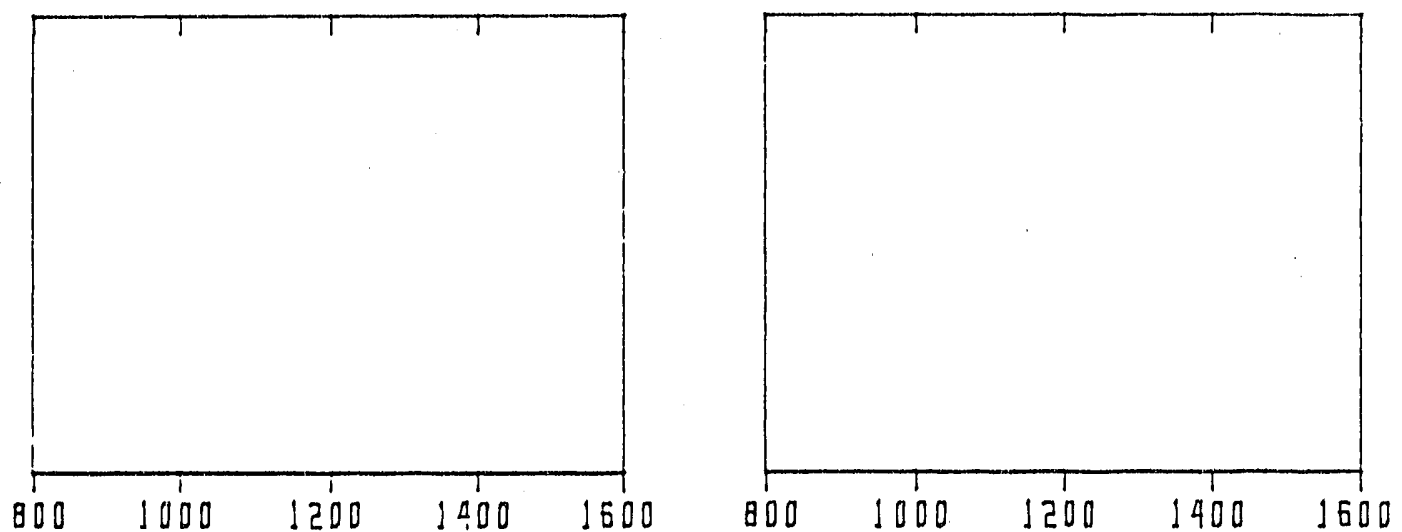

$10^{-1} \quad H Z L I N$

$10^{-1} \quad H Z L I N$

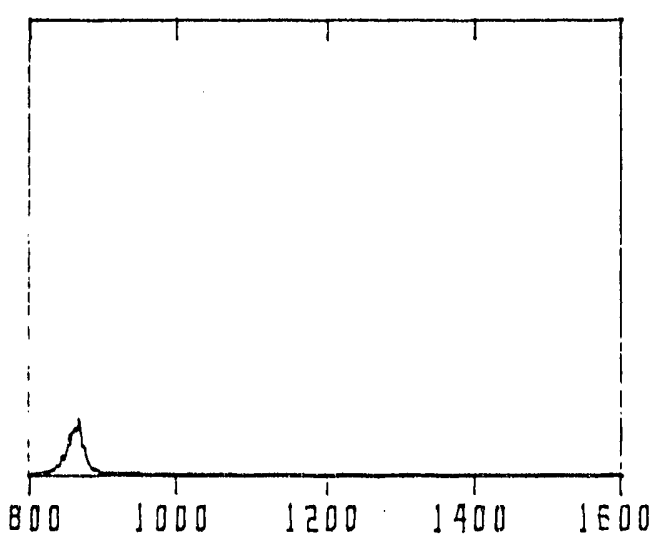

$10^{-1} \quad H Z L I N$

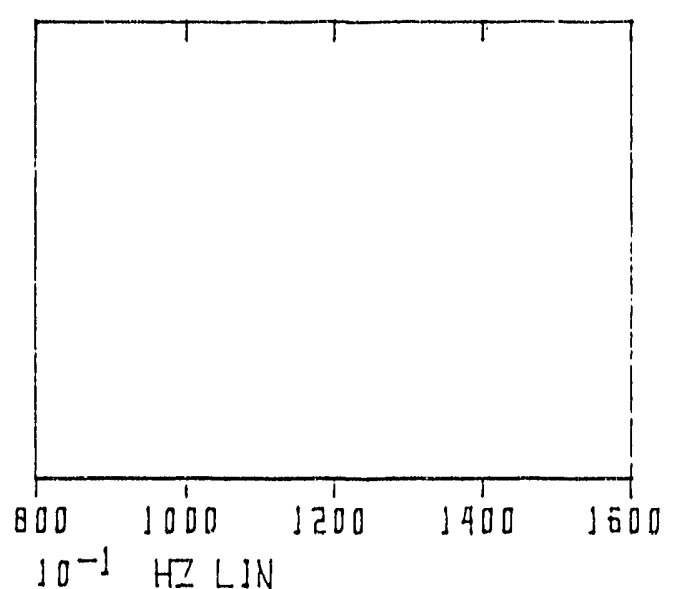

\section{Girder Disp.Response}

Y Girder Disp. Response

Z Girder Disp. Response
X Vacuum Chamber Disp. Response.

Y Vacuum Chamber Disp. Response

Z Vacuum Chamber Disp. Response 

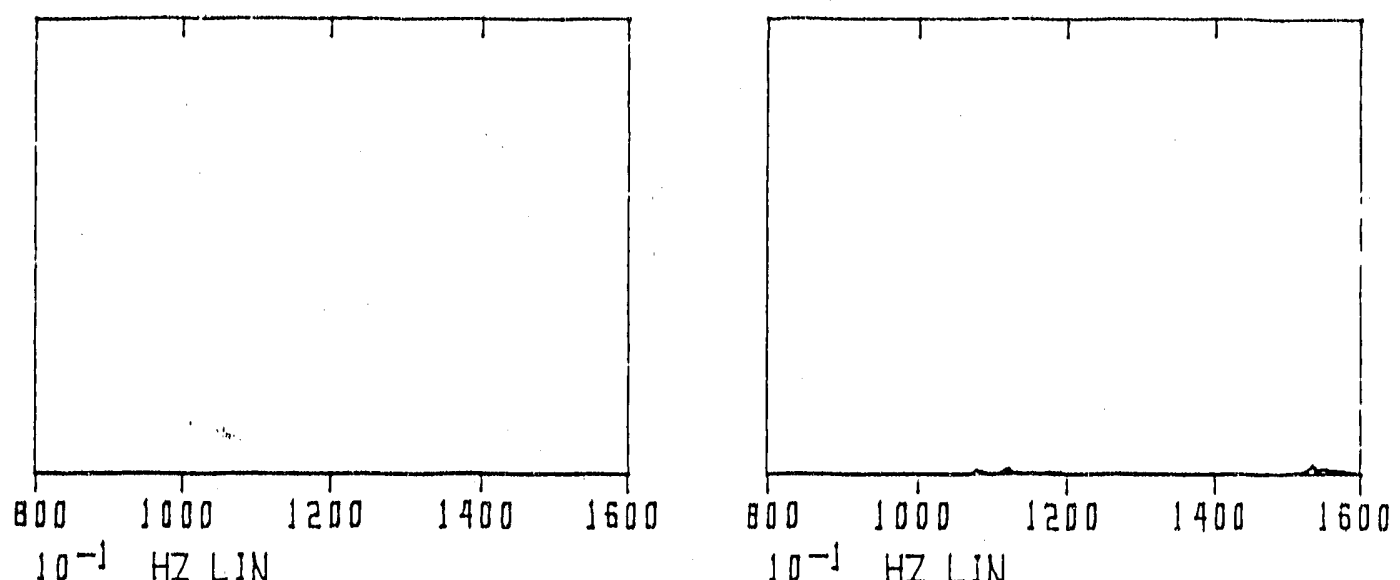

$10^{-1} H Z \operatorname{LIN}$

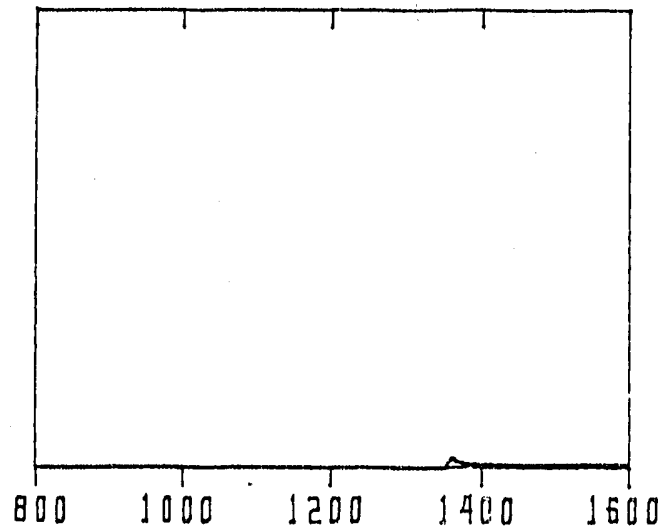

$10^{-1} H Z$ LIN
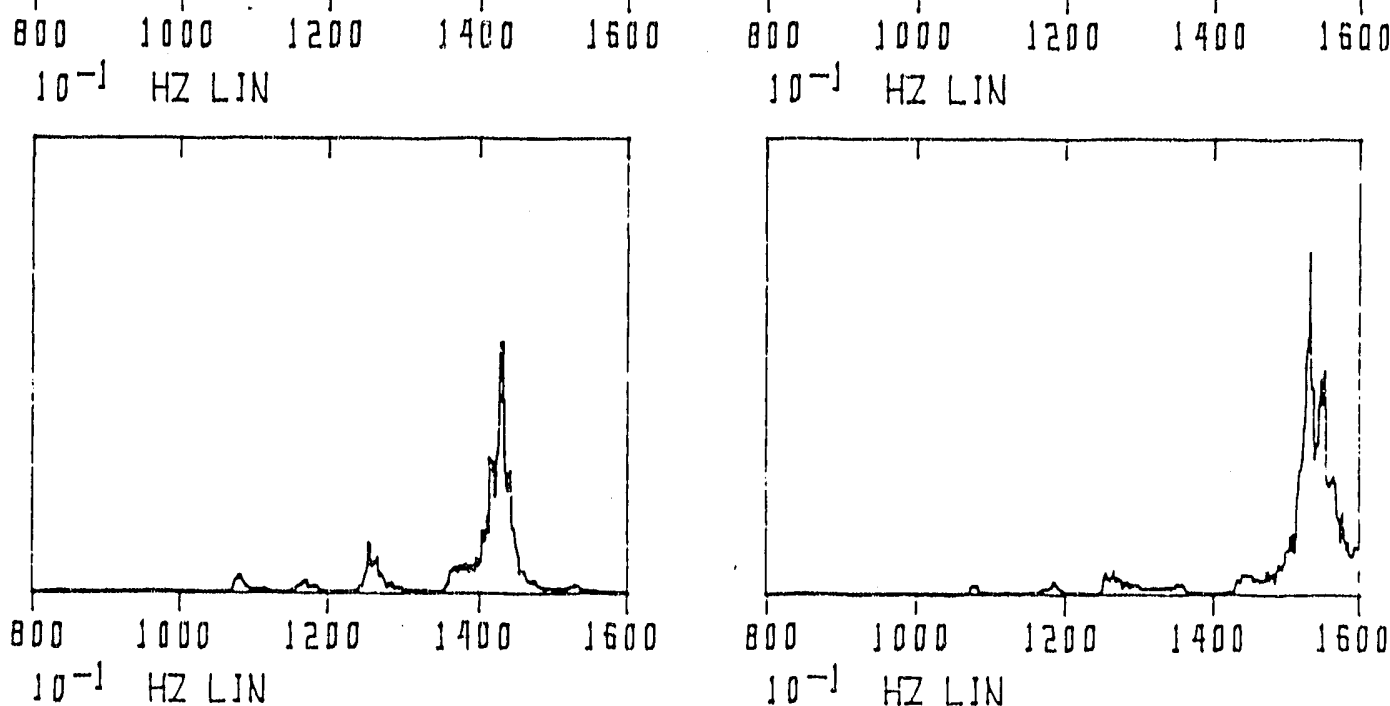

$10^{-1} \quad H Z L I N$

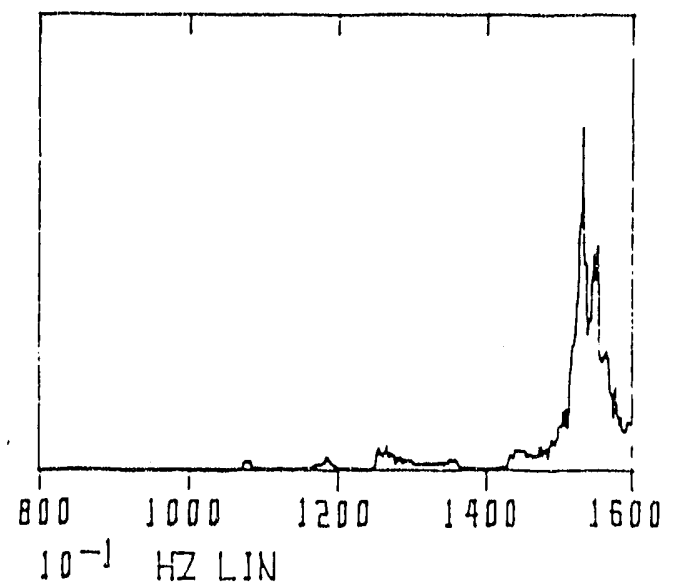

X Girder Disp.Response

$X$ Vacuum Chamber Disp. Response.

Y Girder Disp. Response

Y Vacuum Chamber Disp. Response

Z Girder Disp. Response

Z Vacuum Chamber Disp. Response

TEST 1

$Z$ Direction Excitation

Excitation Leve! = o.E 

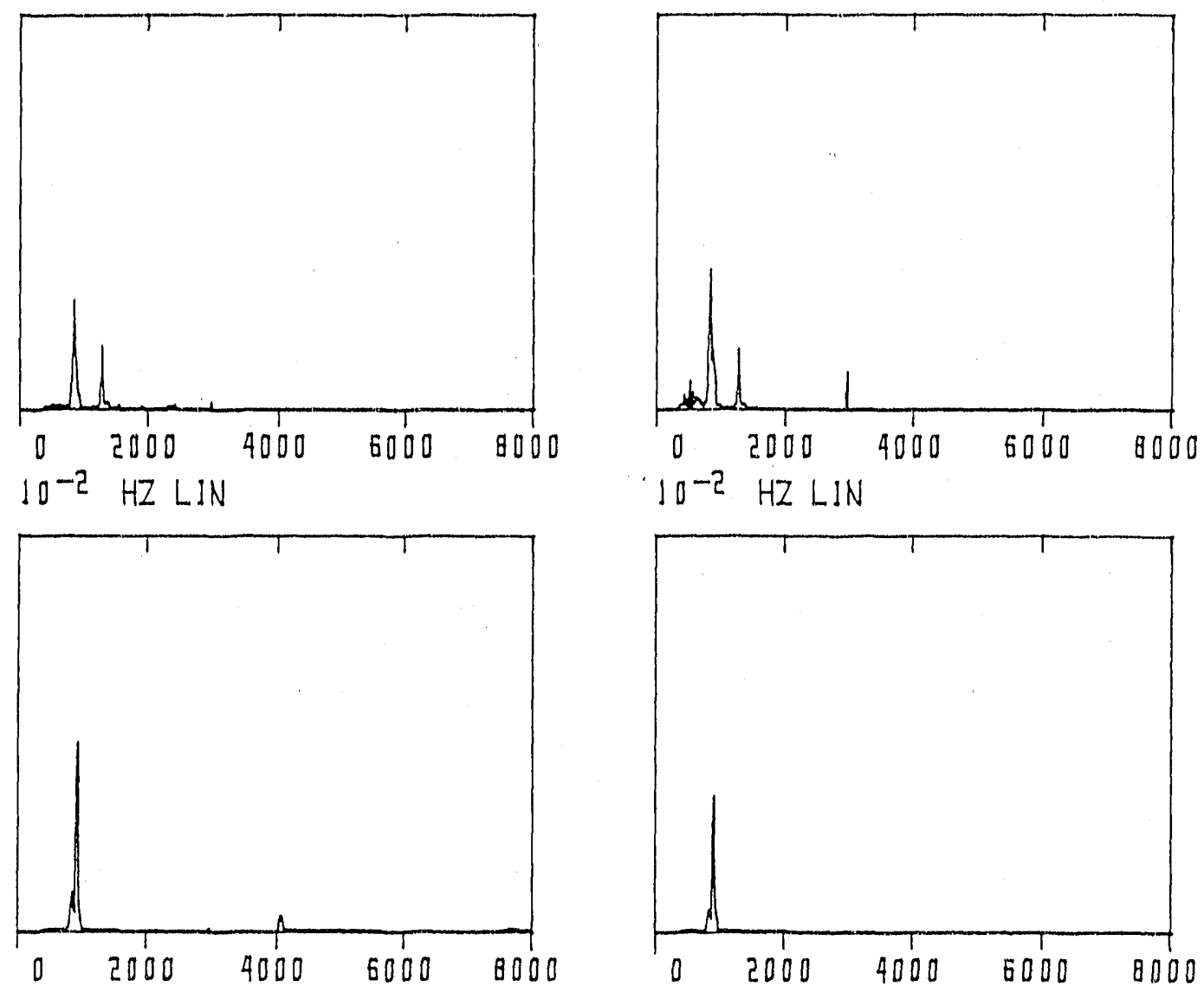

$10^{-2} \quad H Z L I N$
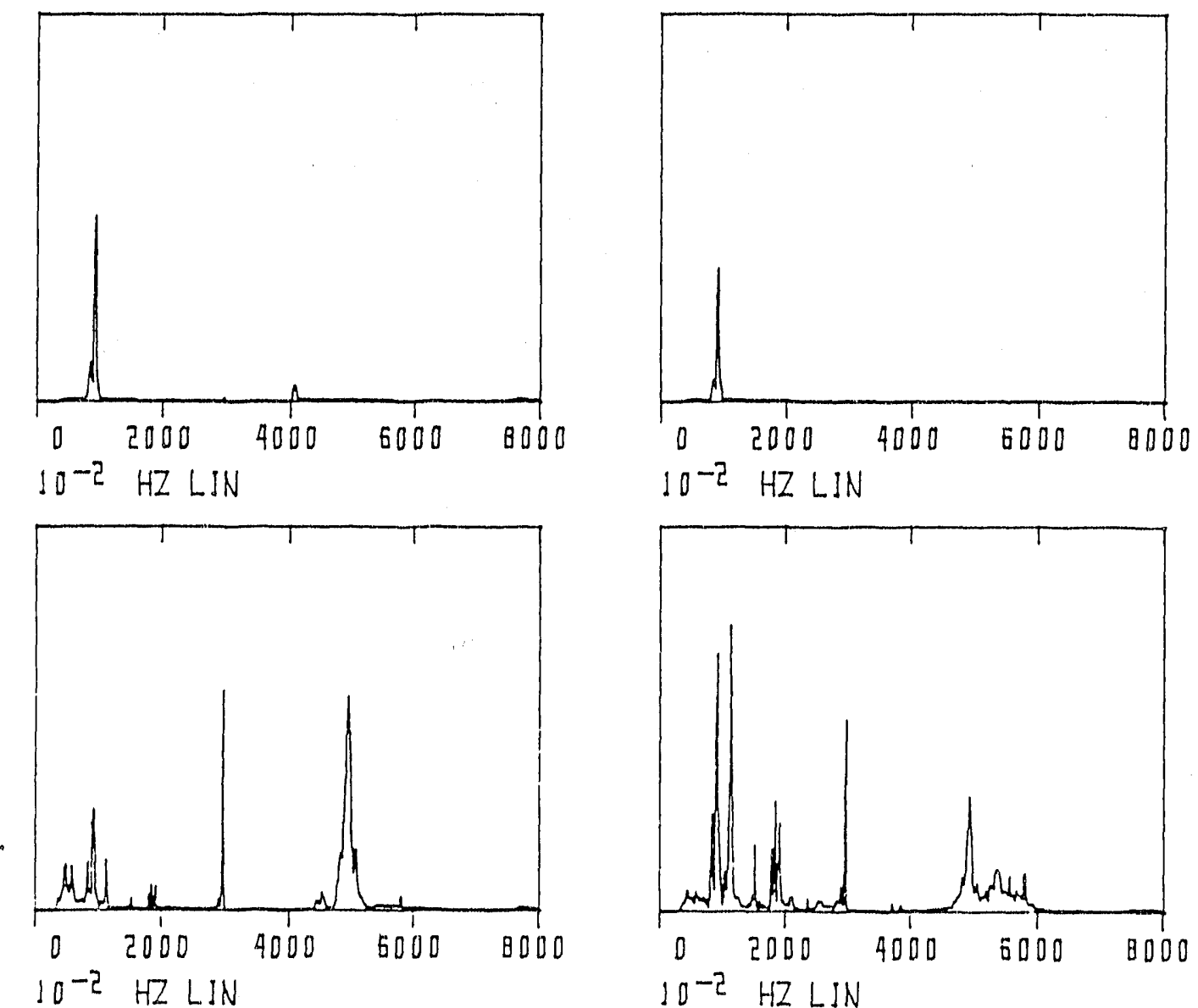

\section{$X$ Girder Disp.Response}

$X$ Vacuum Chamber Disp. Response.

Y Girder Disp. Response

Y Vacuum Chamber Disp. Response

Z Girder Disp. Response

$Z$ Vacuum Chamber Disp. Response

TEST 2

$x$ Direction Excitation

Excitation Level $=0.6$ 

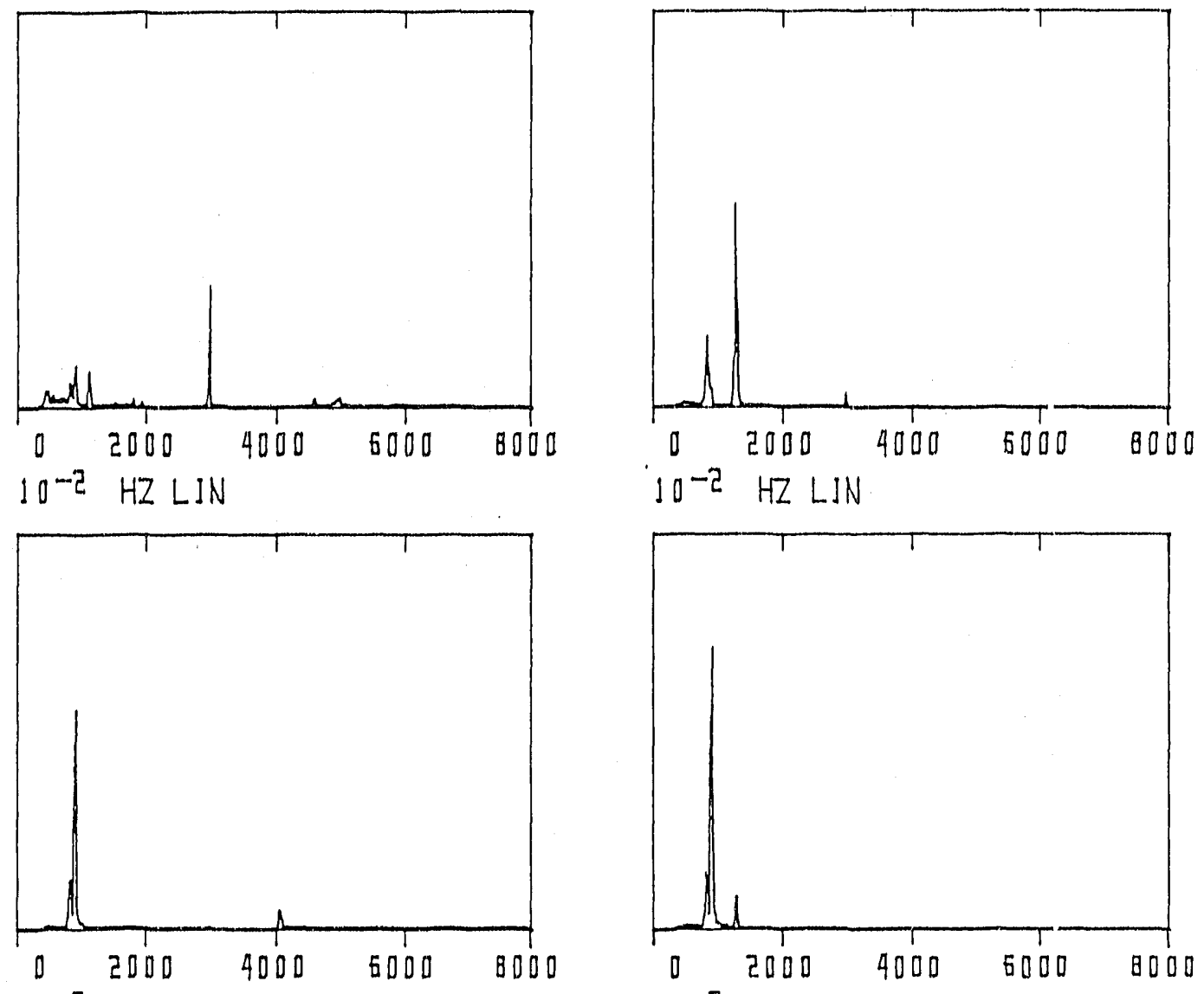

$10^{-2} \quad H Z$ LIN

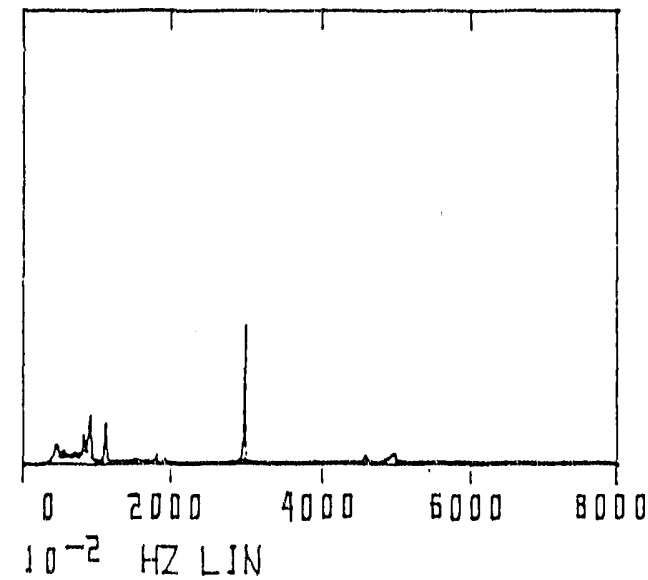

$10^{-2} \quad H Z L I N$

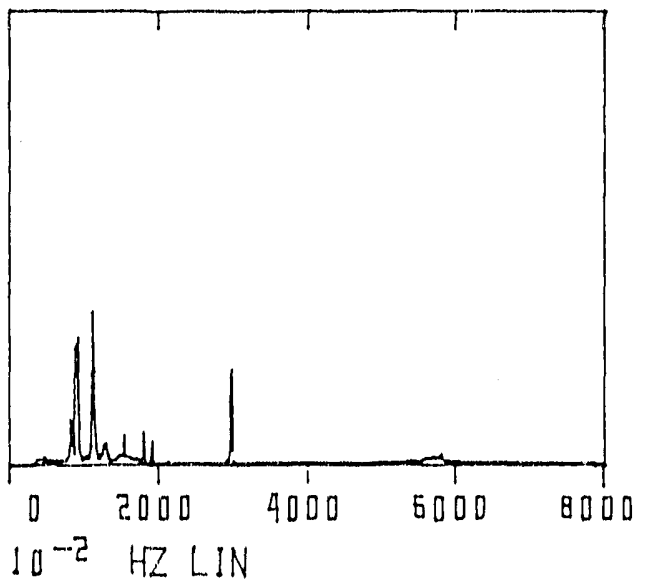

X Girder Disp.Response

X Vacuum Chamber Disp. Response.

Y Girder Disp. Response

Y Vacuum Chamber Disp. Response

Z Girder Disp. Response

I Vacuum Chamber Disp. Response

TEST 2

$Y$ Direction Excitation

Excitation Level $=0.6$ 

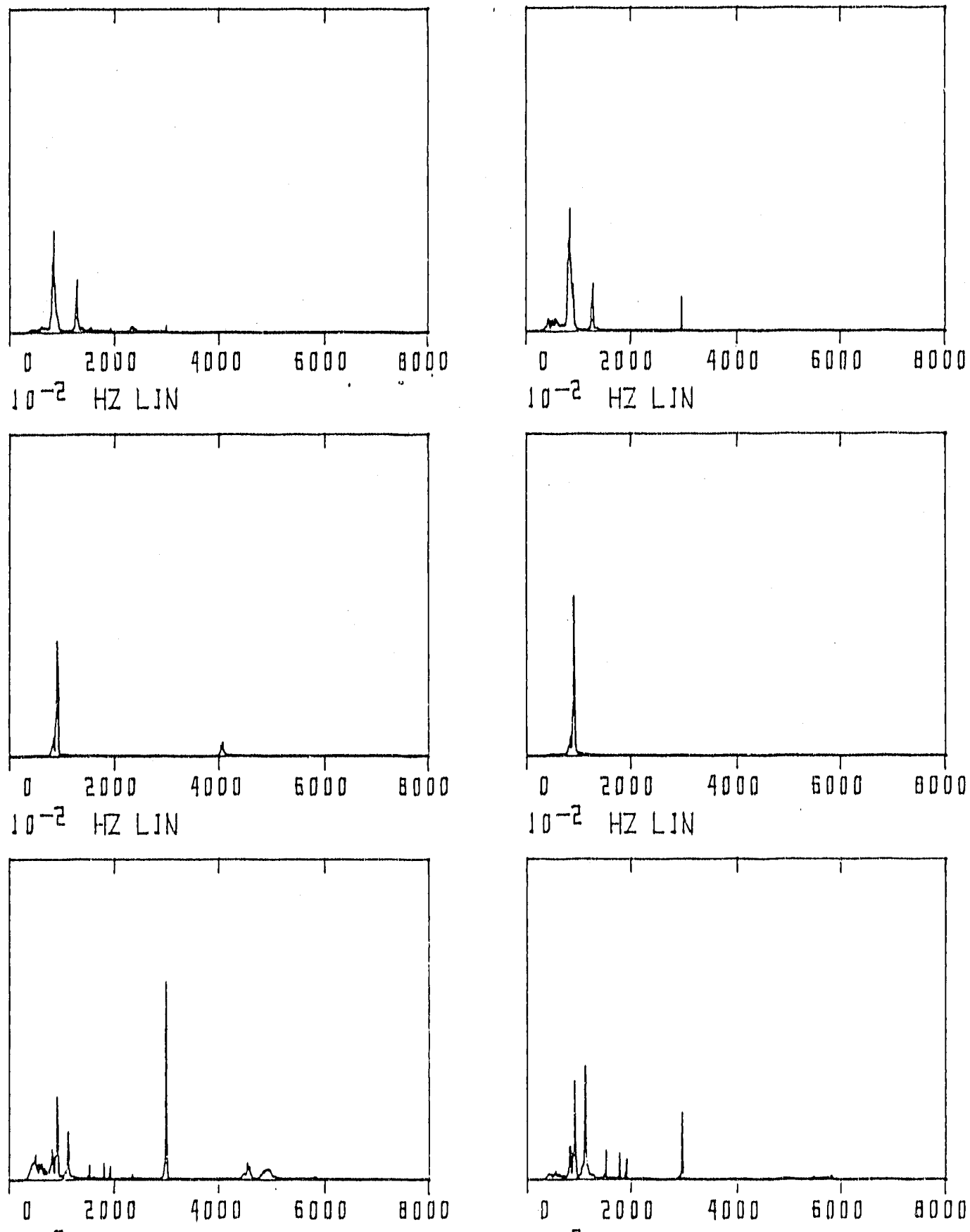

$10^{-2}$ HZ LIN

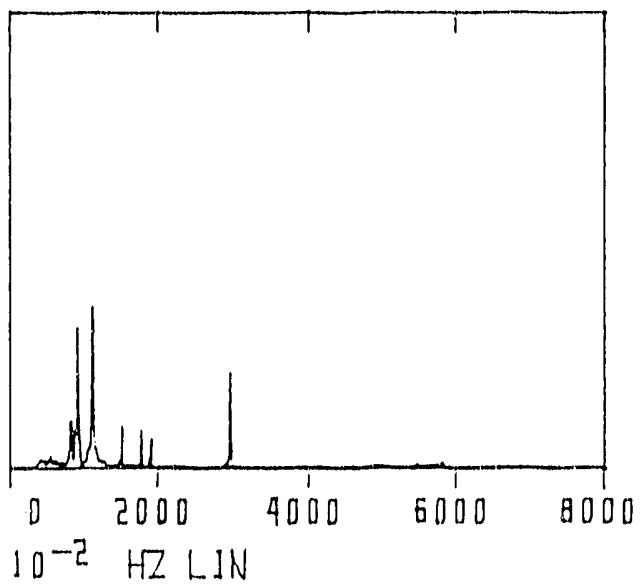

X Girder Disp.Response

Y Girder Disp. Response

$z$ Girder Disp. Response
$X$ Vacuum Chamber Disp. Response.

Y Vacuum Chamber Disp. Response

Z Vacuum Chamber Disp. Response

TEST 2

$z$ Direction Excitation

Excitation Level $=0.6$ 

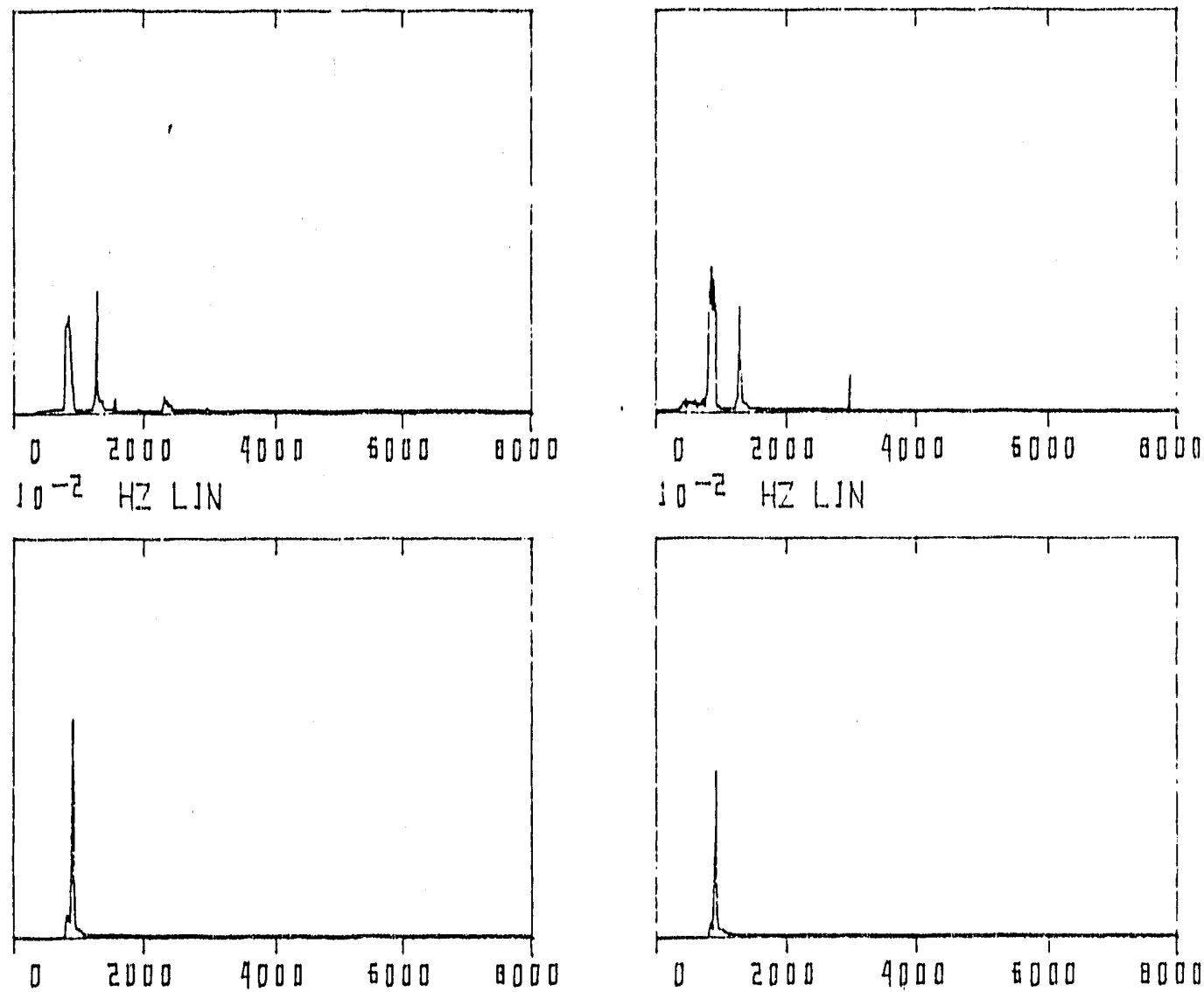

$10^{-2} \quad H Z L I N$

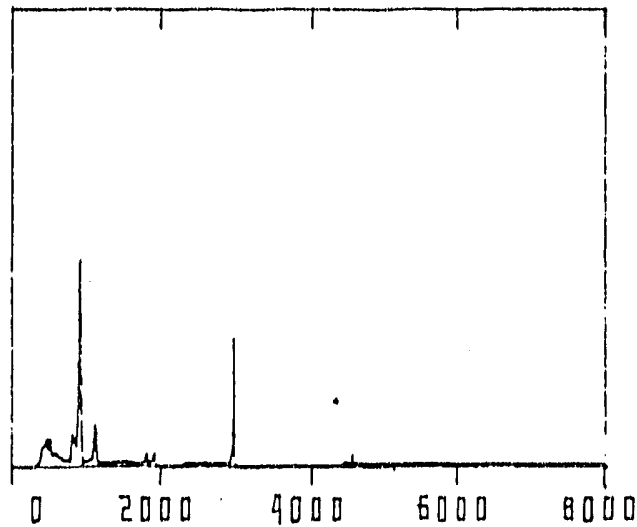

$10^{-2}$ HZ LIN

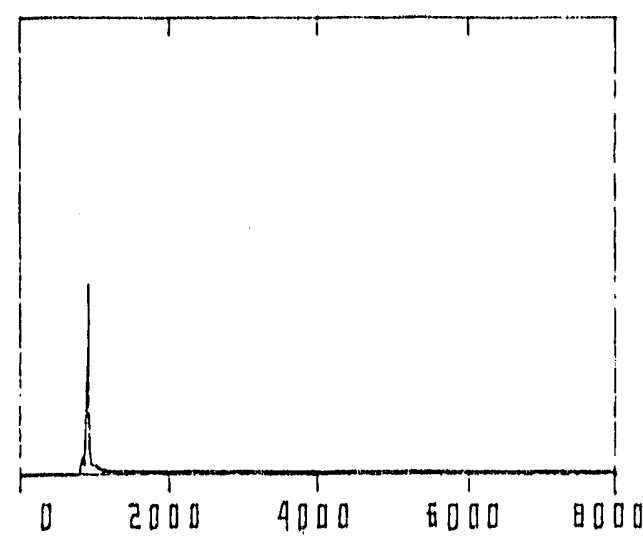

$10^{-2} \quad H Z$ LISH

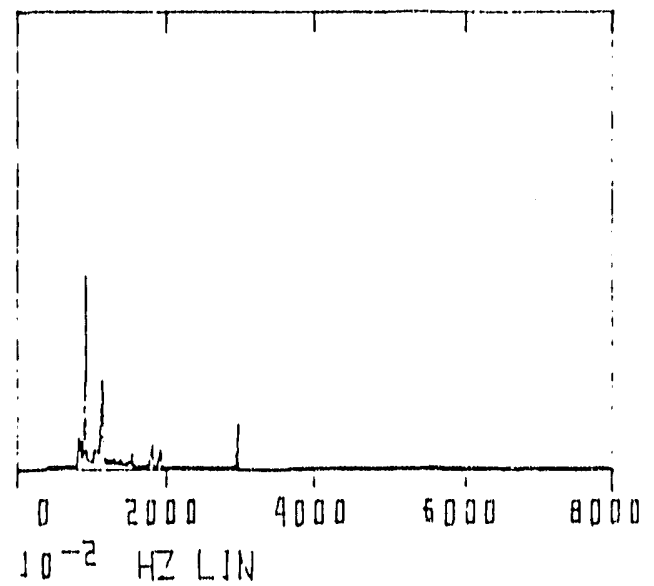

\section{Girder Disp.Response}

X Vacuum Chamber Disp. Response.

Y Girder Disp. Resporise

Y Vacuum Chamber Disp. Response

Z Girder Disp. Response

$Z$ Vacuum Chamber Disp. Response 

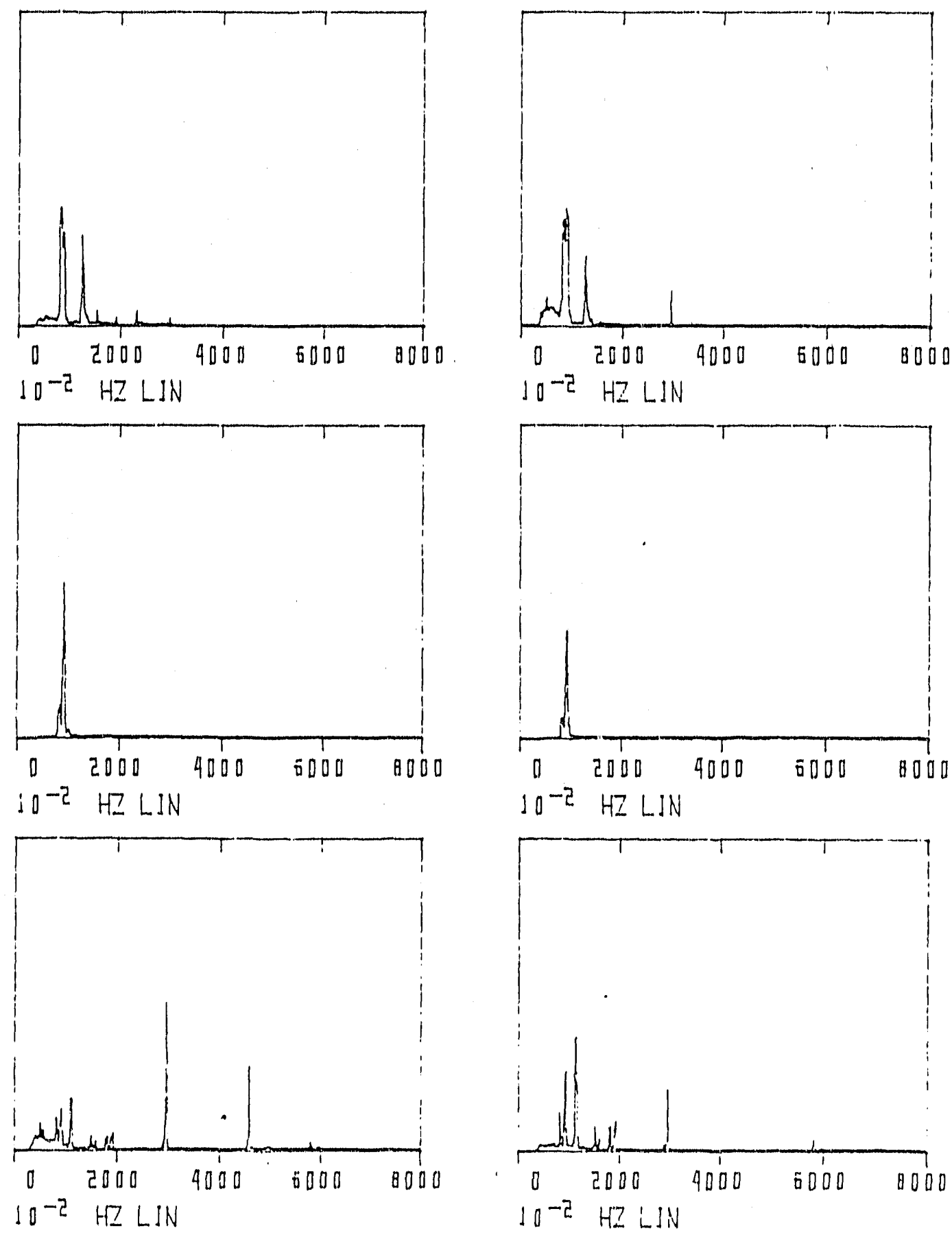

X Girder Disp.Response

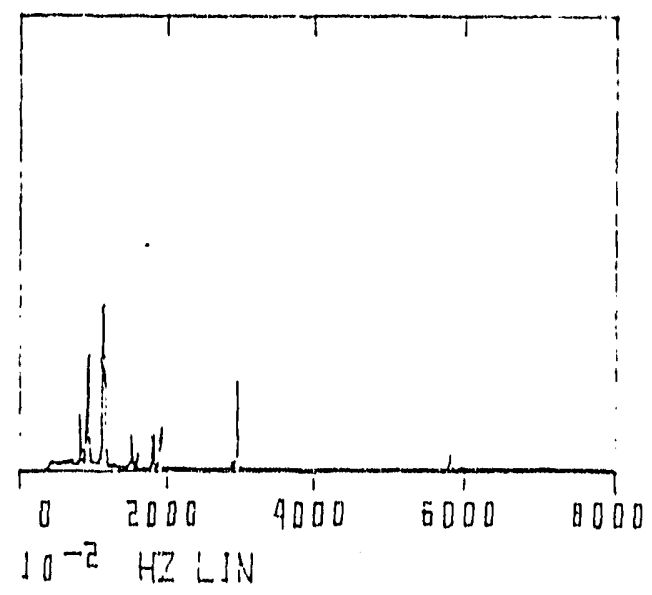

$Y$ Girder Disp. Response

$X$ Vacuum Chamber Disp. Response.

Y Vacuum Chamber Disp. Response

Z Girder Disp. Response

Z Vacuum Chamber Disp. Resporise

TEST 3

Amblent Response

Data: 1/24, 9:40 AM 

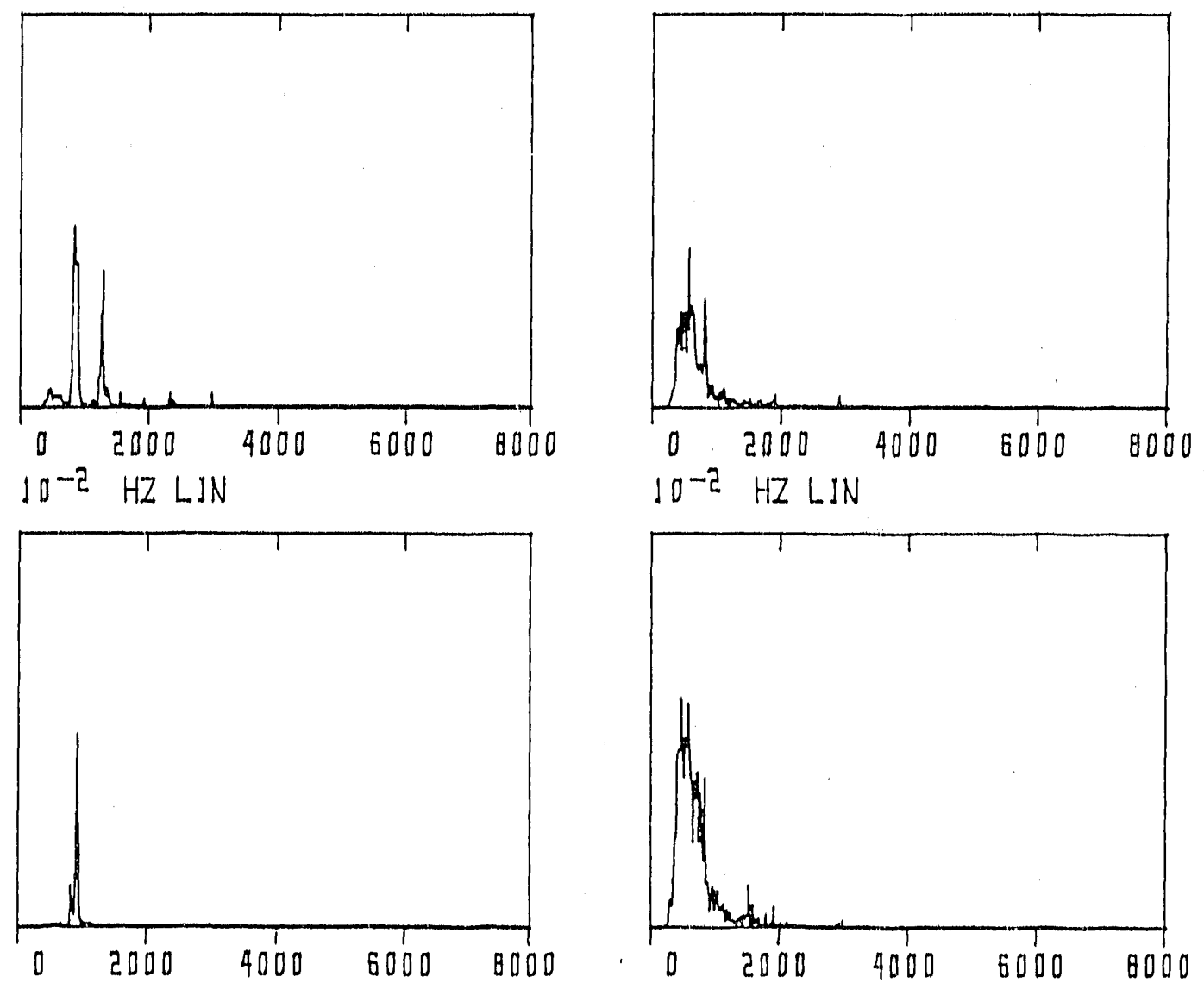

$10^{-2} \quad H Z$ LIN
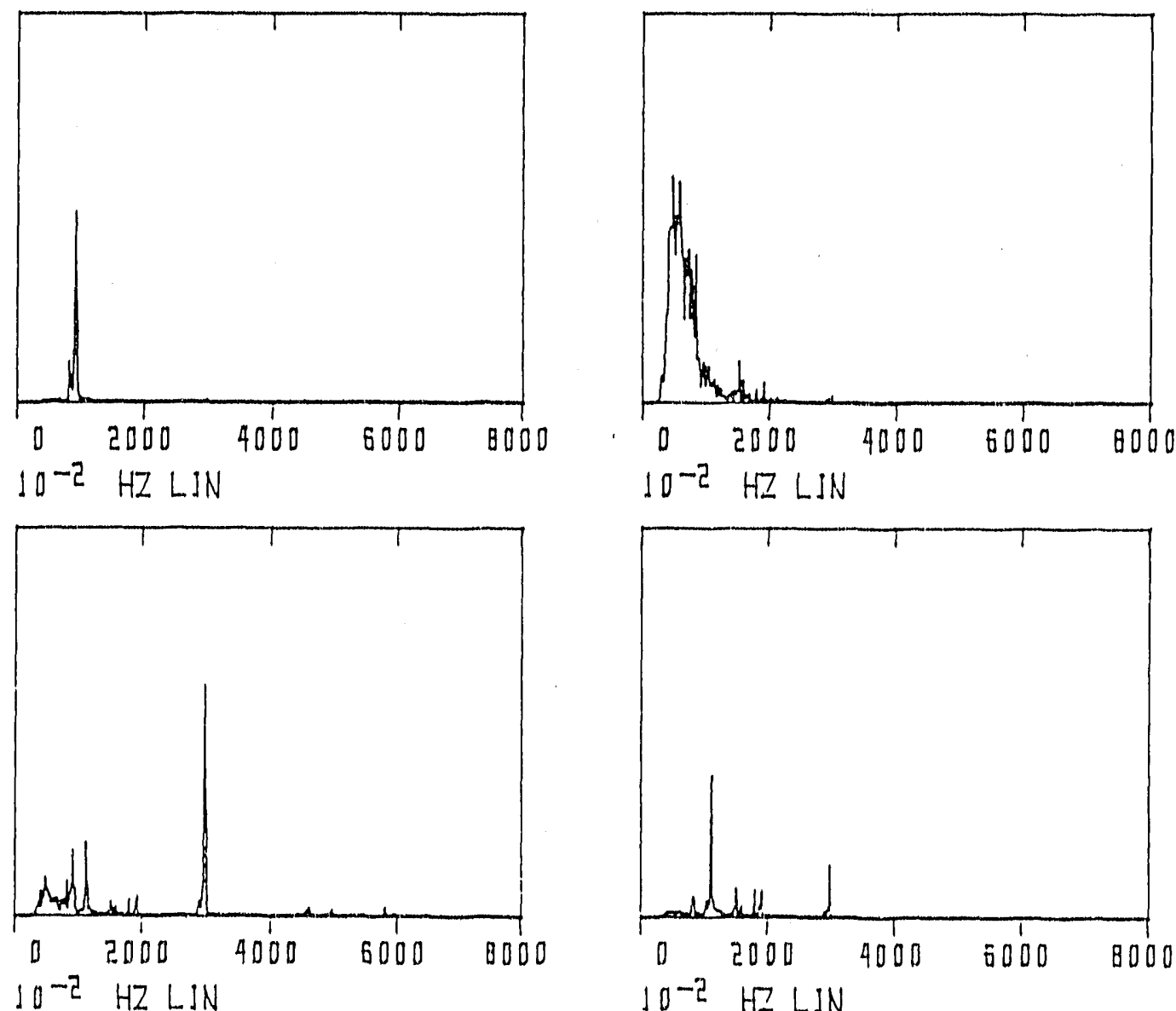

X Floor Disp.Response

$X$ Vacuum Chamber Disp. Response.

Y Floor Dlsp. Response

Y Vacuum Chamber Dlsp. Response

Z Floor Disp. Response

$Z$ Vacuum Chamber Disp. Flesponse

TEST 4

$X$ Direction Excltation

Excitation Level $=0.6$ 

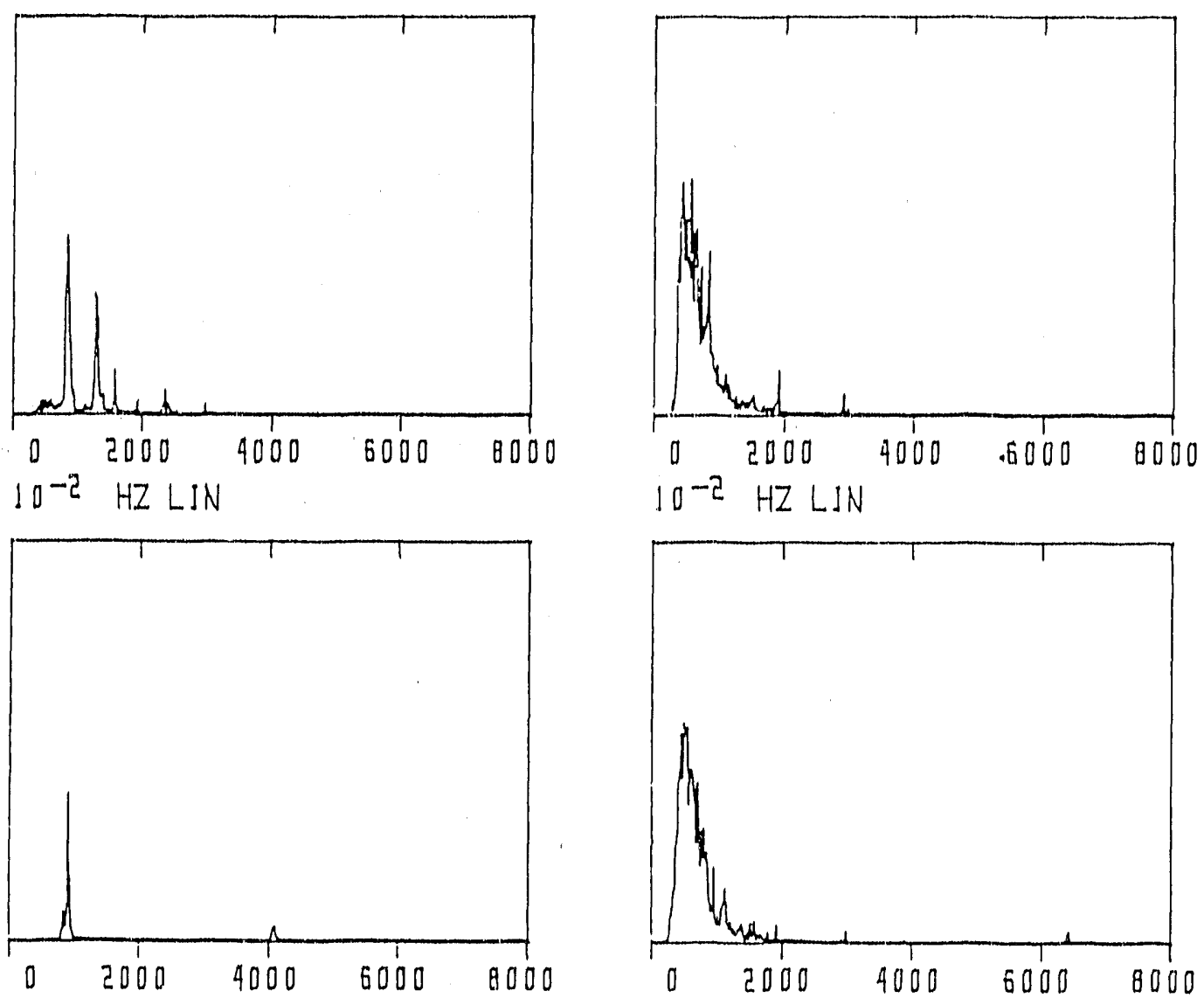

$10^{--2}$ HZ LIN
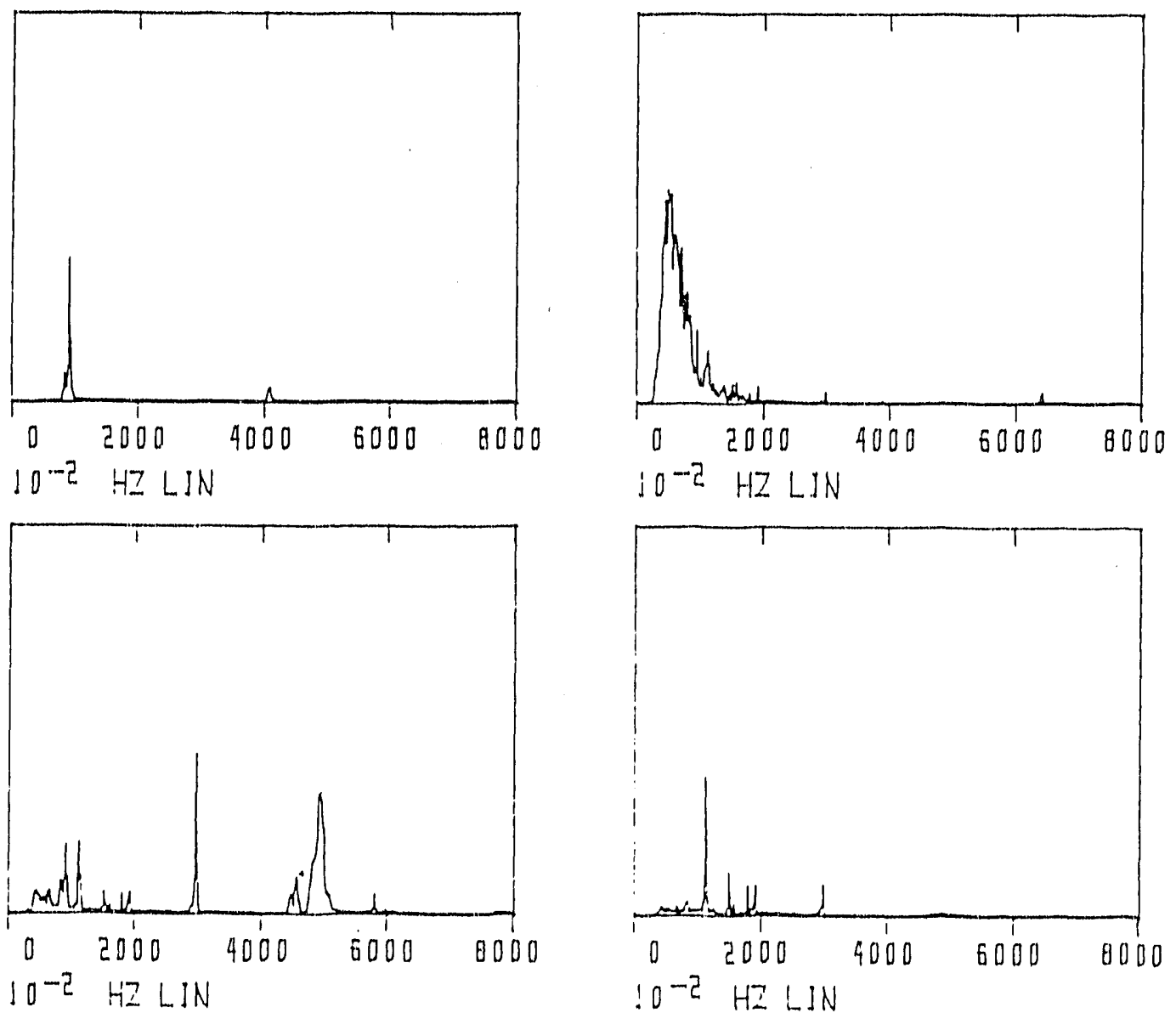

$X$ Floor Disp.Response

Y Floor Disp. Response

Z Floor Disp. Response
$X$ Vacuum Chamber Disp. Response.

Y Vacuum Chamber Disp. Response

Z Vacuum Chamber Disp. Response

TEST 4 

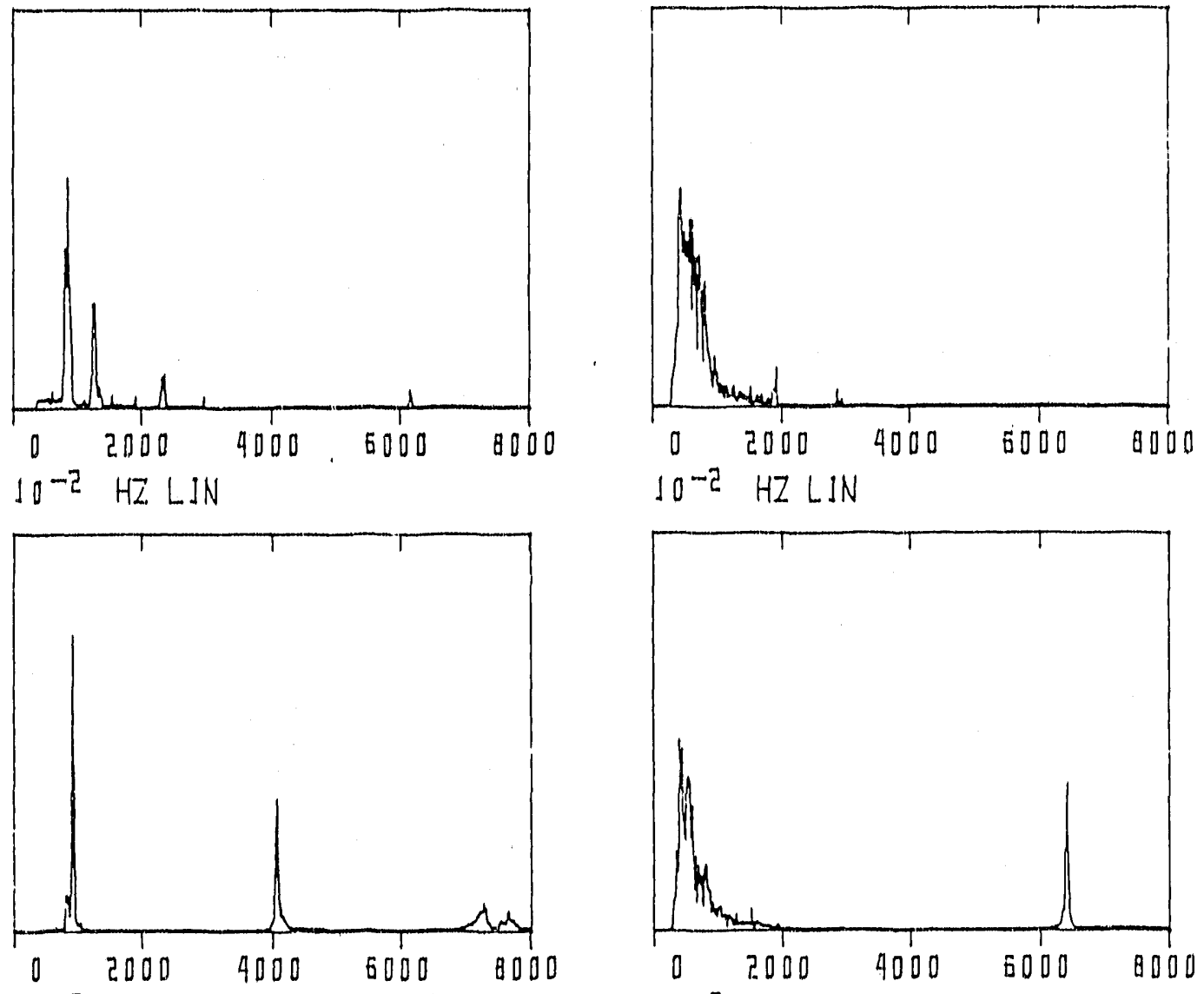

$10^{-2} \quad H Z L I N$

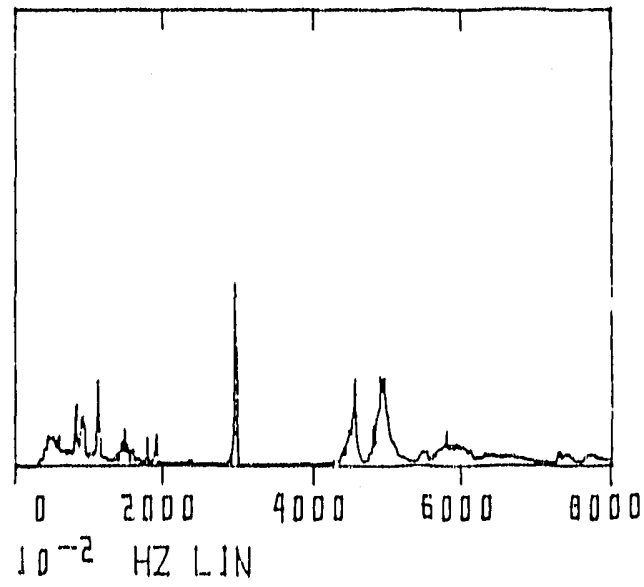

$10^{-?} \quad H Z L I N$

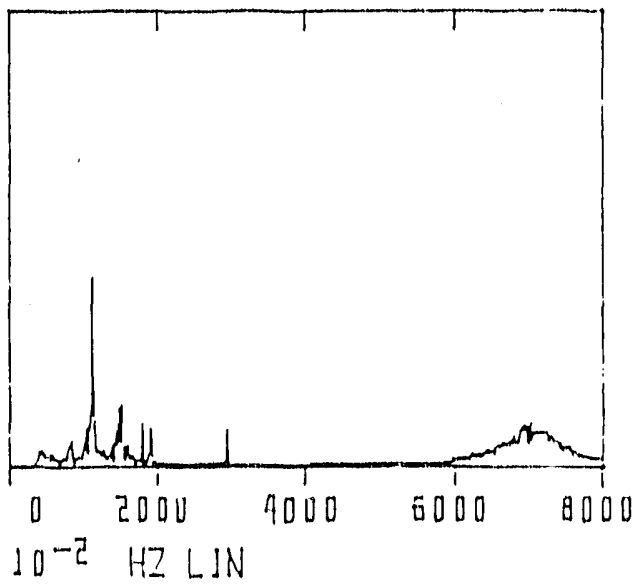

$X$ Floor Disp.Response

Y Floor Disp. Response

Z Floor Disp. Response
$X$ Vacuum Chamber Disp. Response.

Y Vacuum Chamber Dlsp. Response

$Z$ Vacuum Chamber Disp. Response 

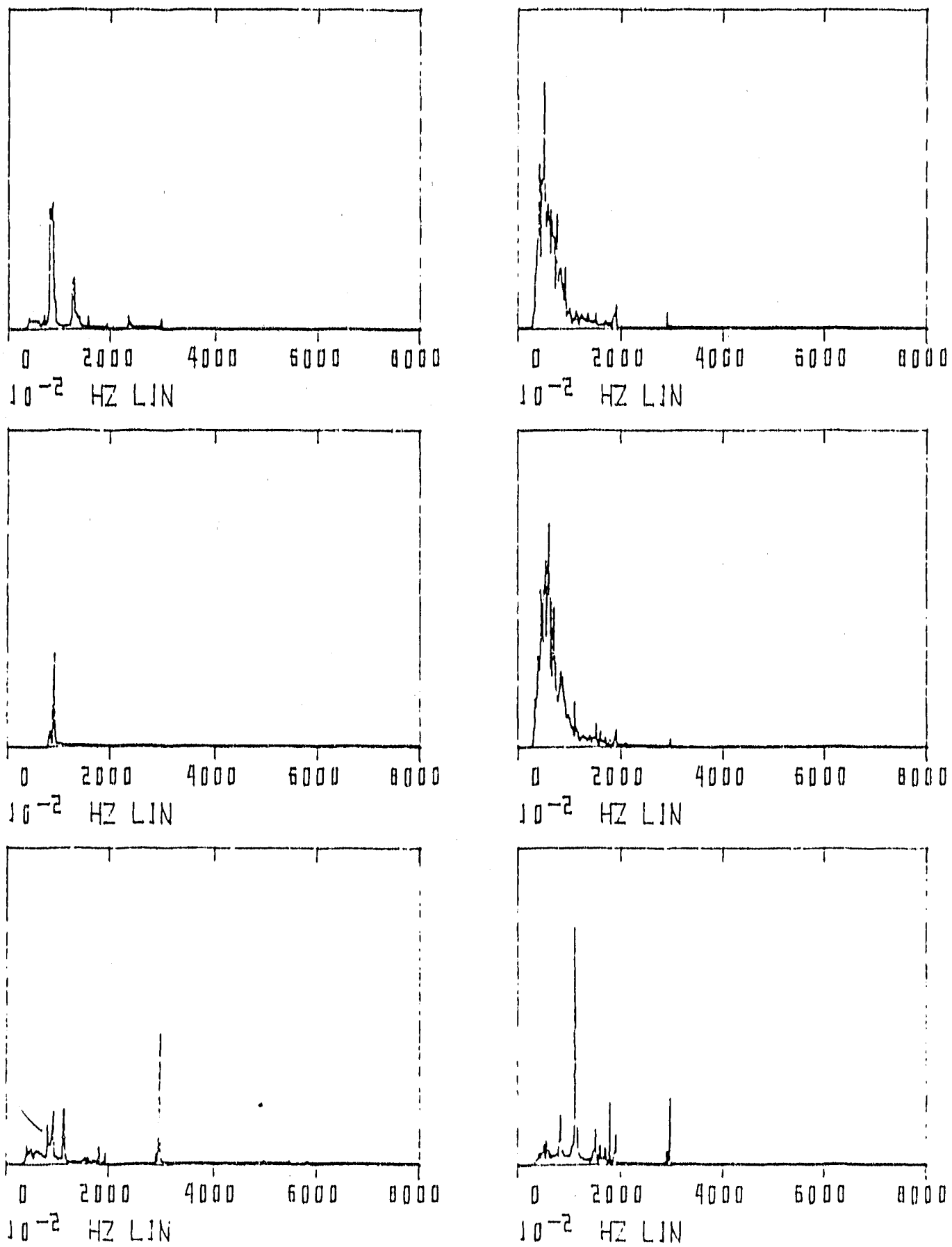

$X$ Floor Disp. Response

$X$ Vacuum Chamber Disp. Response.

Y Floor Disp. Response

Y Vacuum Chamber Disp. Response

Z Floor Disp. Response

$Z$ Vacuum Chamber Disp. Response 

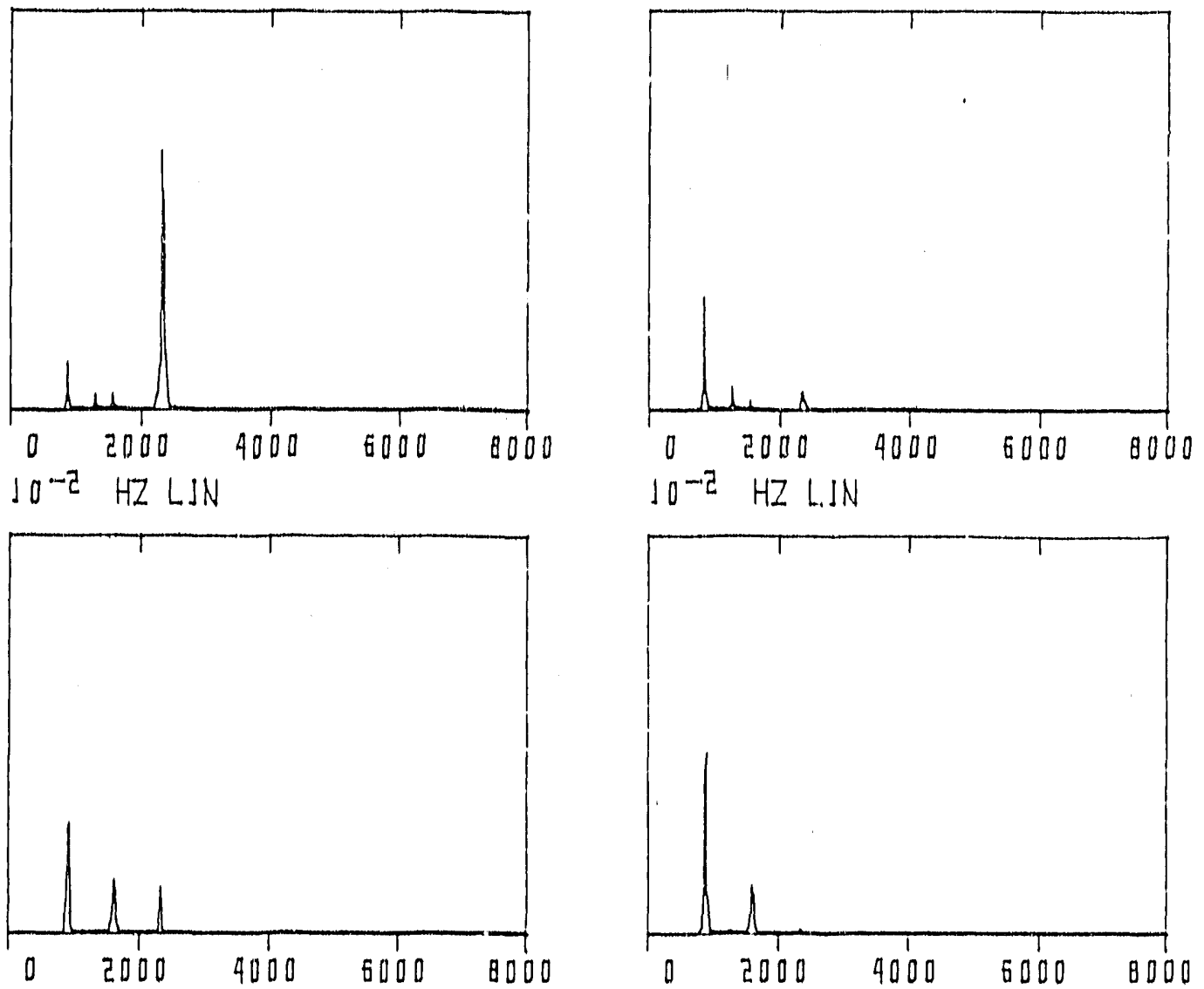

$10^{-2}$ HI LIN

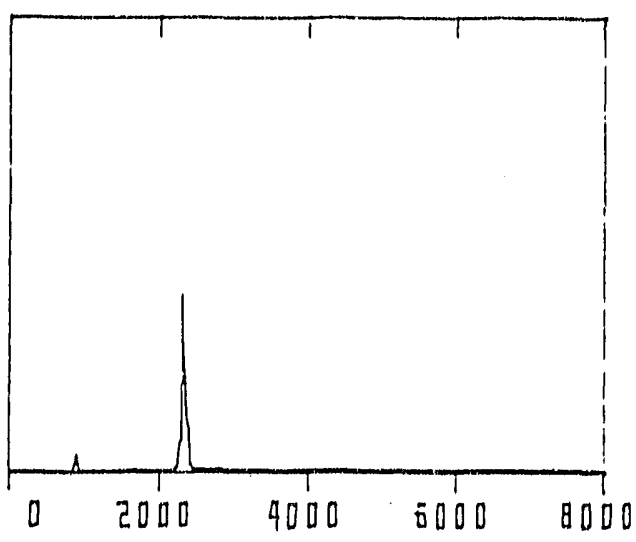

$10^{-2}$ H.Z LJN
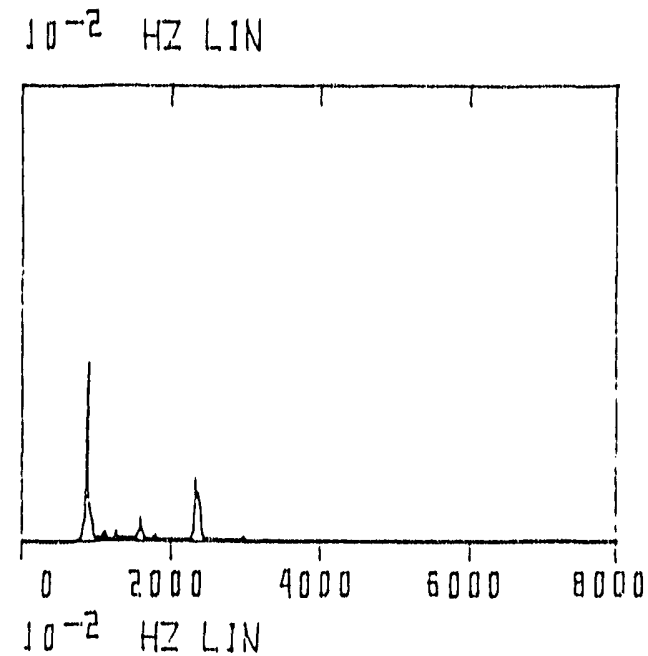

$X$ Girder Disp.Fesponse

$X$ Vacuum Chamber DIsp. Response.

Y Girder Dlsp. Response

Y Vacuum Chamber Disp. Response

Z Girder Dlsp. Response

$Z$ Vacuum Chamber Disp. Response 

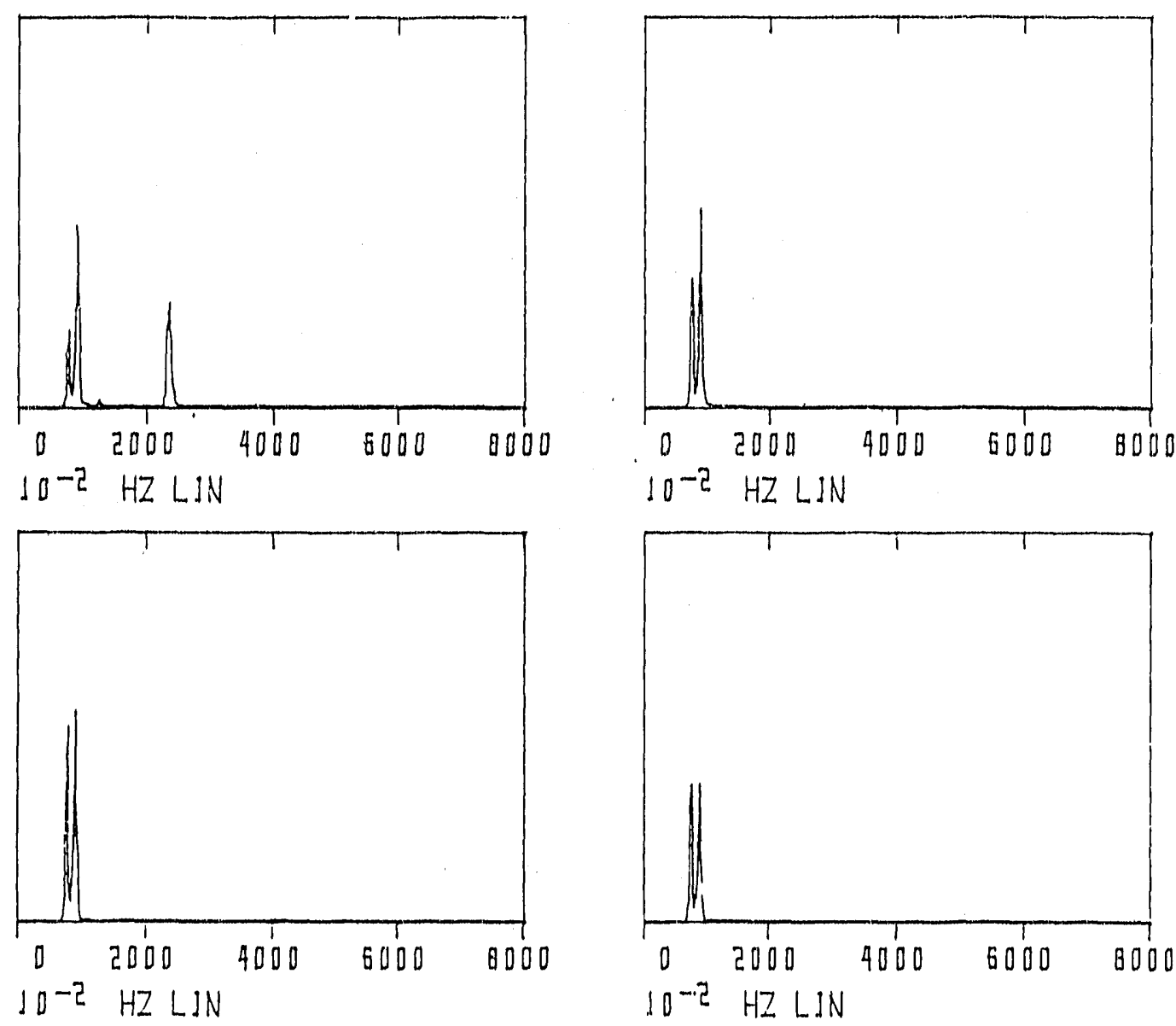

$10^{-2} \quad H Z L I N$
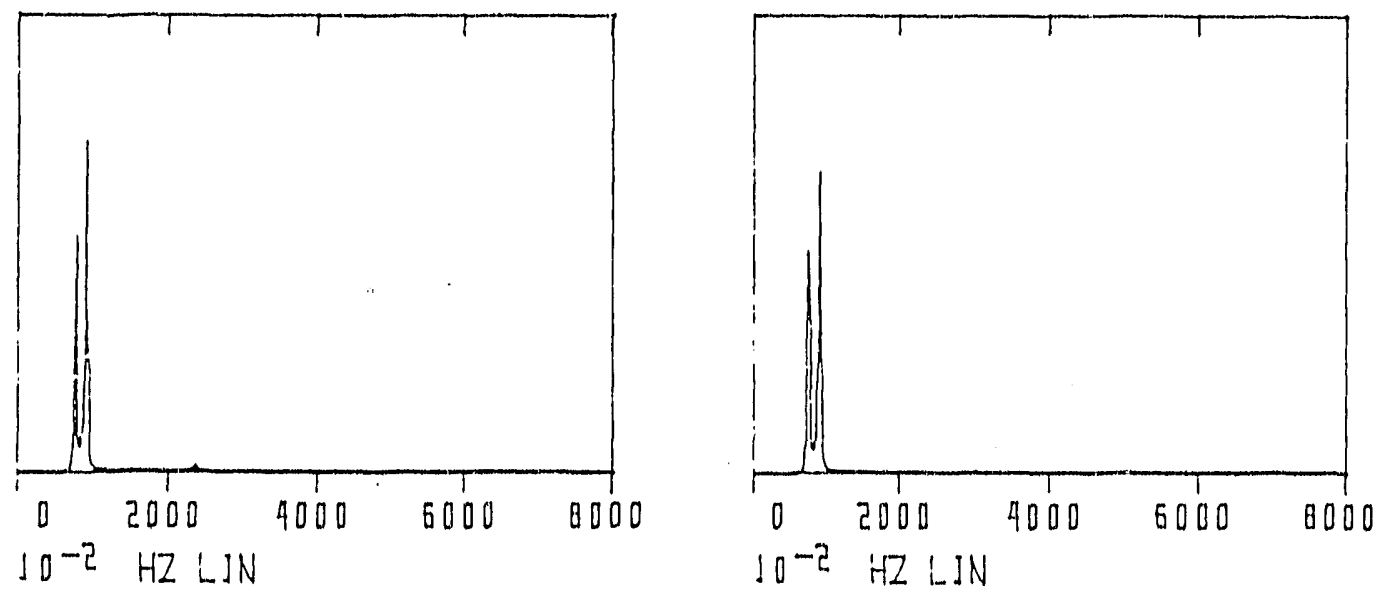

X Girder Disp.Response

Y Girder Disp. Response

$Z$ Girder Disp. Response
$X$ Vacuum Chamber Disp. Response.

Y Vacuum Chamber Disp. Response

Z Vacuum Chamber Disp. Response

TEST 7

$Y$ Direction Excitation

Excitation Level $=0.6$ 

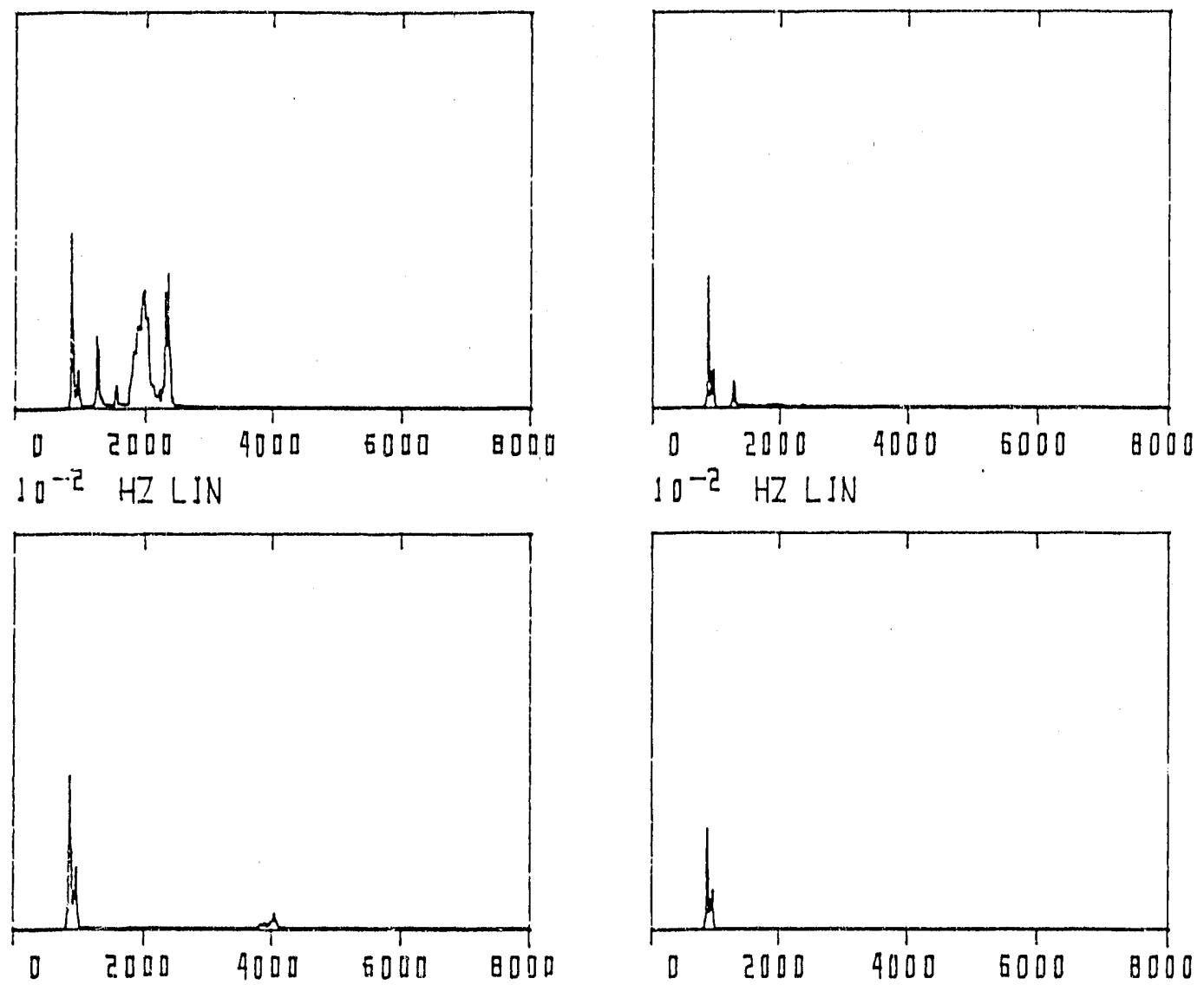

$10^{-2} \quad H Z L I N$
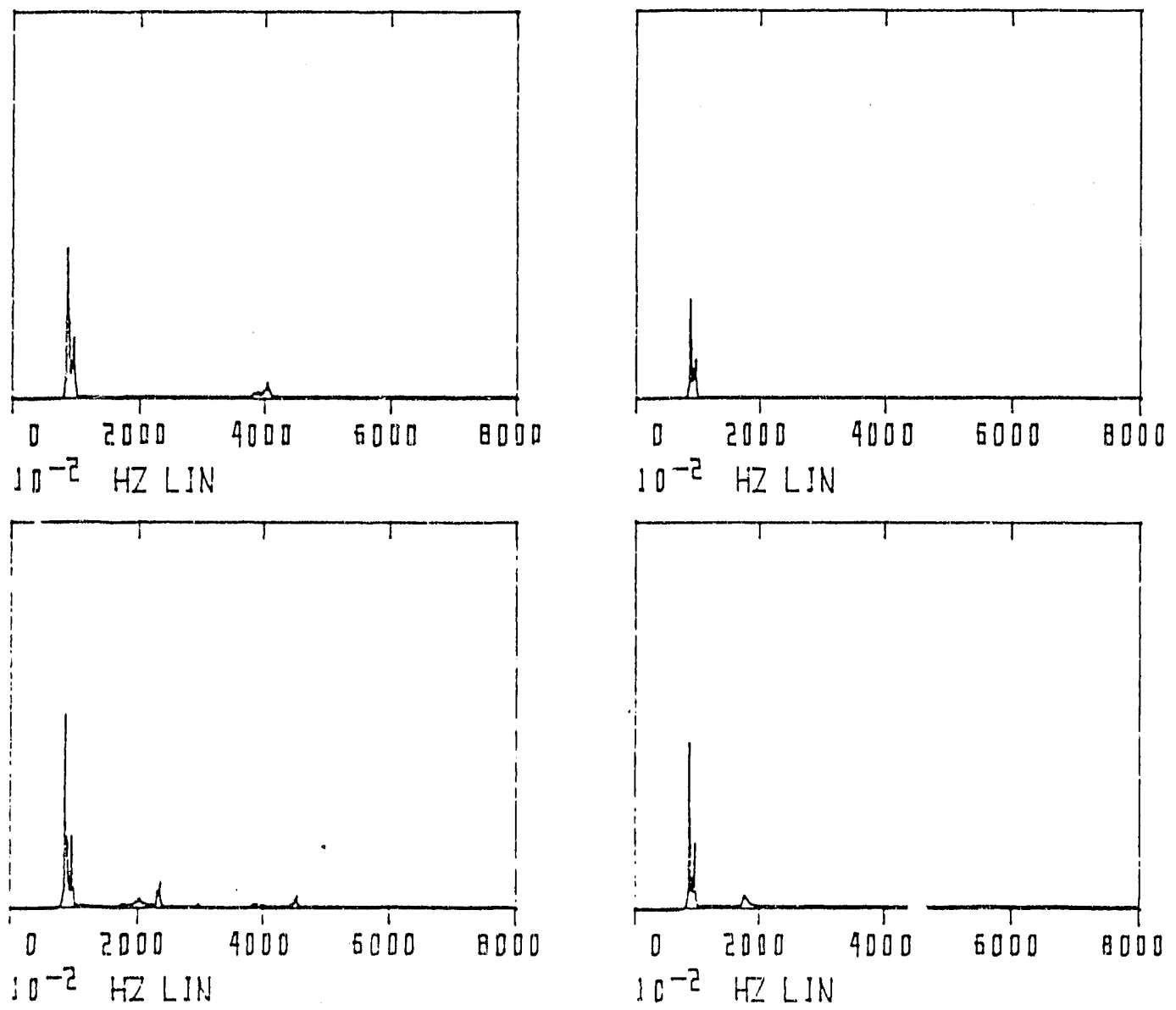

X Girder Disp.Response

Y Girder Disp. Response

Z Girder Disp. Response
$X$ Vacuum Chamber Disp. Response.

Y Vacuum Chamber Disp. Response

$Z$ Vacuum Chamber Disp. Response 
APPENDIX B - RMS Response Amplitudes and Transfor Functions 
RMS TF,Test $1,8 . .8 \mathrm{~Hz}$

\begin{tabular}{|c|c|c|c|c|c|c|c|c|}
\hline EXDir & ExLeV & $\# 1,(X, G)$ & $\# 2,(Y, G)$ & $\# 3,(Z, G)$ & $\# 4,(X, V C)$ & $\# 5,(Y, V C)$ & $\# 6,(Z, V C)$ \\
\hline & & mic. RMS & mic. RMS & mic. RMS & mic. RMS & mic. RMS & mic. RMS \\
\hline$x$ & 0.6 & 1.1810 & 0.7237 & 0.2026 & 0.8931 & 0.4859 & 0.0642 \\
\hline$x$ & 0.4 & 0.7949 & 0.4276 & 0.1247 & 0.5947 & 0.2760 & 0.0347 \\
\hline$x$ & 0.1 & 0.1748 & 0.1181 & 0.0319 & 0.1311 & 0.0848 & 0.0158 \\
\hline$z$ & 0.6 & 0.3080 & 0.3319 & 0.0794 & 0.2357 & 0.2507 & 0.0511 \\
\hline$z$ & 0.4 & 0.1934 & 0.1909 & 0.0511 & 0.1486 & 0.1427 & 0.0295 \\
\hline$z$ & 0.1 & 0.0903 & 0.0880 & 0.0256 & 0.0668 & 0.0629 & 0.0132 \\
\hline$y$ & 0.6 & 1.1827 & 1.4794 & 0.3005 & 0.8975 & 1.1236 & 0.2312 \\
\hline$y$ & 0.4 & 0.7591 & 0.8221 & 0.1877 & 0.5668 & 0.6122 & 0.1317 \\
\hline$y$ & 0.1 & 0.1844 & 0.1747 & 0.0422 & 0.1401 & 0.1338 & 0.0158 \\
\hline & & & & & & & \\
\hline & & $T F, X$ & $T F, y$ & $T F, z$ & & & \\
\hline$x$ & 0.6 & 0.76 & 0.67 & 0.32 & & & \\
\hline$x$ & 0.4 & 0.75 & 0.65 & 0.28 & & & \\
\hline$x$ & 0.1 & 0.75 & 0.72 & 0.50 & & & \\
\hline$z$ & 0.6 & 0.77 & 0.76 & 0.64 & & & \\
\hline$z$ & 0.4 & 0.77 & 0.75 & 0.58 & & & \\
\hline$z$ & 0.1 & 0.74 & 0.71 & 0.52 & & & \\
\hline$y$ & 0.6 & 0.76 & 0.76 & 0.77 & & & \\
\hline$y$ & 0.4 & 0.75 & 0.74 & 0.70 & & & \\
\hline$y$ & 0.1 & 0.76 & 0.77 & 0.37 & & & \\
\hline & & & & & & & \\
\hline & AVG. & 0.75 & 0.72 & 0.52 & & & \\
\hline
\end{tabular}


.7MS TF, Test $1,9.5 \mathrm{~Hz}$

\begin{tabular}{|c|c|c|c|c|c|c|c|c|}
\hline EXDir EXLeV & $\# 1,(X, G)$ & $\# 2,(Y, G)$ & $\# 3,(Z, G)$ & $\# 4,(X, V C$ & $\# 5,(Y, V C)$ & $\# 6,(Z, V C)$ \\
\hline & & mic. RMS & mic. RMS & mic. RMS & mic. RMS & mic. RMS & mic. RMS \\
\hline$x$ & 0.6 & 0.3735 & 0.7928 & 0.1328 & 0.3239 & 0.6258 & 0.1364 \\
\hline$x$ & 0.4 & 0.2878 & 0.5738 & 0.1056 & 0.2343 & 0.4462 & 0.0918 \\
\hline$x$ & 0.1 & 0.0668 & 0.2086 & 0.0289 & 0.0581 & 0.1644 & 0.0269 \\
\hline$z$ & 0.6 & 0.1476 & 0.6522 & 0.1306 & 0.1488 & 0.5198 & 0.1048 \\
\hline$z$ & 0.4 & 0.1095 & 0.3987 & 0.0673 & 0.1078 & 0.3202 & 0.0581 \\
\hline$z$ & 0.1 & 0.0439 & 0.1841 & 0.0322 & 0.0428 & 0.1455 & 0.0297 \\
\hline$y$ & 0.6 & 0.6215 & 2.7016 & 0.4495 & 0.6271 & 2.1424 & 0.4096 \\
\hline$y$ & 0.4 & 0.4514 & 1.7578 & 0.2888 & 0.4502 & 1.3953 & 0.2652 \\
\hline$y$ & 0.1 & 0.1125 & 0.4096 & 0.0729 & 0.1133 & 0.3297 & 0.0697 \\
\hline & & & & & & & \\
\hline & & $T F, x$ & $T F, y$ & $T F, z$ & & & \\
\hline$x$ & 0.6 & 0.87 & 0.79 & 1.03 & & & \\
\hline$x$ & 0.4 & 0.81 & 0.78 & 0.87 & & & \\
\hline$x$ & 0.1 & 0.87 & 0.79 & 0.93 & & & \\
\hline$z$ & 0.6 & 1.01 & 0.80 & 0.80 & & & \\
\hline$z$ & 0.4 & 0.98 & 0.80 & 0.86 & & & \\
\hline$z$ & 0.1 & 0.97 & 0.79 & 0.92 & & & \\
\hline$y$ & 0.6 & 1.01 & 0.79 & 0.91 & & & \\
\hline$y$ & 0.4 & 1.00 & 0.79 & 0.92 & & & \\
\hline$y$ & 0.1 & 1.01 & 0.80 & 0.96 & & & \\
\hline & & & & & & & \\
\hline & AVG & 0.95 & 0.79 & 0.91 & & & \\
\hline
\end{tabular}


RMS TF, Test1,12.9Hz

\begin{tabular}{|c|c|c|c|c|c|c|}
\hline ExLeV & $\# 1,(X, G)$ & $\# 2,(Y, G)$ & $\# 3,(Z, G)$ & $\# 4,(X, V C)$ & $\# 5,(Y, V C)$ & $\# 6,(Z, V C)$ \\
\hline & mic. RMS & mic. RMS & mic. RMS & mic. RMS & mic. RMS & mic. RMS \\
\hline 0.6 & 1.4398 & 0.0671 & 0.0687 & 0.8719 & 0.3736 & 0.0639 \\
\hline 0.4 & 0.8957 & 0.0490 & 0.0434 & 0.5389 & 0.2300 & 0.0401 \\
\hline 0.1 & 0.1754 & 0.0149 & 0.0129 & 0.1051 & 0.0464 & 0.0117 \\
\hline 0.6 & 0.1740 & 0.0510 & 0.0335 & 0.1046 & 0.0632 & 0.0230 \\
\hline 0.4 & 0.0825 & 0.0337 & 0.0183 & 0.0494 & 0.0353 & 0.0100 \\
\hline 0.1 & 0.1059 & 0.0186 & 0.0131 & 0.0638 & 0.0304 & 0.0138 \\
\hline 0.6 & 0.4823 & 0.2978 & 0.0689 & 0.2884 & 0.2671 & 0.0491 \\
\hline 0.4 & 0.3018 & 0.1989 & 0.0375 & 0.1795 & 0.1772 & 0.0277 \\
\hline 0.1 & 0.0986 & 0.0450 & 0.0117 & 0.0587 & 0.0434 & 0.0096 \\
\hline & & & & & & \\
\hline & $T F, X$ & $T F, y$ & $T F, Z$ & & & \\
\hline 0.6 & 0.61 & 5.57 & 0.93 & & & \\
\hline 0.4 & 0.60 & 4.69 & 0.93 & & & \\
\hline 0.1 & 0.60 & 3.11 & 0.91 & & & \\
\hline 0.6 & 0.60 & 1.24 & 0.69 & & & \\
\hline 0.4 & 0.60 & 1.05 & 0.55 & & & \\
\hline 0.1 & 0.60 & 1.64 & 1.05 & & & \\
\hline 0.6 & 0.60 & 0.90 & 0.71 & & & \\
\hline 0.4 & 0.59 & 0.89 & 0.74 & & & \\
\hline 0.1 & 0.60 & 0.97 & 0.82 & & & \\
\hline & & & & & & \\
\hline AVG & 0.60 & 2.23 & 0.81 & & & \\
\hline
\end{tabular}


RMS TF, Test $1,15.6 \mathrm{~Hz}$

\begin{tabular}{|c|c|c|c|c|c|c|c|}
\hline \multicolumn{2}{|c|}{ EXDir EXLeV } & $\# 1,(\mathrm{X}, G)$ & $\# 2,(Y, G)$ & $\# 3,(Z, G)$ & $\# 4,(X, V C)$ & $\# 5,(Y, V C)$ & $\# 6,(Z, V C)$ \\
\hline & & mic. RMS & mic. RMS & mic. RMS & mic. RMS & mic. RMS & mic. RMS \\
\hline$x$ & 0.6 & 0.6633 & 0.0451 & 0.0844 & 0.2613 & 0.0513 & 0.0207 \\
\hline$x$ & 0.4 & 0.4105 & 0.0326 & 0.0562 & 0.1591 & 0.0319 & 0.0166 \\
\hline$x$ & 0.1 & 0.0969 & 0.0092 & 0.0157 & 0.0377 & 0.0079 & 0.0107 \\
\hline$z$ & 0.6 & 0.0363 & 0.0315 & 0.0257 & 0.0164 & 0.0223 & 0.0183 \\
\hline$z$ & 0.4 & 0.0148 & 0.0194 & 0.0145 & 0.0073 & 0.0150 & 0.0097 \\
\hline$z$ & 0.1 & 0.0261 & 0.0105 & 0.0165 & 0.0104 & 0.0084 & 0.0168 \\
\hline$y$ & 0.6 & 0.1171 & 0.1709 & 0.0410 & 0.0551 & 0.1194 & 0.0320 \\
\hline$y$ & 0.4 & 0.0825 & 0.1091 & 0.0283 & 0.0335 & 0.0787 & 0.0219 \\
\hline$y$ & 0.1 & 0.0340 & 0.0269 & 0.0127 & 0.0134 & 0.0195 & 0.0119 \\
\hline & & & & & & & \\
\hline & & TF,X & TF,y & TF,z & & & \\
\hline$x$ & 0.6 & 0.39 & 1.14 & 0.25 & & & \\
\hline$x$ & 0.4 & 0.39 & 0.98 & 0.30 & & & \\
\hline$x$ & 0.1 & 0.39 & 0.86 & 0.68 & & & \\
\hline$z$ & 0.6 & 0.45 & 0.71 & 0.71 & & & \\
\hline$z$ & 0.4 & 0.49 & 0.78 & 0.67 & & & \\
\hline$z$ & 0.1 & 0.40 & 0.80 & 1.02 & & & \\
\hline$y$ & 0.6 & 0.47 & 0.70 & 0.78 & & & \\
\hline$y$ & 0.4 & 0.41 & 0.72 & 0.77 & & & \\
\hline$y$ & 0.1 & 0.39 & 0.72 & 0.94 & & & \\
\hline & & & & & & & \\
\hline & AVG & 0.42 & 0.82 & 0.68 & & & \\
\hline
\end{tabular}


RMS Tf,Test1, 23.7Hz

\begin{tabular}{|c|c|c|c|c|c|c|c|}
\hline EXDir & EXLeV & $\# 1,(X, G)$ & $\# 2,(Y, G)$ & $\# 3,(Z, G)$ & $\# 4,(X, V C)$ & $\# 5,(Y, V C)$ & $\# 6,(Z, V C)$ \\
\hline & & mlc. RMS & mlc. RMS & mlc. RMS & mlc. RMS & mlo. RMS & mlc. RMS \\
\hline$x$ & 0.6 & 3.0701 & 0.3281 & 0.7874 & 0.4404 & 0.0678 & 0.1400 \\
\hline$x$ & 0.4 & 1.7730 & 0.1981 & 0.4587 & 0.2585 & 0.0424 & 0.0814 \\
\hline$x$ & 0.1 & 0.4341 & 0.0509 & 0.1063 & 0.0633 & 0.0111 & 0.0191 \\
\hline$z$ & 0.6 & 0.8569 & 0.1306 & 0.2053 & 0.1232 & 0.0365 & 0.0393 \\
\hline$z$ & 0.4 & 0.4394 & 0.0666 & 0.1129 & 0.0632 & 0.0188 & 0.0216 \\
\hline$z$ & 0.1 & 0.0297 & 0.0060 & 0.0105 & 0.0044 & 0.0029 & 0.0058 \\
\hline$y$ & 0.6 & 1.9494 & 0.3286 & 0.4885 & 0.2644 & 0.1058 & 0.0895 \\
\hline$y$ & 0.4 & 1.2678 & 0.1928 & 0.3477 & 0.1762 & 0.0633 & 0.0635 \\
\hline$y$ & 0.1 & 0.2997 & 0.0461 & 0.0728 & 0.0419 & 0.0144 & 0.0132 \\
\hline & & & & & & & \\
\hline & & $T F, x$ & $T F, y$ & $T F, z$ & & & \\
\hline$x$ & 0.6 & 0.14 & 0.21 & 0.18 & & & \\
\hline$x$ & 0.4 & 0.15 & 0.21 & 0.18 & & & \\
\hline$x$ & 0.1 & 0.15 & 0.22 & 0.18 & & & \\
\hline$z$ & 0.6 & 0.14 & 0.28 & 0.19 & & & \\
\hline$z$ & 0.4 & 0.14 & 0.28 & 0.19 & & & \\
\hline$z$ & 0.1 & 0.15 & 0.48 & 0.55 & & & \\
\hline$y$ & 0.6 & 0.14 & 0.32 & 0.18 & & & \\
\hline$y$ & 0.4 & 0.14 & 0.33 & 0.18 & & & \\
\hline$y$ & 0.1 & 0.14 & 0.31 & 0.18 & & & \\
\hline & & & & & & & \\
\hline & AVG & 0.14 & 0.29 & 0.22 & & & \\
\hline
\end{tabular}


RMS TF, Test $1,30.0 \mathrm{~Hz}$

\begin{tabular}{|c|c|c|c|c|c|c|c|}
\hline EXDir EXLeV & $\# 1,(X, G)$ & $\# 2,(Y, G)$ & $\# 3,(Z, G)$ & $\# 4,(X, V C)$ & $\# 5,(Y, V C)$ & $\# 6,(Z, V C)$ \\
\hline & & mic. RMS & mic. RMS & mic. RMS & mic. RMS & mlo. RMS & mlc. RMS \\
\hline$x$ & 0.6 & 0.0813 & 0.0334 & 0.0579 & 0.0645 & 0.0204 & 0.0199 \\
\hline$x$ & 0.4 & 0.0737 & 0.0223 & 0.0398 & 0.0415 & 0.0147 & 0.0146 \\
\hline$x$ & 0.1 & 0.0172 & 0.0146 & 0.0300 & 0.0189 & 0.0092 & 0.0131 \\
\hline$z$ & 0.6 & 0.0257 & 0.0480 & 0.0502 & 0.0304 & 0.0305 & 0.0181 \\
\hline$z$ & 0.4 & 0.0167 & 0.0341 & 0.0397 & 0.0224 & 0.0216 & 0.0156 \\
\hline$z$ & 0.1 & 0.0113 & 0.0143 & 0.0327 & 0.0167 & 0.0093 & 0.0142 \\
\hline$y$ & 0.6 & 0.1693 & 0.3627 & 0.2814 & 0.1844 & 0.1917 & 0.1102 \\
\hline$y$ & 0.4 & 0.0665 & 0.1714 & 0.1286 & 0.0780 & 0.0891 & 0.0496 \\
\hline$y$ & 0.1 & 0.0175 & 0.0284 & 0.0379 & 0.0220 & 0.0164 & 0.0143 \\
\hline & & & & & & & \\
\hline & & $T F, x$ & $T F, y$ & $T F, z$ & & & \\
\hline$x$ & 0.6 & 0.79 & 0.61 & 0.34 & & & \\
\hline$x$ & 0.4 & 0.56 & 0.66 & 0.37 & & & \\
\hline$x$ & 0.1 & 1.10 & 0.63 & 0.43 & & & \\
\hline$z$ & 0.6 & 1.18 & 0.63 & 0.36 & & & \\
\hline$z$ & 0.4 & 1.34 & 0.63 & 0.39 & & & \\
\hline$z$ & 0.1 & 1.47 & 0.65 & 0.43 & & & \\
\hline$y$ & 0.6 & 1.09 & 0.53 & 0.39 & & & \\
\hline$y$ & 0.4 & 1.17 & 0.52 & 0.39 & & & \\
\hline$y$ & 0.1 & 1.26 & 0.58 & 0.38 & & & \\
\hline & & & & & & & \\
\hline & $A V G$ & 1.11 & 0.60 & 0.39 & & & \\
\hline
\end{tabular}


RMS TF, TøSt1,45.9Hz

\begin{tabular}{|c|c|c|c|c|c|c|c|}
\hline EXDir & ExLev & $\# 1,(x, G)$ & $\# 2,(Y, Q)$ & $\# 3,(2, G)$ & $\# 4,(X, \vee C)$ & $\# 5,(Y, \vee C)$ & $\# 6,(Z, \vee C)$ \\
\hline & & mlc. RMS & mlc. RMS & mlc. RMS & mic. AMS & mic. FMS & mic. $R M S$ \\
\hline$x$ & 0.6 & 0.0237 & 0.0160 & 0.1383 & 0.0355 & 0.0094 & 0.0149 \\
\hline$x$ & 0.4 & 0.0214 & 0.0106 & 0.0684 & 0.0210 & 0.0078 & 0.0092 \\
\hline$x$ & 0.1 & 0.0038 & 0.0043 & 0.0240 & 0.0050 & 0.0013 & 0.0029 \\
\hline$z$ & 0.6 & 0.0131 & 0.0384 & 0.2634 & 0.0044 & 0.0055 & 0.0291 \\
\hline 2 & 0.4 & 0.0086 & 0.0257 & 0.1642 & 0.0030 & 0.0037 & 0.0203 \\
\hline$z$ & 0.1 & 0.0022 & 0.0063 & 0.0375 & 0.0011 & 0.0014 & 0.0058 \\
\hline$y$ & 0.6 & 0.0192 & 0.0333 & 0.2170 & 0.0099 & 0.0148 & 0.0258 \\
\hline$y$ & 0.4 & 0.0100 & 0.0188 & 0.1376 & 0.0076 & 0.0113 & 0.0163 \\
\hline \multirow[t]{3}{*}{$y$} & 0.1 & 0.0034 & 0.0099 & 0.0263 & 0.0014 & 0.0029 & 0.0029 \\
\hline & & & & & & & \\
\hline & & $T F, x$ & $T F, y$ & $T f, 2$ & & & \\
\hline$x$ & 0.6 & 1.50 & 0.59 & 0.11 & & & \\
\hline$x$ & 0.4 & 0.98 & 0.74 & 0.14 & & & \\
\hline$x$ & 0.1 & 1.34 & 0.29 & 0.12 & & & \\
\hline 2 & 0.6 & 0.34 & 0.14 & 0.11 & & & \\
\hline$z$ & 0.4 & 0.34 & 0.14 & 0.12 & & & \\
\hline 2 & 0.1 & 0.51 & 0.22 & 0.15 & & & \\
\hline$y$ & 0.6 & 0.52 & 0.44 & 0.12 & & & \\
\hline$y$ & 0.4 & 0.76 & 0.60 & 0.12 & & & \\
\hline \multirow[t]{3}{*}{$y$} & 0.1 & 0.42 & 0.30 & 0.11 & & & \\
\hline & & & & & & & \\
\hline & AVG & 0.75 & 0.39 & 0.12 & & & \\
\hline
\end{tabular}


RMS TF, Test $1,86.7 \mathrm{~Hz}$

\begin{tabular}{|c|c|c|c|c|c|c|c|}
\hline ExDir & EXLeV & $\# 1,(X, G)$ & $\# 2,(Y, Q)$ & $\$ 3,(Z, Q)$ & $\# 4,(X, V C)$ & $\# 5,(Y, V C)$ & $\# 6,(Z, V C)$ \\
\hline & & mio. RMS & mlc. RMS & mic. RMS & mlc. RMS & mlc. RMS & mlc. RMS \\
\hline$x$ & 0.6 & 0.0378 & 0.0459 & 0.1647 & 0.0135 & 0.0162 & 0.0264 \\
\hline$x$ & 0.4 & 0.0258 & 0.0300 & 0.0957 & 0.0120 & 0.0119 & 0.0175 \\
\hline$x$ & 0.1 & 0.0051 & 0.0066 & 0.0224 & 0.0014 & 0.0019 & 0.0035 \\
\hline$z$ & 0.6 & 0.0208 & 0.0399 & 0.1024 & 0.0030 & 0.0054 & 0.0160 \\
\hline$z$ & 0.4 & 0.0177 & 0.0331 & 0.0870 & 0.0024 & 0.0044 & 0.0129 \\
\hline$z$ & 0.1 & 0.0069 & 0.0122 & 0.0326 & 0.0014 & 0.0021 & 0.0045 \\
\hline$y$ & 0.6 & 0.0904 & 0.2778 & 0.4631 & 0.0194 & 0.0563 & 0.0788 \\
\hline$y$ & 0.4 & 0.0584 & 0.1758 & 0.3004 & 0.0134 & 0.0347 & 0.0519 \\
\hline \multirow[t]{3}{*}{$y$} & 0.1 & 0.0123 & 0.0397 & 0.0 .672 & 0.0022 & 0.0066 & 0.0113 \\
\hline & & & & & & & \\
\hline & & $T F, X$ & $T F, Y$ & $T F, z$ & & & \\
\hline$x$ & 0.6 & 0.36 & 0.35 & 0.16 & & & \\
\hline$x$ & 0.4 & 0.46 & 0.40 & 0.18 & & & \\
\hline$x$ & 0.1 & 0.27 & 0.29 & 0.15 & & & \\
\hline 2 & 0.6 & 0.14 & 0.13 & 0.16 & & & \\
\hline$z$ & 0.4 & 0.14 & 0.13 & 0.15 & & & \\
\hline$z$ & 0.1 & 0.20 & 0.17 & 0.14 & & & \\
\hline$y$ & 0.6 & 0.22 & 0.20 & 0.17 & & & \\
\hline$y$ & 0.4 & 0.23 & 0.20 & 0.17 & & & \\
\hline \multirow[t]{3}{*}{$y$} & 0.1 & 0.18 & 0.17 & 0.17 & & & \\
\hline & & & & & & & \\
\hline & AVG & 0.24 & 0.23 & 0.16 & & & \\
\hline
\end{tabular}


RMS TF, Test1, 108.1 Hz

\begin{tabular}{|c|c|c|c|c|c|c|c|}
\hline EXDIr & EXLOV & $\# 1,(X, Q)$ & $\# 2,(Y, G)$ & $\# 3,(Z, G)$ & $\# 4,(X, V C)$ & $\# 5,(Y, \vee C)$ & $\# 6,(2, \vee C)$ \\
\hline & & mic. RMS & mlo. RMS & mlc. RMS & mlo: RMS & mlc. AMS & mlo. RMS \\
\hline$x$ & 0.6 & 0.0240 & 0.0695 & 0.1635 & 0.0345 & 0.0219 & 0.0387 \\
\hline$x$ & 0.4 & 0.0233 & 0.0460 & 0.0960 & 0.0244 & 0.0193 & 0.0252 \\
\hline$x$ & 0.1 & 0.0032 & 0.0110 & 0.0242 & 0.0034 & 0.0023 & 0.0050 \\
\hline$z$ & 0.6 & 0.0135 & 0.1265 & $0 . \overline{2574}$ & 0.0639 & 0.0144 & 0.0573 \\
\hline$z$ & 0.4 & 0.0088 & 0.0830 & 0.1786 & 0.0392 & 0.0098 & 0.0382 \\
\hline$z$ & 0.1 & 0.0025 & 0.0175 & 0.0374 & 0.0062 & 0.0028 & 0.0078 \\
\hline$y$ & 0.6 & 0.0184 & 0.0260 & 0.0302 & 0.0160 & 0.0190 & 0.0168 \\
\hline$y$ & 0.4 & 0.0171 & 0.0212 & 0.0220 & 0.0162 & 0.0176 & 0.0146 \\
\hline \multirow[t]{3}{*}{$y$} & 0.1 & 0.0023 & 0.0048 & 0.0062 & 0.0020 & 0.0026 & 0.0021 \\
\hline & & & & & & & \\
\hline & & $T F, x$ & $T F, y$ & $T f, 2$ & & & \\
\hline$x$ & 0.6 & 1.43 & 0.31 & 0.24 & & & \\
\hline$x$ & 0.4 & 1.05 & 0.42 & 0.26 & & & \\
\hline$x$ & 0.1 & 1.08 & 0.21 & 0.21 & & & \\
\hline 2 & 0.6 & 4.72 & 0.11 & 0.22 & & & \\
\hline 2 & 0.4 & 4.44 & 0.12 & 0.21 & & & \\
\hline 2 & 0.1 & 2.45 & 0.16 & 0.21 & & & \\
\hline$y$ & 0.6 & 0.87 & 0.73 & 0.56 & & & \\
\hline$y$ & 0.4 & 0.95 & 0.83 & 0.66 & & & \\
\hline \multirow[t]{3}{*}{$y$} & 0.1 & 0.87 & 0.54 & 0.34 & & & \\
\hline & & & & & & & \\
\hline & AVG & 1.98 & 0.38 & 0.32 & & & \\
\hline
\end{tabular}


RMS TF, Test1,116.9Hz

\begin{tabular}{|c|c|c|c|c|c|c|c|}
\hline EXDIr & EXLeV & $\# 1,(X, G)$ & $\# 2,(Y, Q)$ & $\# 3,(Z, G)$ & $\# 4,(X, V C)$ & \multicolumn{2}{|c|}{$\# 5,(Y, V C) \quad \# 6,(Z, V C)$} \\
\hline & & mlc. RMS & mlo. RMS & mlo. RMS & mlo. RMS & mlo. RMS & mic. $F M S$ \\
\hline$x$ & 0.6 & 0.0229 & 0.0442 & 0.0991 & 0.0520 & 0.0181 & 0.0350 \\
\hline$x$ & 0.4 & 0.0210 & 0.0290 & 0.0547 & 0.0376 & 0.0171 & 0.0249 \\
\hline$x$ & 0.1 & 0.0034 & 0.0059 & 0.0152 & 0.0132 & 0.0023 & 0.0063 \\
\hline$z$ & 0.6 & 0.0226 & 0.1221 & 0.2511 & 0.0716 & 0.0115 & 0.0729 \\
\hline$z$ & 0.4 & 0.0146 & 0.0789 & 0.1712 & 0.0557 & 0.0078 & 0.0498 \\
\hline$z$ & 0.1 & 0.0035 & 0.0156 & 0.0351 & 0.0208 & 0.0024 & 0.0109 \\
\hline$y$ & 0.6 & 0.0186 & 0.0243 & 0.0324 & 0.0252 & 0.0179 & 0.0176 \\
\hline$y$ & 0.4 & 0.0148 & 0.0184 & 0.0208 & 0.0202 & 0.0159 & 0.0150 \\
\hline$y$ & 0.1 & 0.0022 & 0.0043 & 0.0093 & 0.0110 & 0.0025 & 0.0051 \\
\hline & & & & & & & \\
\hline & & $T F, x$ & $T F, Y$ & $T F, z$ & & & \\
\hline$x$ & 0.6 & 2.27 & 0.41 & 0.35 & & & \\
\hline$x$ & 0.4 & 1.79 & 0.59 & 0.46 & & & \\
\hline$x$ & 0.1 & 3.91 & 0.39 & 0.42 & & . & \\
\hline$z$ & 0.6 & 3.17 & 0.09 & 0.29 & & & \\
\hline$z$ & 0.4 & 3.83 & 0.10 & 0.29 & & & \\
\hline$z$ & 0.1 & 6.00 & 0.15 & 0.31 & & & \\
\hline$y$ & 0.6 & 1.36 & 0.74 & 0.54 & & & \\
\hline$y$ & 0.4 & 1.36 & 0.86 & 0.72 & & & \\
\hline$y$ & 0.1 & 4.93 & 0.58 & 0.55 & & & \\
\hline & & & & & & & \\
\hline & $A \vee G$ & 3.18 & 0.43 & 0.44 & & & \\
\hline
\end{tabular}


RMS TF, Test1,126Hz

\begin{tabular}{|c|c|c|c|c|c|c|c|}
\hline ExDir & ExLeV & $\# 1,(X, G)$ & $\# 2,(Y, G)$ & $\# 3,(Z, G)$ & $\# 4_{1}(x, \vee C)$ & $\# 5,(Y, \vee C)$ & $\# 6,(z, \vee C)$ \\
\hline & & mlc. RMS & mlo. RMS & mic. RMS & mlo. RMS & mlo. RMS & mlc. RMS \\
\hline$x$ & 0.6 & 0.0237 & 0.0722 & 0.1654 & 0.0264 & 0.0166 & 0.0446 \\
\hline$x$ & 0.4 & 0.0217 & 0.0439 & 0.0870 & 0.0215 & 0.0162 & 0.0254 \\
\hline$x$ & 0.1 & 0.0030 & 0.0104 & 0.0208 & 0.0043 & 0.0017 & 0.0054 \\
\hline$z$ & 0.6 & 0.0341 & 0.1862 & 0.4259 & 0.0443 & 0.0093 & 0.1038 \\
\hline$z$ & 0.4 & 0.0223 & 0.1315 & 0.2818 & 0.0297 & 0.0063 & 0.0674 \\
\hline$z$ & 0.1 & 0.0048 & 0.0275 & 0.0579 & 0.0080 & 0.0021 & 0.0140 \\
\hline$y$ & 0.6 & 0.0200 & 0.0333 & 0.0585 & 0.0195 & 0.0177 & 0.0223 \\
\hline$y$ & 0.4 & 0.0156 & 0.0218 & 0.0354 & 0.0169 & 0.0157 & 0.0181 \\
\hline \multirow[t]{3}{*}{$y$} & 0.1 & 0.0022 & 0.0048 & 0.0074 & 0.0026 & 0.0023 & 0.0028 \\
\hline & & & & & & & \\
\hline & & $T F, x$ & $T F, y$ & $T F, z$ & & & \\
\hline$x$ & 0.6 & 1.11 & 0.23 & 0.27 & & & \\
\hline$x$ & 0.4 & 0.99 & 0.37 & 0.29 & & & \\
\hline$x$ & 0.1 & 1.41 & 0.17 & 0.26 & & & \\
\hline$z$ & 0.6 & 1.30 & 0.05 & 0.24 & & & \\
\hline$z$ & 0.4 & 1.33 & 0.05 & 0.24 & & & \\
\hline$z$ & 0.1 & 1.66 & 0.08 & 0.24 & & & \\
\hline$y$ & 0.6 & 0.97 & 0.53 & 0.38 & & & \\
\hline$y$ & 0.4 & 1.08 & 0.72 & 0.51 & & & \\
\hline \multirow[t]{3}{*}{$y$} & 0.1 & 1.18 & 0.49 & 0.37 & & & \\
\hline & & & & & & & \\
\hline & $A \vee G$ & 1.23 & 0.30 & 0.31 & & & \\
\hline
\end{tabular}


RMS, TF, Test $4,8,8 \mathrm{~Hz}$

\begin{tabular}{|c|c|c|c|c|c|c|c|}
\hline EXDir & ExLeV & $\# 1,(X, F)$ & $\# 2,(Y, F)$ & $\# 3,(Z, F)$ & $\# 4,(x, V C)$ & $\# 5,(Y, V C)$ & $\# 6,(Z, V C)$ \\
\hline & & mic. RMS & mic. RMS & mlo. RMS & mic. AMS & mic. RMS & mlc. RMS \\
\hline$x$ & 0.6 & 0.0470 & 0.0540 & 0.0149 & 0.00931 & 0.0075 & 0.0065 \\
\hline$x$ & 0.4 & 0.0463 & 0.0471 & 0.0150 & 0.0071 & 0.0072 & 0.0072 \\
\hline$x$ & 0.1 & 0.0476 & 0.0499 & 0.0141 & 0.0075 & 0.0076 & 0.0075 \\
\hline$y$ & 0.6 & 0.0492 & 0.0459 & 0.0131 & 0.0092 & 0.0082 & 0.0072 \\
\hline$y$ & $0.4 !$ & 0.0552 & 0.0501 & 0.0155 & 0.0072 & 0.0084 & 0.0077 \\
\hline$y$ & 0.1 & 0.0509 & 0.0479 & 0.0143 & 0.0073 & 0.0083 & 0.0074 \\
\hline$z$ & 0.6 & 0.0517 & 0.0467 & 0.0155 & 0.0083 & 0.0087 & 0.0076 \\
\hline$z$ & 0.4 & 0.0842 & 0.0696 & 0.0205 & 0.0083 & 0.0077 & 0.0085 \\
\hline \multirow[t]{3}{*}{$z$} & 0.1 & 0.0516 & 0.0508 & 0.0149 & 0.0076 & 0.0070 & 0.0065 \\
\hline & & & & & & & \\
\hline & & $T F, x$ & $T F, y$ & $T F, z$ & & & \\
\hline$x$ & 0.6 & 0.20 & 0.14 & 0.43 & & & \\
\hline$x$ & 0.4 & 0.15 & 0.15 & 0.48 & & & \\
\hline$x$ & 0.1 & 0.16 & 0.15 & 0.53 & & & \\
\hline$y$ & 0.6 & 0.19 & 0.18 & 0.55 & & & \\
\hline$y$ & 0.4 & 0.13 & 0.17 & 0.50 & & & \\
\hline$y$ & 0.1 & 0.14 & 0.17 & 0.52 & & & \\
\hline$z$ & 0.6 & 0.16 & 0.19 & 0.49 & & & \\
\hline$z$ & 0.4 & 0.10 & 0.11 & 0.41 & & & \\
\hline \multirow[t]{3}{*}{$z$} & 0.1 & 0.15 & 0.14 & 0.43 & & & \\
\hline & & & & & & & \\
\hline & $A \vee G$ & 0.15 & 0.16 & 0.48 & & & \\
\hline
\end{tabular}


RMS, TF, Test $4,9.5 \mathrm{~Hz}$

\begin{tabular}{|c|c|c|c|c|c|c|c|}
\hline EXDir & ExLev & $\# 1,(X, F)$ & $\# 2,(Y, F)$ & $\# 3,(Z, F)$ & $\# 4,(X, V C)$ & $\# 5,(Y, V C)$ & $\# 6,(Z, V C)$ \\
\hline & & mic. RMS & mic. RMS & mic. RMS & mic. RMS & mic. RMS & mic. RMS \\
\hline$x$ & $0.6 !$ & 0.0248 & 0.1099 & 0.0192 & 0.0060 & 0.0059 & 0.0047 \\
\hline$x$ & 0.4 & 0.0225 & 0.0930 & 0.01761 & 0.0051 & 0.0061 & 0.0039 \\
\hline$x$ & 0.1 & 0.0284 & 0.1067 & 0.0146 & 0.0048 & 0.0062 & 0.0037 \\
\hline$y$ & 0.6 & 0.0315 & 0.0780 & 0.0181 & 0.0055 & 0.0049 & 0.0042 \\
\hline$y$ & 0.4 & 0.0278 & 0.0979 & 0.0194 & 0.0070 & 0.0070 & 0.0047 \\
\hline$y$ & 0.1 & 0.0488 & 0.1052 & 0.02001 & 0.0045 & 0.0055 & 0.0070 \\
\hline$z$ & 0.6 & 0.0913 & 0.1089 & 0.0174 & 0.0050 & 0.0060 & 0.0055 \\
\hline$z$ & 0.4 & 0.0682 & 0.2419 & 0.0306 & 0.0061 & 0.0050 & 0.0077 \\
\hline \multirow[t]{3}{*}{$z$} & 0.1 & 0.0356 & 0.1159 & 0.0241 & 0.0048 & 0.0051 & 0.0054 \\
\hline & & & & & & & \\
\hline & & $T F, x$ & $T F, y$ & $T F, z$ & & & \\
\hline$x$ & 0.61 & 0.24 & 0.05 & 0.24 & & & \\
\hline$x$ & 0.4 & 0.231 & 0.07 & 0.22 & & & \\
\hline$x$ & 0.1 & 0.17 & 0.06 & 0.261 & & & \\
\hline$y$ & 0.61 & 0.17 & 0.06 & $0.23 !$ & & & \\
\hline$y$ & 0.4 & 0.25 & 0.07 & 0.24 & & & \\
\hline$y$ & 0.1 & 0.09 & 0.05 & 0.35 & & & \\
\hline$z$ & 0.6 & 0.05 & 0.06 & 0.32 & & & \\
\hline$z$ & 0.4 & 0.09 & 0.02 & 0.25 & & & \\
\hline$z$ & 0.1 & 0.13 & 0.04 & 0.22 & & & \\
\hline & & & & & & & \\
\hline & AVG & 0.16 & 0.05 & 0.261 & & & \\
\hline
\end{tabular}


RMS, TF, Test4, $12.9 \mathrm{~Hz}$

\begin{tabular}{|l|r|r|r|r|r|r|r|r|}
\hline EXDir & ExLeV & $\# 1,(X, F)$ & $\# 2,(Y, F)$ & $\# 3,(Z, F)$ & $\# 4,(X, V C)$ & $\# 5,(Y, V C)$ & $\# 6,(Z, V C)$ \\
\hline & & mic. RMS & mic. RMS & mic. RMS & mic. RMS & mic. RMS & mic. RMS \\
\hline$x$ & 0.6 & 0.0453 & 0.0090 & 0.0070 & 0.0047 & 0.0048 & 0.0067 \\
\hline$x$ & 0.4 & 0.0352 & 0.0076 & 0.0065 & 0.0048 & 0.0044 & 0.0054 \\
\hline$x$ & 0.1 & 0.0538 & 0.0096 & 0.0056 & 0.0047 & 0.0049 & 0.0049 \\
\hline$y$ & 0.6 & 0.0399 & 0.0071 & 0.0084 & 0.0047 & 0.0040 & 0.0071 \\
\hline$y$ & 0.4 & 0.0495 & 0.0118 & 0.0101 & 0.0048 & 0.0051 & 0.0094 \\
\hline$y$ & 0.1 & 0.0926 & 0.0136 & 0.0154 & 0.0063 & 0.0051 & 0.0168 \\
\hline$z$ & 0.6 & 0.0386 & 0.0077 & 0.0094 & 0.0044 & 0.0056 & 0.0096 \\
\hline$z$ & 0.4 & 0.0875 & 0.0223 & 0.0128 & 0.0073 & 0.0064 & 0.0132 \\
\hline$z$ & 0.1 & 0.0415 & 0.0108 & 0.0089 & 0.0047 & 0.0043 & 0.0090 \\
\hline & & & & & & & & \\
\hline & & $T F, x$ & $T F, y$ & $T F, z$ & & & \\
\hline$x$ & 0.6 & 0.10 & 0.53 & 0.96 & & & \\
\hline$x$ & 0.4 & 0.14 & 0.58 & 0.83 & & & \\
\hline$x$ & 0.1 & 0.09 & 0.51 & 0.86 & & & \\
\hline$y$ & 0.6 & 0.12 & 0.57 & 0.85 & & & \\
\hline$y$ & 0.4 & 0.10 & 0.43 & 0.93 & & & \\
\hline$y$ & 0.1 & 0.07 & 0.38 & 1.09 & & & \\
\hline$z$ & 0.6 & 0.11 & 0.73 & 1.02 & & & \\
\hline$z$ & 0.4 & 0.08 & 0.28 & 1.03 & & & \\
\hline$z$ & 0.1 & 0.11 & 0.40 & 1.01 & & & \\
\hline & & & & & & & & \\
\hline & $A V G$ & 0.10 & 0.49 & 0.95 & & & \\
\hline & & & & & & & & \\
\hline
\end{tabular}


RMS, TF, Test4,15.6 Hz

\begin{tabular}{|l|r|r|r|r|r|r|r|}
\hline EXDir & ExLeV & $\# 1,(X, F)$ & $\# 2,(Y, F)$ & $\# 3,(Z, F)$ & $\# 4,(X, V C)$ & $\# 5,(Y, V C)$ & $\# 6,(Z, V C)$ \\
\hline & & mic. RMS & mic. RMS & mic. RMS & mic. RMS & mic. RMS & mic. RMS \\
\hline$x$ & 0.6 & 0.0210 & 0.0072 & 0.0115 & 0.0048 & 0.0044 & 0.0109 \\
\hline$x$ & 0.4 & 0.0129 & 0.0062 & 0.0100 & 0.0038 & 0.0045 & 0.0090 \\
\hline$x$ & 0.1 & 0.0169 & 0.0075 & 0.0093 & 0.0038 & 0.0043 & 0.0084 \\
\hline$y$ & 0.6 & 0.0120 & 0.0073 & 0.0099 & 0.0040 & 0.0050 & 0.0095 \\
\hline$y$ & 0.4 & 0.0144 & 0.0080 & 0.0110 & 0.0036 & 0.0049 & 0.0102 \\
\hline$y$ & 0.1 & 0.0206 & 0.0091 & 0.0138 & 0.0044 & 0.0047 & 0.0131 \\
\hline$z$ & 0.6 & 0.0119 & 0.0065 & 0.0158 & 0.0037 & 0.0053 & 0.0151 \\
\hline$z$ & 0.4 & 0.0528 & 0.0099 & 0.0230 & 0.0094 & 0.0066 & 0.0170 \\
\hline$z$ & 0.1 & 0.0170 & 0.0070 & 0.0107 & 0.0044 & 0.0044 & 0.0095 \\
\hline & & & & & & & \\
\hline & & $T F, x$ & $T F, y$ & $T F, z$ & & & \\
\hline$x$ & 0.6 & 0.23 & 0.61 & 0.94 & & & \\
\hline$x$ & 0.4 & 0.29 & 0.72 & 0.90 & & & \\
\hline$x$ & 0.1 & 0.22 & 0.58 & 0.90 & & & \\
\hline$y$ & 0.6 & 0.33 & 0.69 & 0.96 & & & \\
\hline$y$ & 0.4 & 0.25 & 0.61 & 0.92 & & & \\
\hline$y$ & 0.1 & 0.21 & 0.51 & 0.94 & & & \\
\hline$z$ & 0.6 & 0.32 & 0.81 & 0.95 & & & \\
\hline$z$ & 0.4 & 0.18 & 0.66 & 0.74 & & & \\
\hline$z$ & 0.1 & 0.26 & 0.63 & 0.89 & & & \\
\hline & & & & & & & \\
\hline & AVG & 0.25 & 0.65 & 0.91 & & & \\
\hline
\end{tabular}


RMS, TF, Tes $\$ 4,29.3 \mathrm{~Hz}$

\begin{tabular}{|c|c|c|c|c|c|c|c|}
\hline EXDir & ExLev & $\# 1,(X, F)$ & $\# 2,(Y, F)$ & $\# 3,(Z, F)$ & $\# 4,(x, V C)$ & $\# 5,(Y, V C)$ & $\# 6,(Z, \vee C)$ \\
\hline & & mic. RMS & mic. RMS & mic. RMS & mic. RMS & mic. RMS & mic. RMS \\
\hline$x$ & 0.6 & 0.0036 & 0.0044 & 0.0126 & 0.0027 & 0.0015 & 0.0054 \\
\hline$x$ & 0.4 & 0.0029 & 0.0037 & 0.01061 & 0.0026 & 0.0014 & 0.0041 \\
\hline$x$ & 0.1 & 0.0028 & 0.0036 & 0.0098 & 0.0024 & 0.0015 & 0.0039 \\
\hline$y$ & 0.6 & 0.0035 & 0.0049 & 0.0133 & 0.0027 & 0.0019 & 0.0054 \\
\hline$y$ & 0.4 & 0.0031 & 0.0039 & 0.0117 & 0.0028 & 0.0016 & 0.0044 \\
\hline$y$ & 0.1 & 0.0030 & 0.0043 & 0.0106 & 0.0026 & 0.0018 & 0.0043 \\
\hline$z$ & 0.6 & 0.0027 & 0.0035 & 0.01101 & 0.0024 & 0.0019 & 0.0048 \\
\hline$z$ & 0.4 & 0.0034 & 0.0054 & 0.01291 & 0.0057 & 0.0025 & 0.0053 \\
\hline \multirow[t]{3}{*}{$z$} & 0.1 & 0.0020 & 0.0025 & 0.00801 & 0.0027 & 0.0014 & 0.0034 \\
\hline & & & & & & & \\
\hline & & $T F, x$ & $T F, y$ & $T F, z$ & & & \\
\hline$x$ & 0.6 & 0.75 & 0.33 & 0.43 & & & \\
\hline$x$ & 0.4 & 0.88 & 0.37 & 0.38 & & & \\
\hline$x$ & 0.1 & 0.85 & 0.41 & 0.39 & & & \\
\hline$y$ & 0.6 & 0.77 & 0.39 & 0.41 & & & \\
\hline$y$ & 0.4 & 0.91 & 0.42 & 0.381 & & & \\
\hline$y$ & 0.1 & 0.89 & 0.43 & 0.41 & & & \\
\hline$z$ & 0.6 & 0.90 & 0.53 & 0.43 & & & \\
\hline$z$ & 0.4 & 1.68 & 0.47 & 0.41 & & & \\
\hline \multirow[t]{3}{*}{$z$} & 0.1 & 1.31 & 0.57 & 0.43 & & & \\
\hline & & & & & & & \\
\hline & $A \vee G$ & 0.99 & 0.44 & 0.41 & & & \\
\hline
\end{tabular}


RMS, TF, Test $4,30.0 \mathrm{~Hz}$

\begin{tabular}{|l|r|r|r|r|r|r|r|r|}
\hline EXDir & ExLeV & $\# 1,(X, F)$ & $\# 2,(Y, F)$ & $\# 3,(Z, F)$ & $\# 4,(X, V C)$ & $\# 5,(Y, V C)$ & $\# 6,(Z, V C)$ \\
\hline & & mic. RMS & mic. RMS & mic. RMS & mic. RMS & mic. RMS & mic. RMS \\
\hline$x$ & 0.6 & 0.0090 & 0.0097 & 0.0245 & 0.0021 & 0.0021 & 0.0079 \\
\hline$x$ & 0.4 & 0.0077 & 0.0091 & 0.0233 & 0.0018 & $0.0020 !$ & 0.0074 \\
\hline$x$ & 0.1 & 0.0074 & 0.0088 & 0.0221 & 0.0018 & 0.0020 & 0.0070 \\
\hline$y$ & 0.6 & 0.0095 & 0.0114 & 0.0284 & 0.0017 & 0.0021 & 0.0095 \\
\hline$y$ & 0.4 & 0.0084 & 0.0098 & 0.0231 & 0.0021 & 0.0021 & 0.0072 \\
\hline$y$ & 0.1 & 0.0071 & 0.0082 & 0.0208 & 0.0018 & 0.0022 & 0.0065 \\
\hline$z$ & 0.6 & 0.0079 & 0.0090 & 0.0241 & 0.0019 & $0.0022 !$ & 0.0075 \\
\hline$z$ & 0.4 & 0.0087 & 0.0112 & 0.0241 & 0.0062 & $0.0032 !$ & 0.0076 \\
\hline$z$ & 0.1 & 0.0081 & 0.0092 & 0.0232 & 0.0020 & $0.0019 !$ & 0.0071 \\
\hline & & & & & & & & \\
\hline & & $T F, x$ & $T F, y$ & $T F, z$ & & & & \\
\hline$x$ & 0.6 & 0.23 & 0.21 & 0.32 & & & \\
\hline$x$ & 0.4 & 0.24 & 0.22 & 0.32 & & & \\
\hline$x$ & 0.1 & 0.24 & 0.23 & 0.32 & & & \\
\hline$y$ & 0.6 & 0.18 & 0.19 & 0.34 & & & \\
\hline$y$ & 0.4 & 0.24 & 0.21 & 0.31 & & & \\
\hline$y$ & 0.1 & 0.25 & 0.27 & 0.31 & & & \\
\hline$z$ & 0.6 & 0.25 & 0.24 & 0.31 & & & \\
\hline$z$ & 0.4 & -- & 0.28 & 0.32 & & & \\
\hline$z$ & 0.1 & 0.25 & 0.21 & 0.31 & & & \\
\hline & & & & & & & & \\
\hline & AVG & 0.24 & 0.23 & 0.32 & & & \\
\hline
\end{tabular}


RMS, TF, Test $4,49.5 \mathrm{~Hz}$

\begin{tabular}{|l|r|r|r|r|r|r|r|}
\hline EXDir & EXLeV & $\# 1,(X, F)$ & $\# 2,(Y, F)$ & $\# 3,(Z, F)$ & $\# 4,(X, V C)$ & $\# 5,(Y, V C)$ & $\# 6,(Z, V C)$ \\
\hline & & mic. RMS & mic. RMS & mic. RMS & mic. RMS & mic. RMS & mlc. RMS \\
\hline$x$ & 0.6 & 0.0013 & 0.0116 & 0.0466 & 0.0024 & 0.0017 & 0.0066 \\
\hline$x$ & 0.4 & 0.0009 & 0.0066 & 0.0254 & 0.0015 & 0.0011 & 0.0034 \\
\hline$x$ & 0.1 & 0.0007 & 0.0014 & 0.0064 & 0.0003 & 0.0003 & 0.0005 \\
\hline$y$ & 0.6 & 0.0005 & 0.0015 & 0.0082 & 0.0003 & 0.0003 & 0.0006 \\
\hline$y$ & 0.4 & 0.0007 & 0.0021 & 0.0122 & 0.0004 & 0.0004 & 0.0009 \\
\hline$y$ & 0.1 & 0.0010 & 0.0019 & 0.0096 & 0.0003 & 0.0003 & 0.0007 \\
\hline$z$ & 0.6 & 0.0021 & 0.0096 & 0.0367 & 0.0011 & 0.0014 & 0.0060 \\
\hline$z$ & 0.4 & 0.0018 & 0.0075 & 0.0308 & 0.0010 & 0.0013 & 0.0040 \\
\hline$z$ & 0.1 & 0.0012 & 0.0025 & 0.0106 & 0.0009 & 0.0009 & 0.0015 \\
\hline & & & & & & & \\
\hline & & $T F, x$ & $T F, y$ & $T F, z$ & & & \\
\hline$x$ & 0.6 & 1.90 & 0.15 & 0.14 & & & \\
\hline$x$ & 0.4 & 1.56 & 0.16 & 0.13 & & & \\
\hline$x$ & 0.1 & 0.47 & 0.23 & 0.08 & & & \\
\hline$y$ & 0.6 & 0.64 & 0.23 & 0.08 & & & \\
\hline$y$ & 0.4 & 0.58 & 0.20 & 0.07 & & & \\
\hline$y$ & 0.1 & 0.30 & 0.18 & 0.08 & & & \\
\hline$z$ & 0.6 & 0.50 & 0.15 & 0.16 & & & \\
\hline$z$ & 0.4 & 0.58 & 0.17 & 0.13 & & & \\
\hline$z$ & 0.1 & 0.72 & 0.34 & 0.14 & & & \\
\hline & & & & & & & \\
\hline & AVG & 0.81 & 0.20 & 0.11 & & & \\
\hline
\end{tabular}


$-60-$

APPENDIX C - Transient Time Histories 

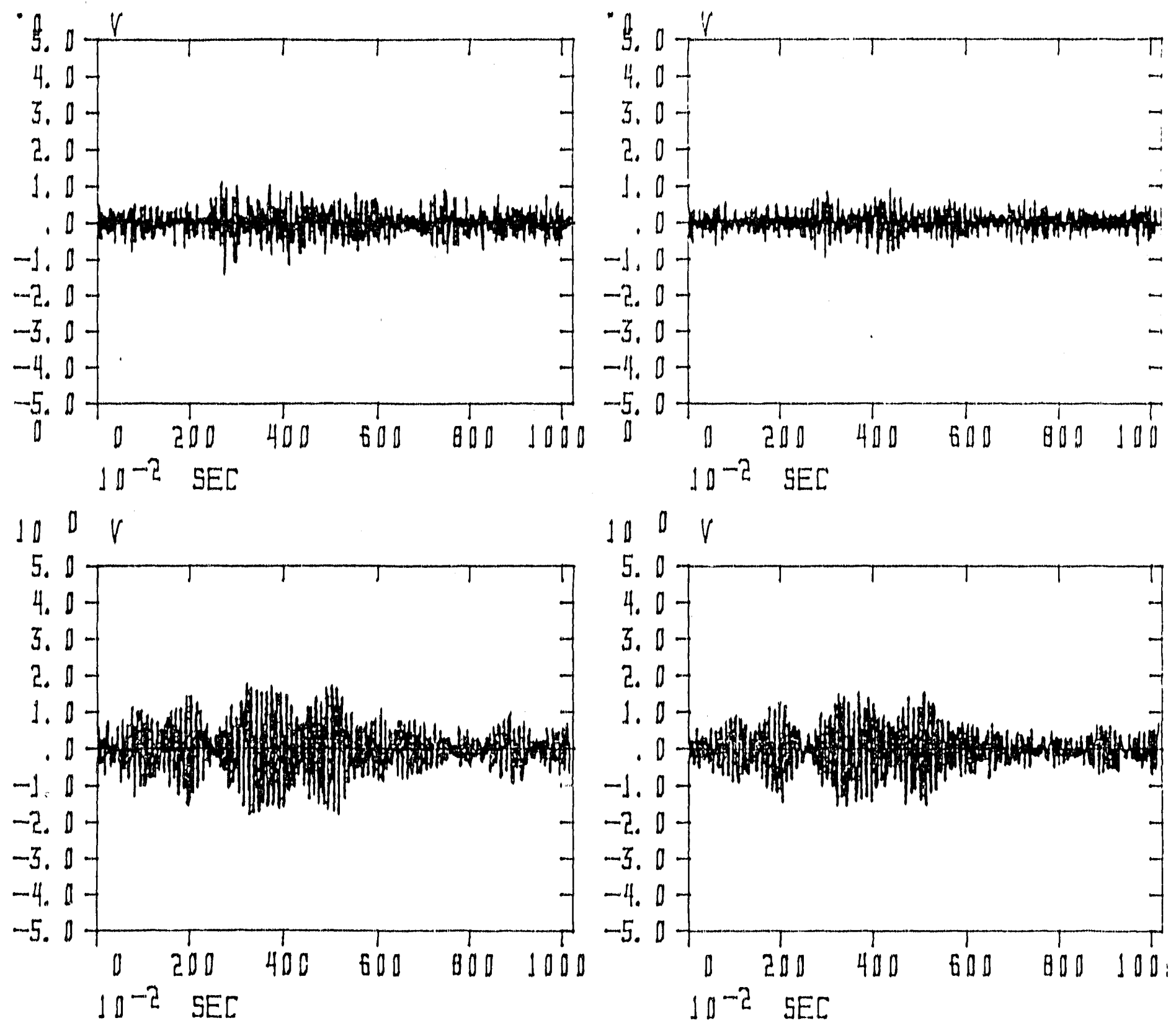

GIRDER

$X$ Measurement Direction

Primary Resp. Freq. $=8.8,9.5,12.9 \mathrm{~Hz}$

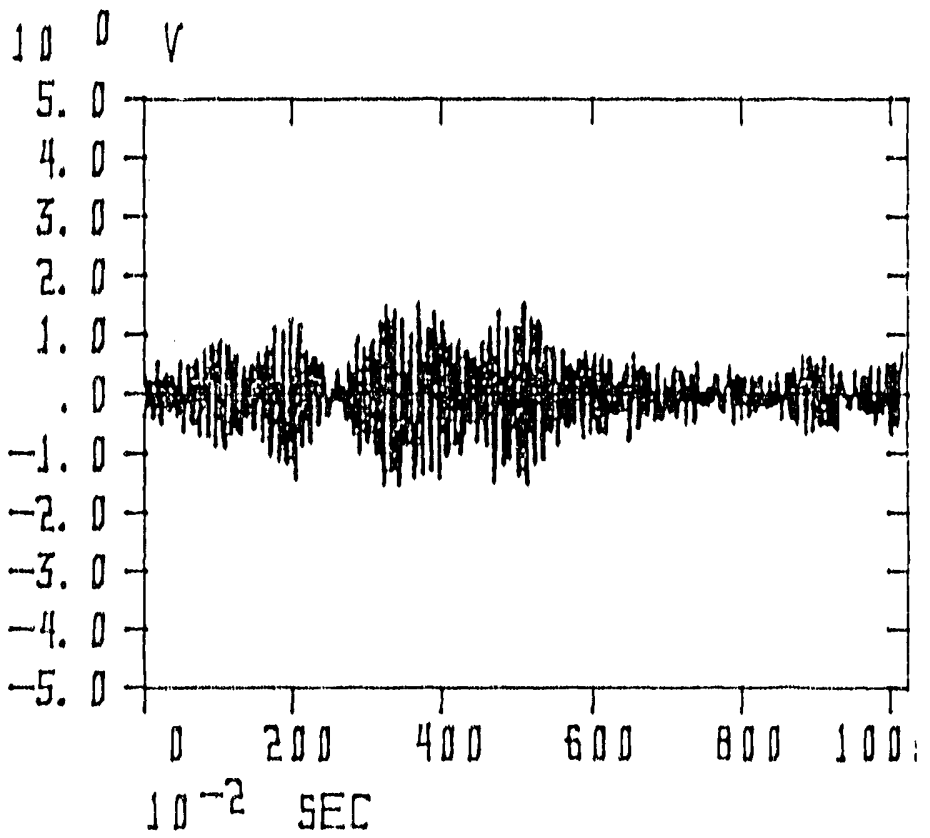

VACUUM CHAMBER

$X$ Measurement Direction

Primary Resp. Freq. $=9.5,12.9 \mathrm{~Hz}$

GIFDER

$Y$ Measurement Direction

VACUUM CHAMBER

Primary Resp Freq. $=9.5 \mathrm{~Hz}$

$Y$ Direction Measurement

Primary Resp. Freq. $=9.5 \mathrm{~Hz}$ 


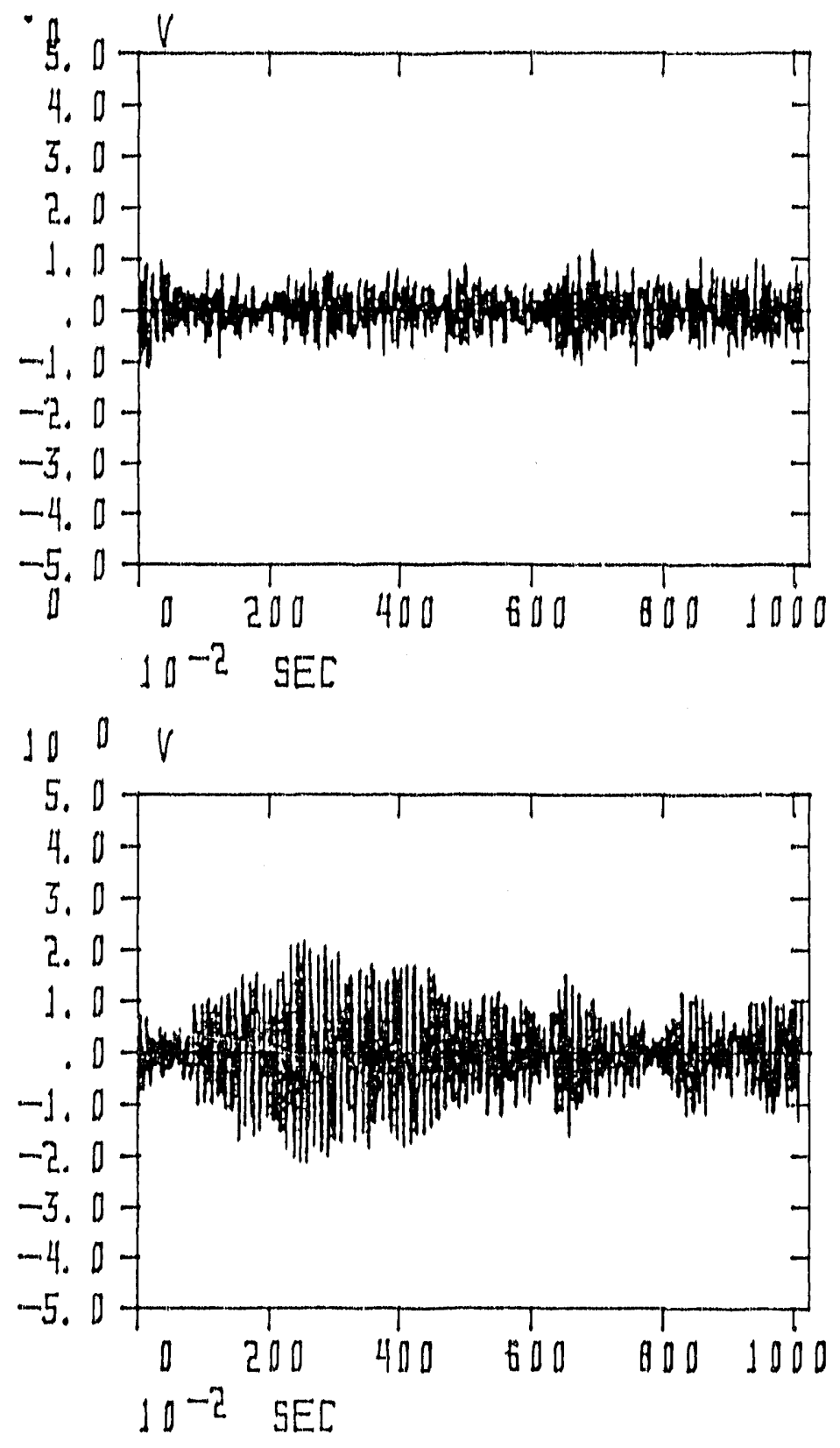

GIRDER

$X$ Measurement Direction

Primary Resp. Freq. $=0.8,23.7 \mathrm{~Hz}$

GIRDEA

Y Measurement Direction

Primary Resp Freq. $=9.5 \mathrm{~Hz}$
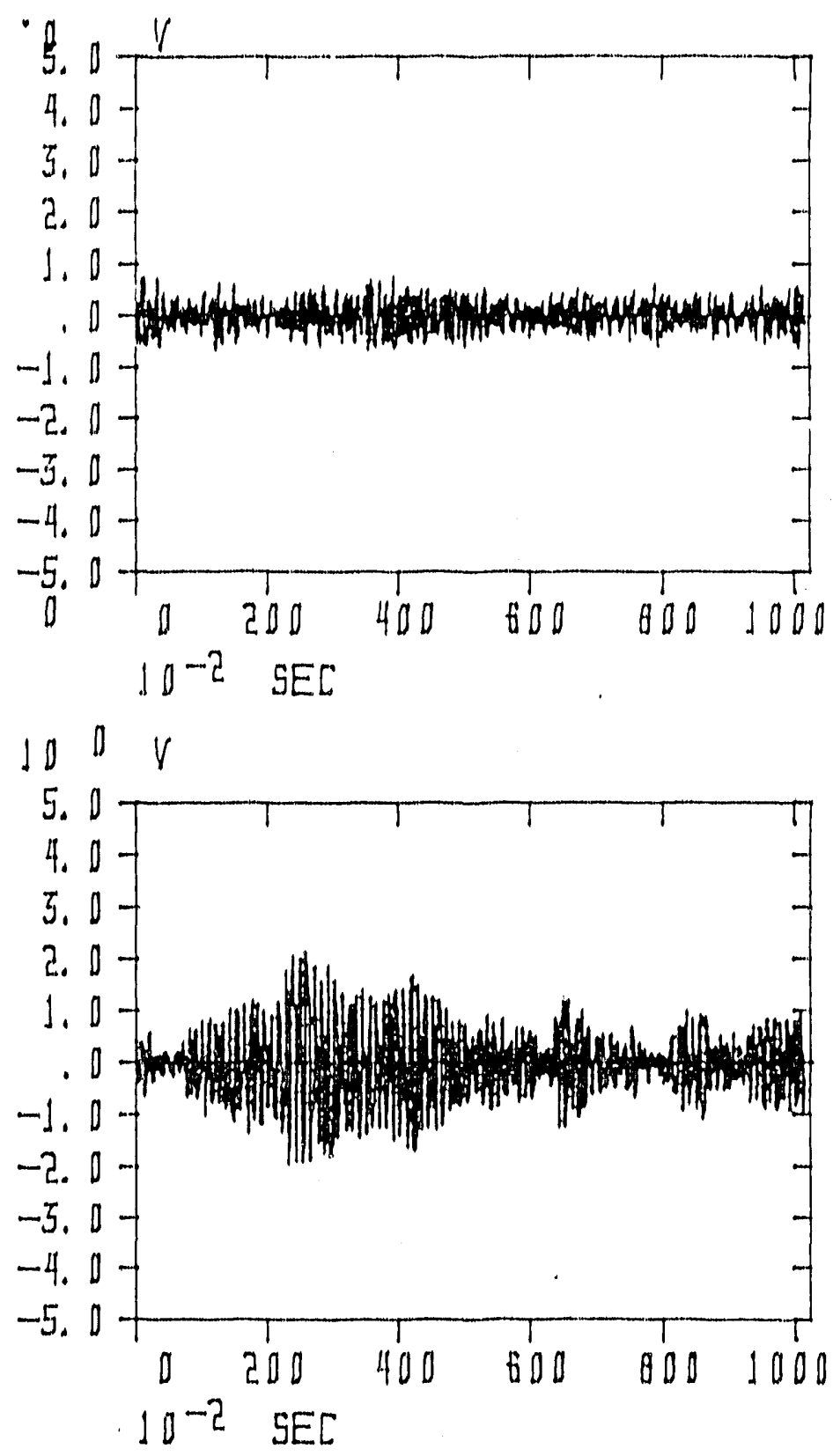

VACUUM CHAMGER

$X$ Measurement Direction

Primary Resp. Freq. $=8.8,9.5 \mathrm{~Hz}$

VACUUM CHAMBER

$Y$ Direction Measurement

Primary Resp. Freq. $=9.5 \mathrm{~Hz}$ 

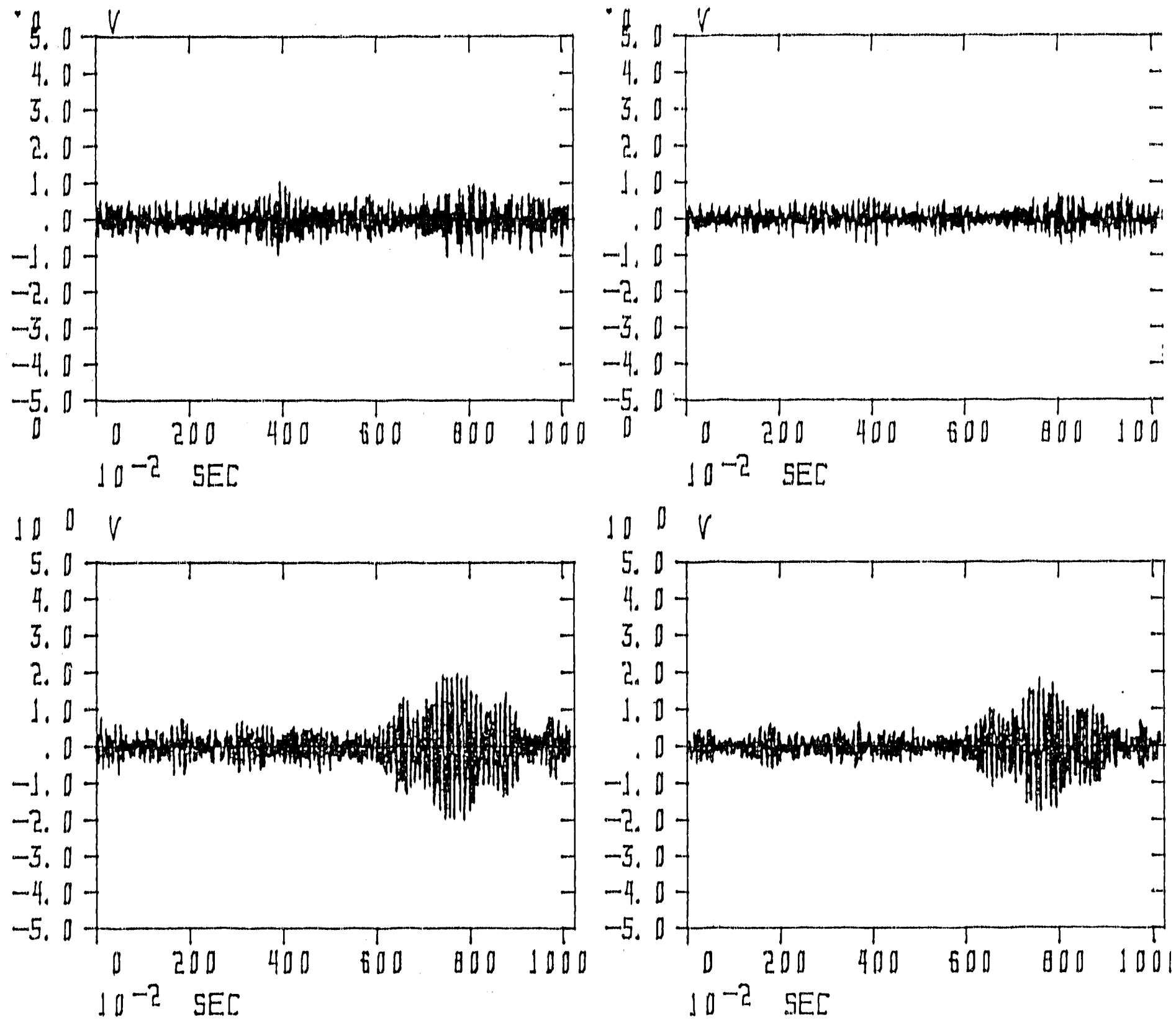

GIRDER

$X$ Measurement Direction

Primary Resp. Freq. $=8.8,12.9 \mathrm{~Hz}$

GIRDEA

$Y$ Measurement Direction

Primary Resp Freq. $=9.5 \mathrm{~Hz}$
VACUUM CHAMBEA

$X$ Measurement Direction

Prlmary Resp. Freq. $=8.8,9.5 \mathrm{~Hz}$

VACUUM CHAMBER

$Y$ Direction Measurement

Primary Resp. Freq. $=9.5 \mathrm{~Hz}$ 

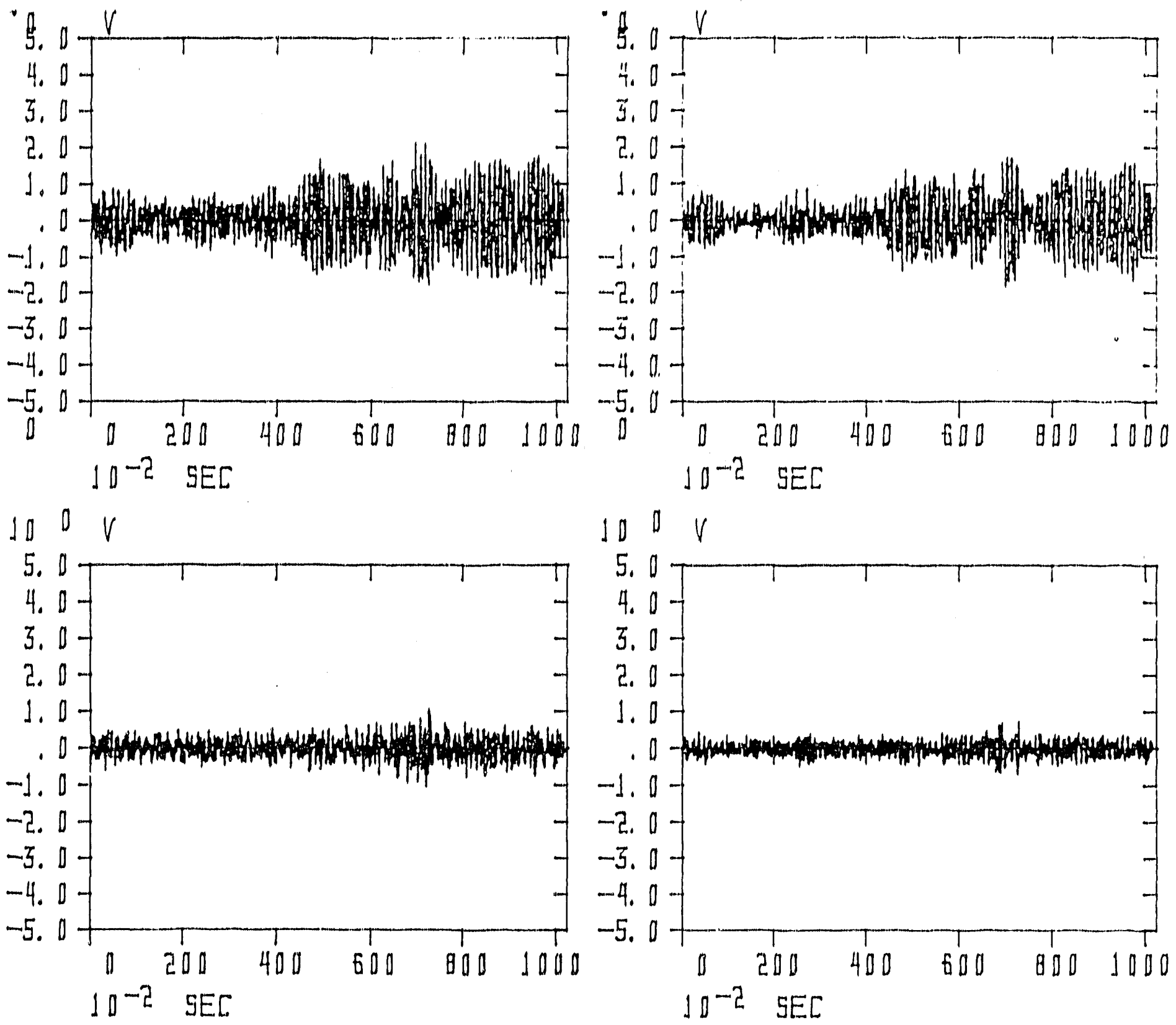

GIRDER

VACUUM CHAMBER

$Y$ Measurement Direction

$Y$ Measurement Direction

Primary Resp. Freq. $=9.5 \mathrm{~Hz}$

Primary Resp. Freq. $=9.5 \mathrm{~Hz}$

GIRDER

2 Measurement Dlrection

Primary Resp Freq. $=9.5 \mathrm{~Hz}$
VACUUM CHAMBEA

2 Directlon Measurement

Primary Resp. Freq. $=9.5,115 \mathrm{~Hz}$ 

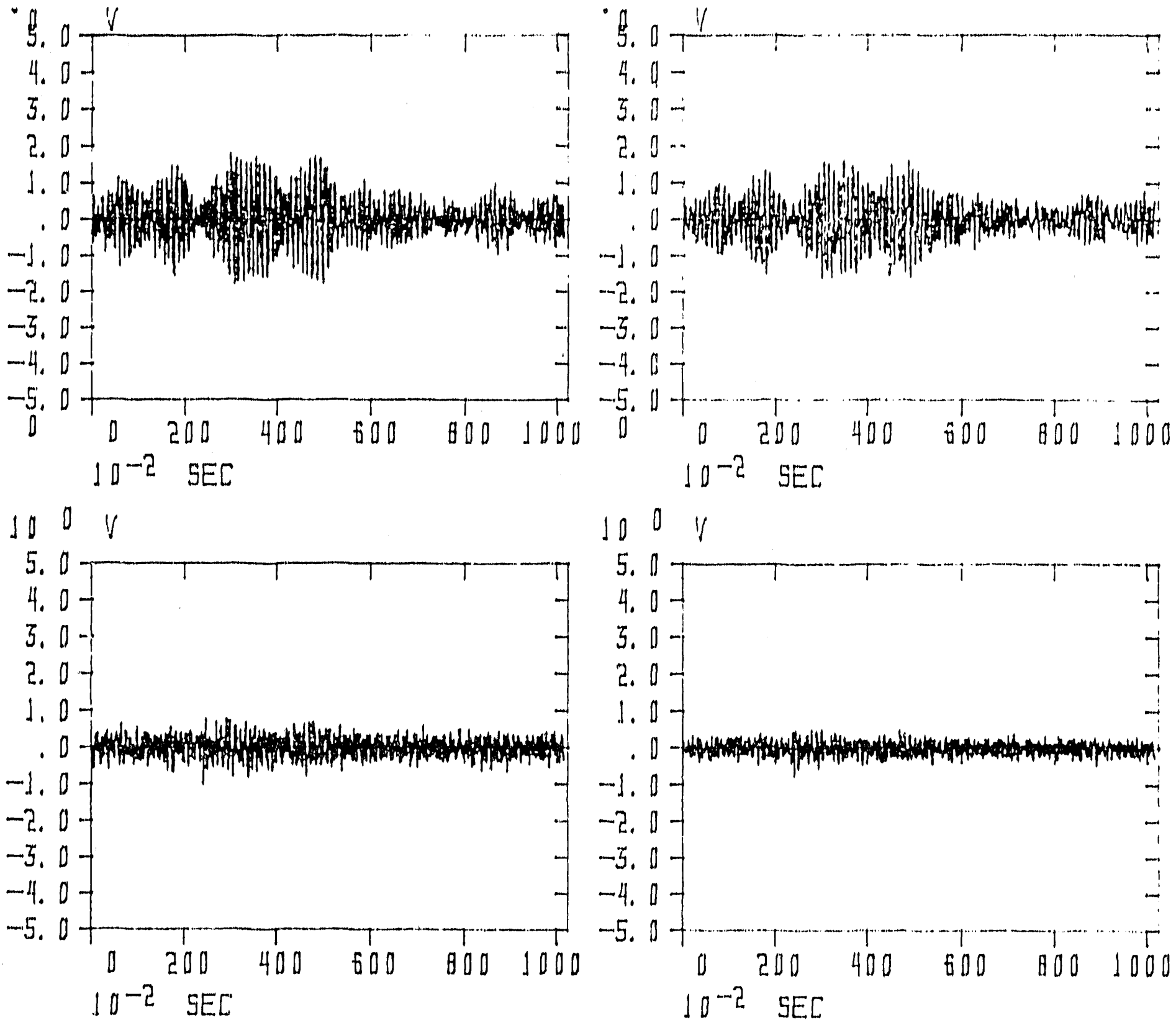

GIRDER

$Y$ Measurement Direction

Prlmary Resp. Freq. $=9.5 \mathrm{~Hz}$
$Z$ Measurement Direction

Primary Resp Freq. $=9.5,30.0 \mathrm{~Hz}$

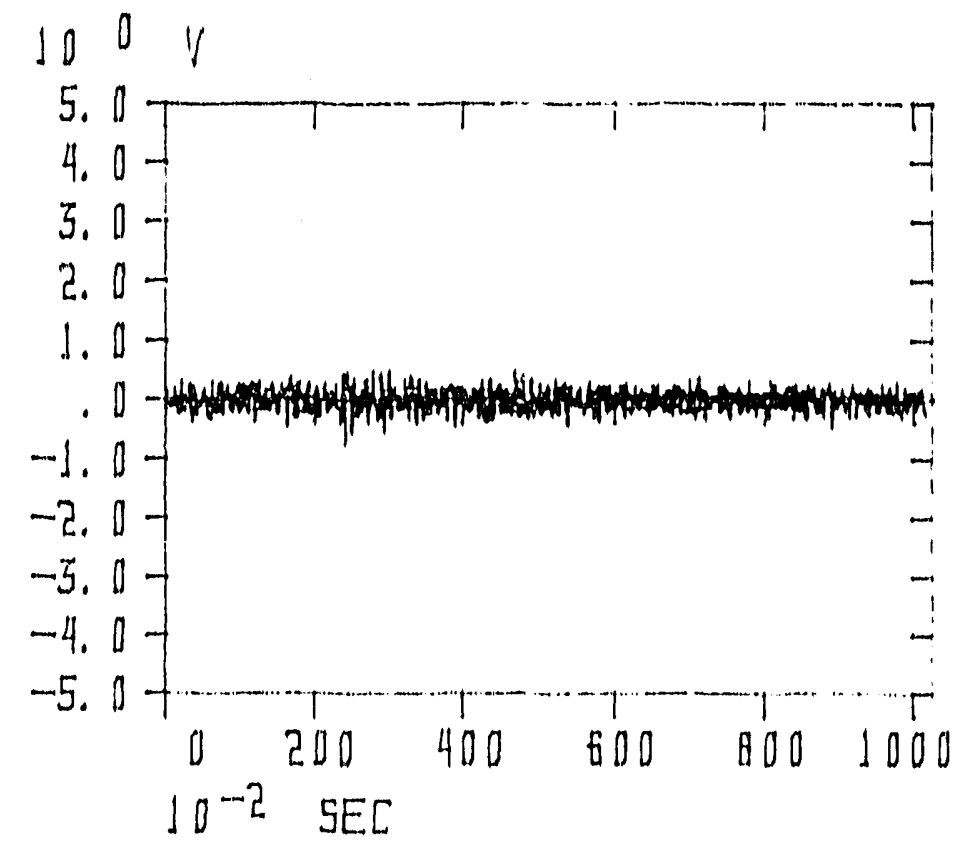

VACUUM CHAMBEA

$Y$ Measurement Directlon

Primary Resp. Freq. $=9.5 \mathrm{~Hz}$

VACUIJM CHAMBER

$Z$ Direction Measurement

Prlmary Resp. Freq. $=9.5,11.5,30.0 \mathrm{~Hz}$
1/23/91,4:30PM Data

0.3125 Microns $=1$ Volt 

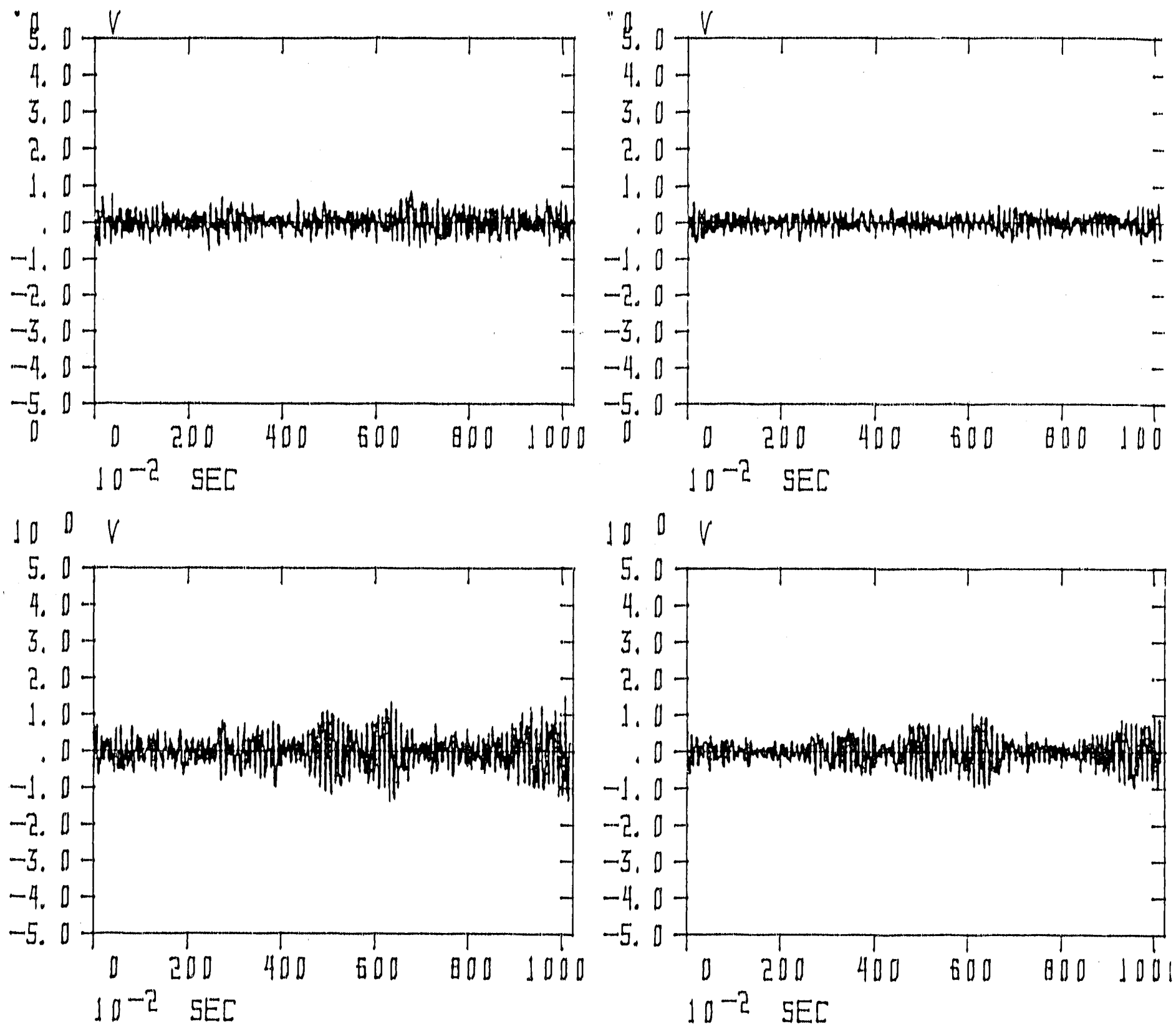

GIRDER

$X$ Measurement Direction

Primary Resp. Freq. $=8.8,12.9,23.7 \mathrm{~Hz}$

GIRDER

$Y$ Measurement Dlrection Primary Resp Freq. $=9.5 \mathrm{~Hz}$
VACUUM CHAMEER

$X$ Measurement Direction

Primary Resp. Freq. $=8.8,9.5 \mathrm{~Hz}$

VACUUM CHAMBER

$Y$ Direction Measurement

Primary Resp. Freq. $=9.5 \mathrm{~Hz}$ 

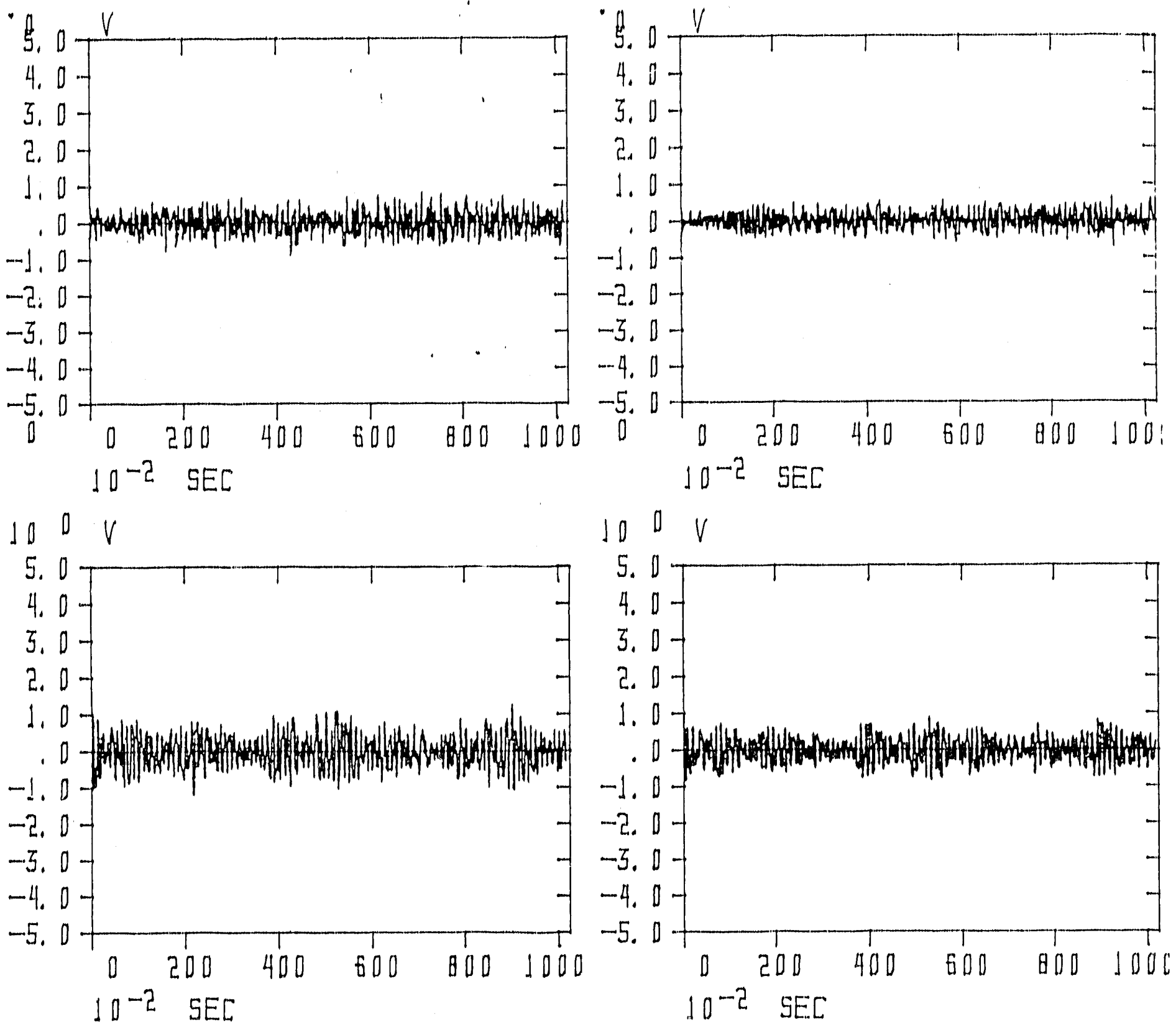

GIFDER

$X$ Measurement Direction

Primary Fesp. Freq. $=8.8,9.5,12.9 \mathrm{~Hz}$

GIRDEA

Y Measurement Directlon

Prlmary Resp Freq. $=9.5 \mathrm{~Hz}$
VACUUM CHAMBER

$X$ Measurement Direction

Primary Resp. Freq. $=8,8,12.9,30.0 \mathrm{~Hz}$

VACUUM CHAMBEA

$Y$ Direction Measurement

Primary Resp. Freq. $=9.5 \mathrm{~Hz}$ 


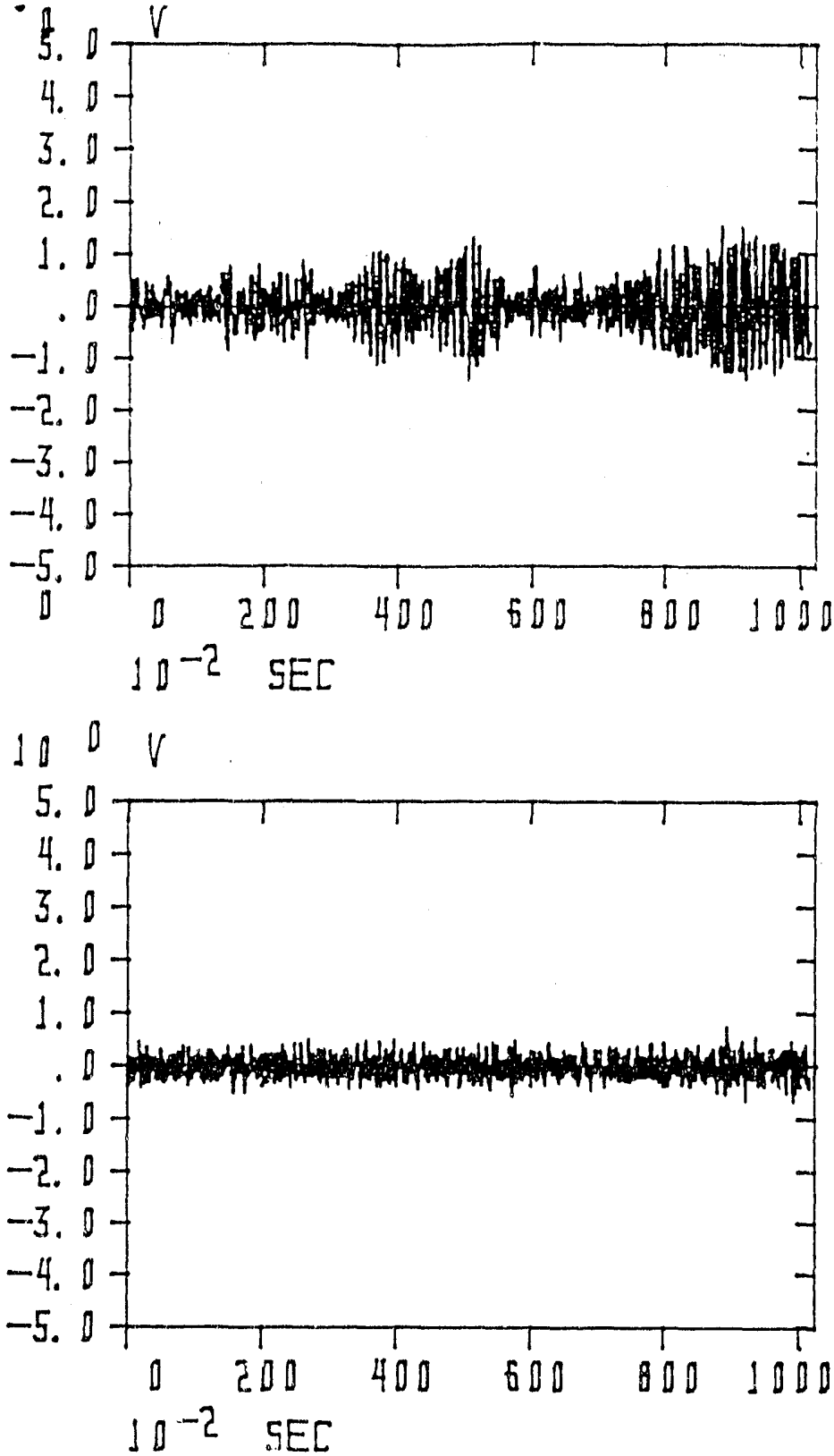

GIRDER

$Y$ Measurement Direction

Primary Resp. Freq. $=9.5 \mathrm{~Hz}$

GIRDER

$Z$ Measurement Direction

Primary Resn Frea.=none
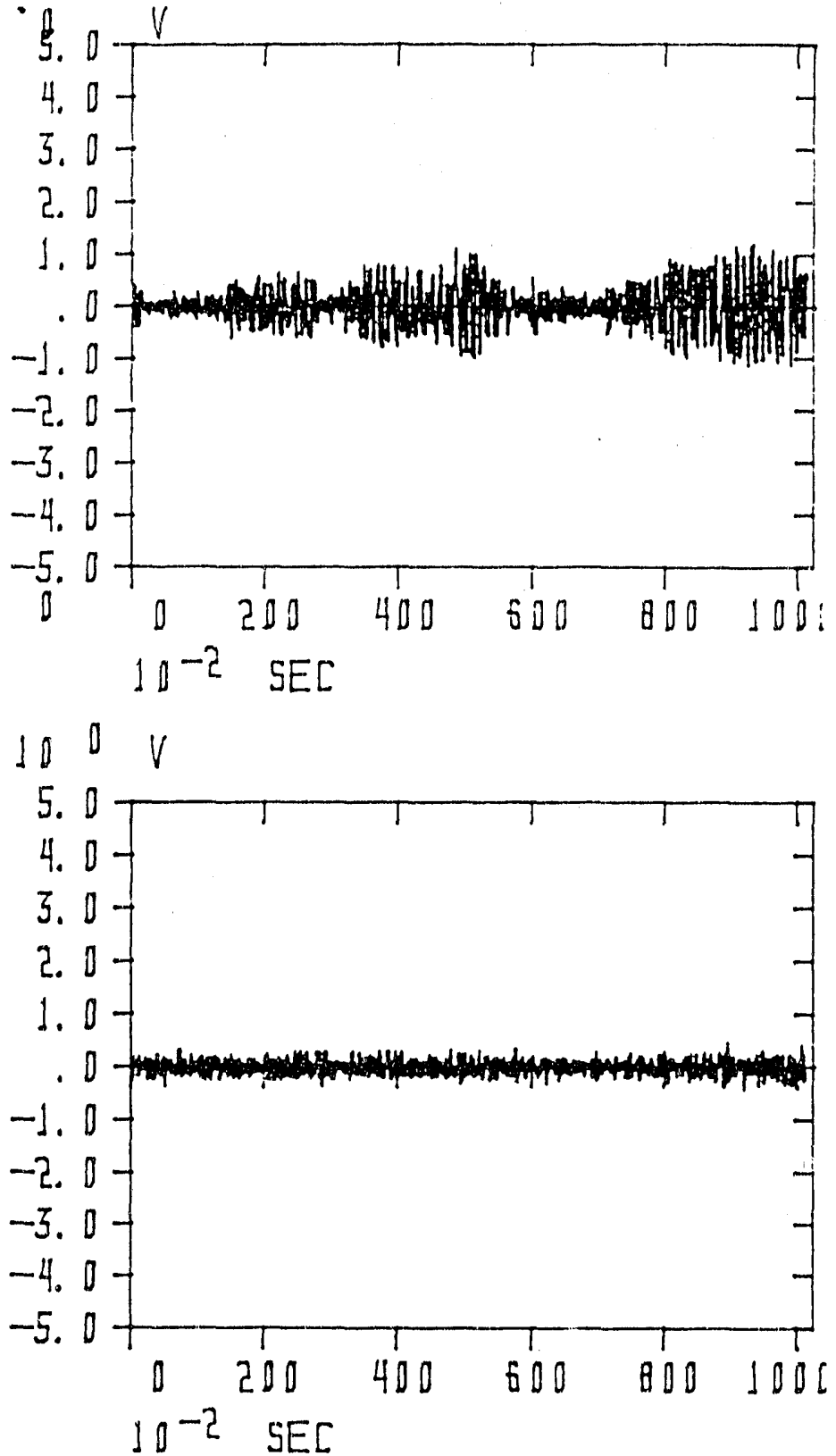

VACUUM CHAMBER

$Y$ Measurement Direction

Primary Resp. Freq. $=9.5 \mathrm{~Hz}$

VACUUM CHAMBER

$Z$ Direction Measurement

Primary Resp. Freq. $=9.5,11.5,19.5 \mathrm{H}$. 


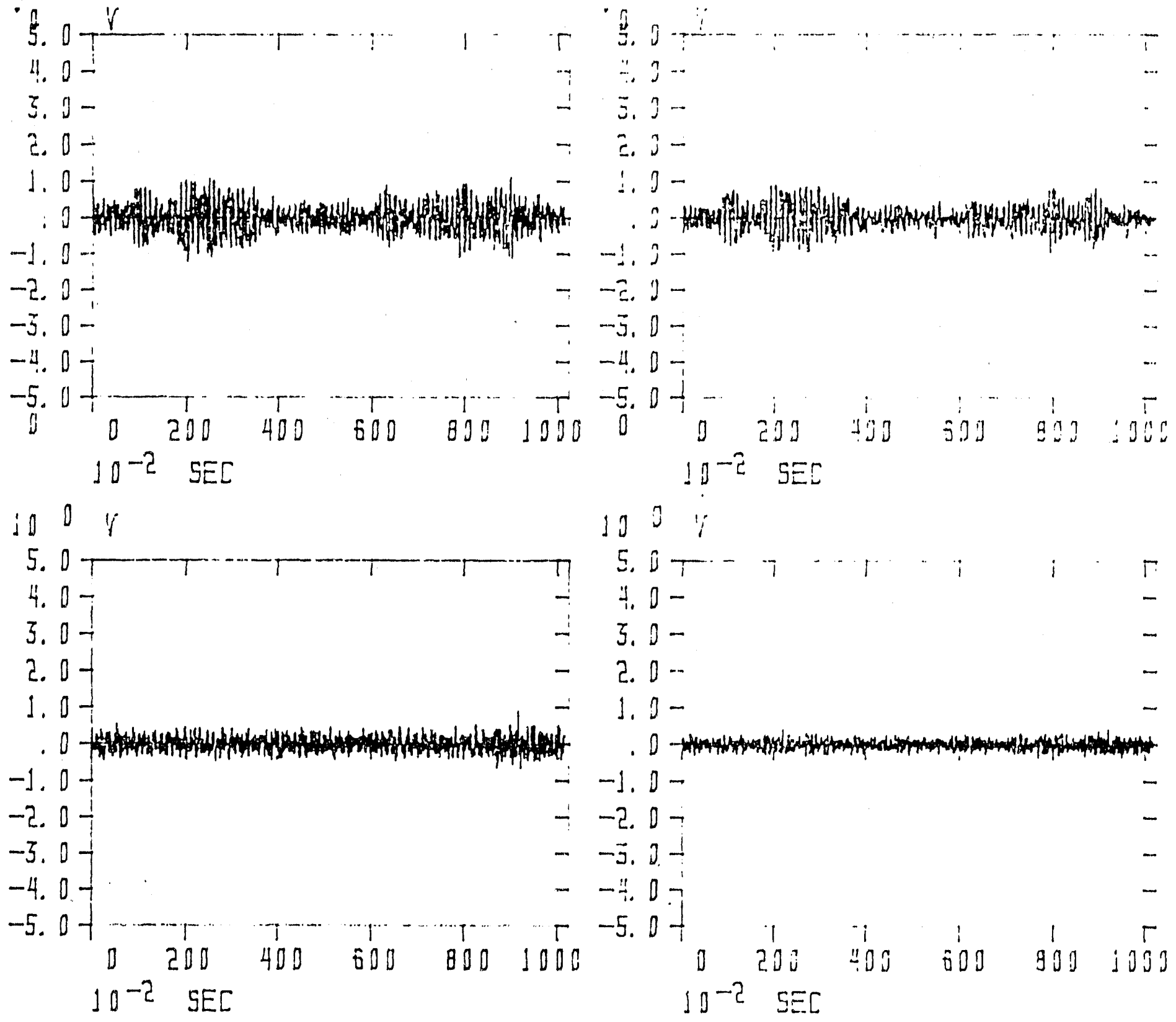

GIRDER

$Y$ Measurement Direction

Primary Resp. Freq. $=9.5 \mathrm{~Hz}$

GIRDER

$Z$ Measurement Direction

Primary Resp Freq.=none
VACUUM CHAMBER

$Y$ Measurement Direction

Primary Resp. Freq. $=9.5 \mathrm{~Hz}$

VACUUM CHAMEER

$Z$ Direction Measurement

Primary Resp. Freq. $=9.5,11.5 \mathrm{~Hz}$ 

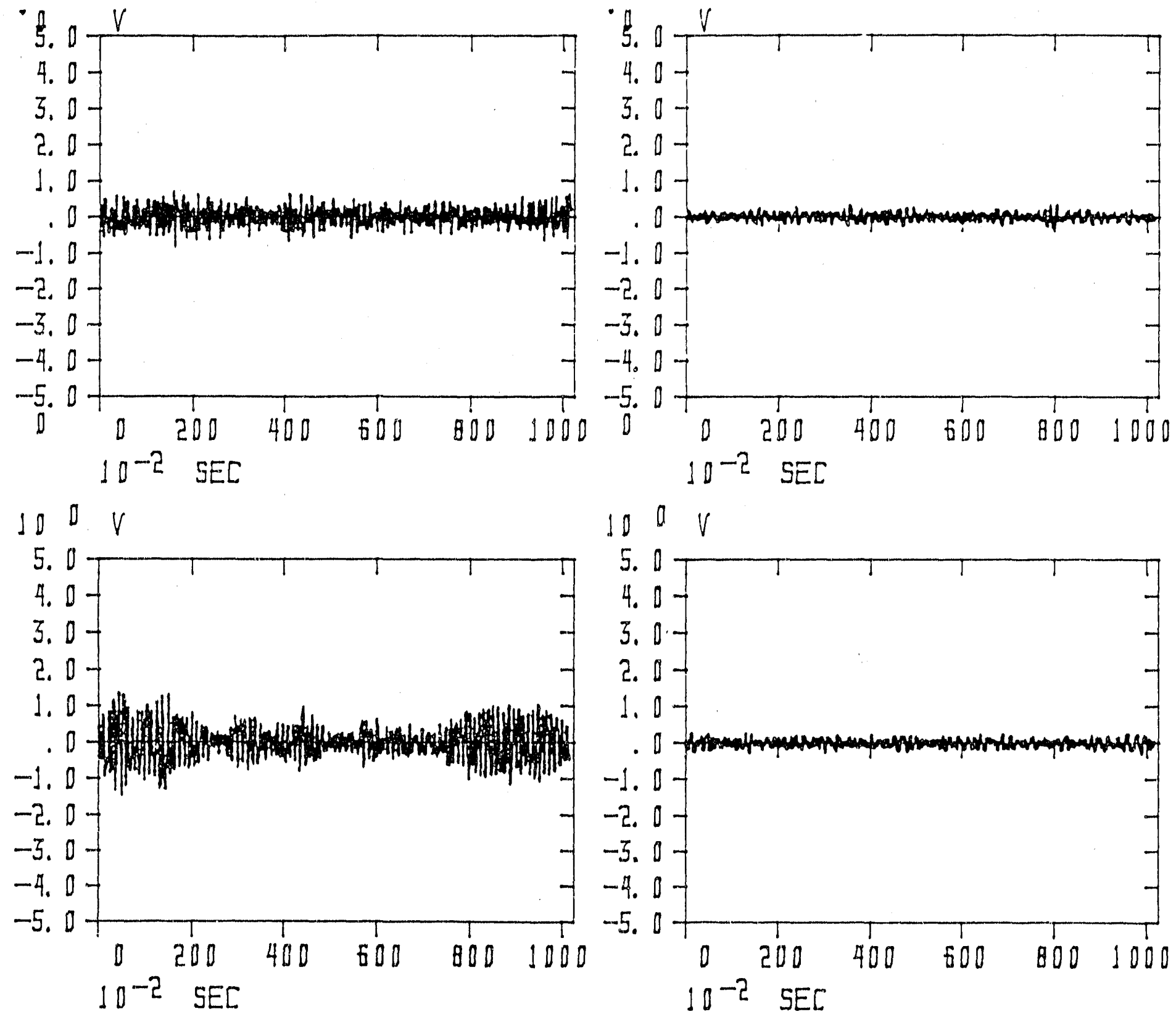

\section{FLOOR}

$X$ Measurement Direction

Primary Resp. Freq. $=8.8,9.5 \mathrm{~Hz}$

FLOOR

$Y$ Measurement Direction

Primary Resp Freq. $=9.5 \mathrm{~Hz}$
VACUUM CHAMBER

$X$ Measurement Direction Primary Resp. Freq. $=8.8 \mathrm{~Hz}$

VACUUM CHAMBER

$Y$ Direction Measurement

Primary Resp. Freq. $=8.8 \mathrm{~Hz}$ 

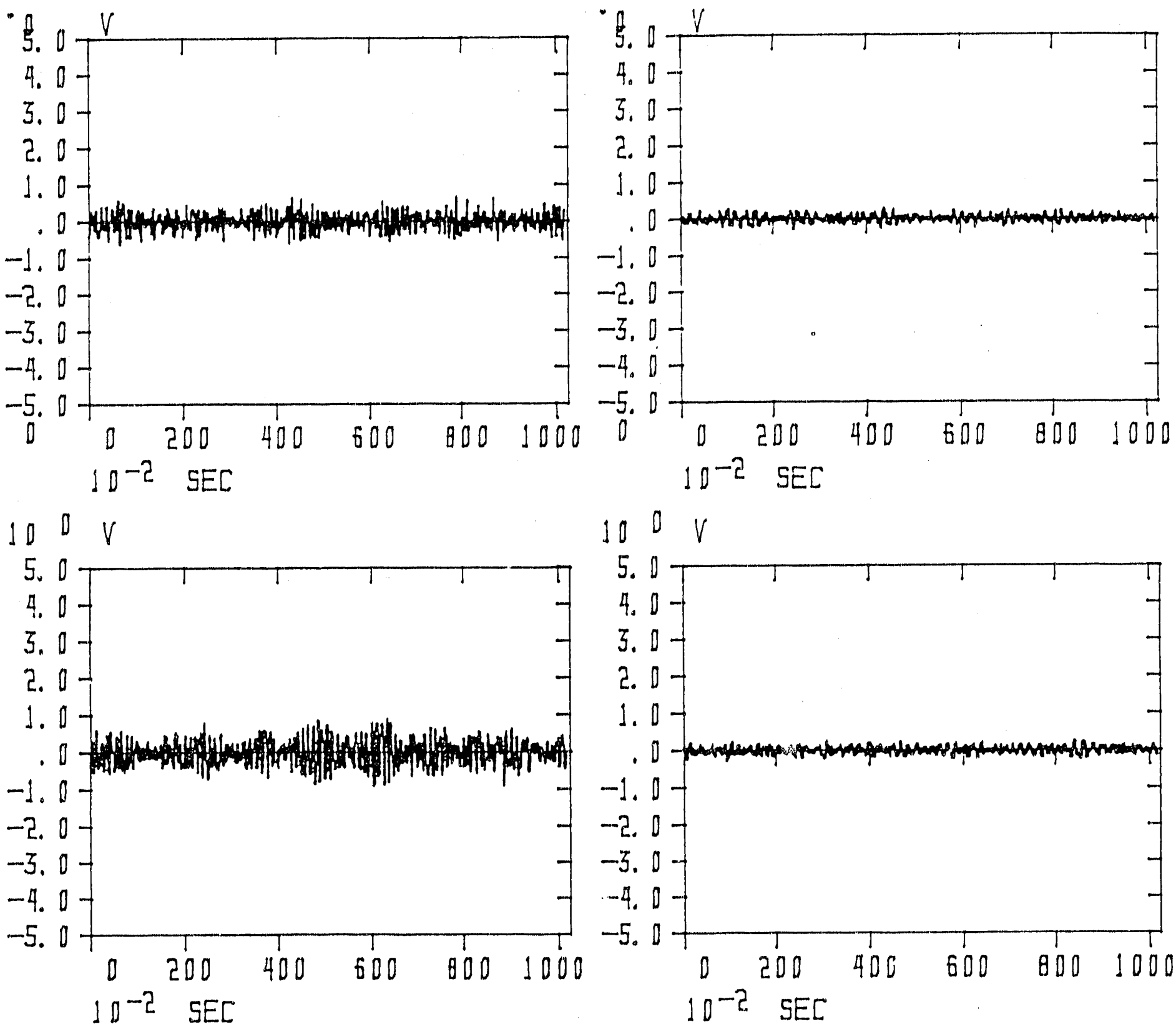

FLOR

$X$ Measurement Direction

Primary Resp. Freq. $=8.8,9.5,12.9 \mathrm{~Hz}$

VACUUM CHAMBER

$X$ Measurement Direction

Primary Resp. Freq. =none

FLOOR

$Y$ Measurement Direction

VACUUM CHAMBER

Primary Resp Freq. $=9.5 \mathrm{~Hz}$

$Y$ Direction Measurement

Primary Resp. Freq.=none 

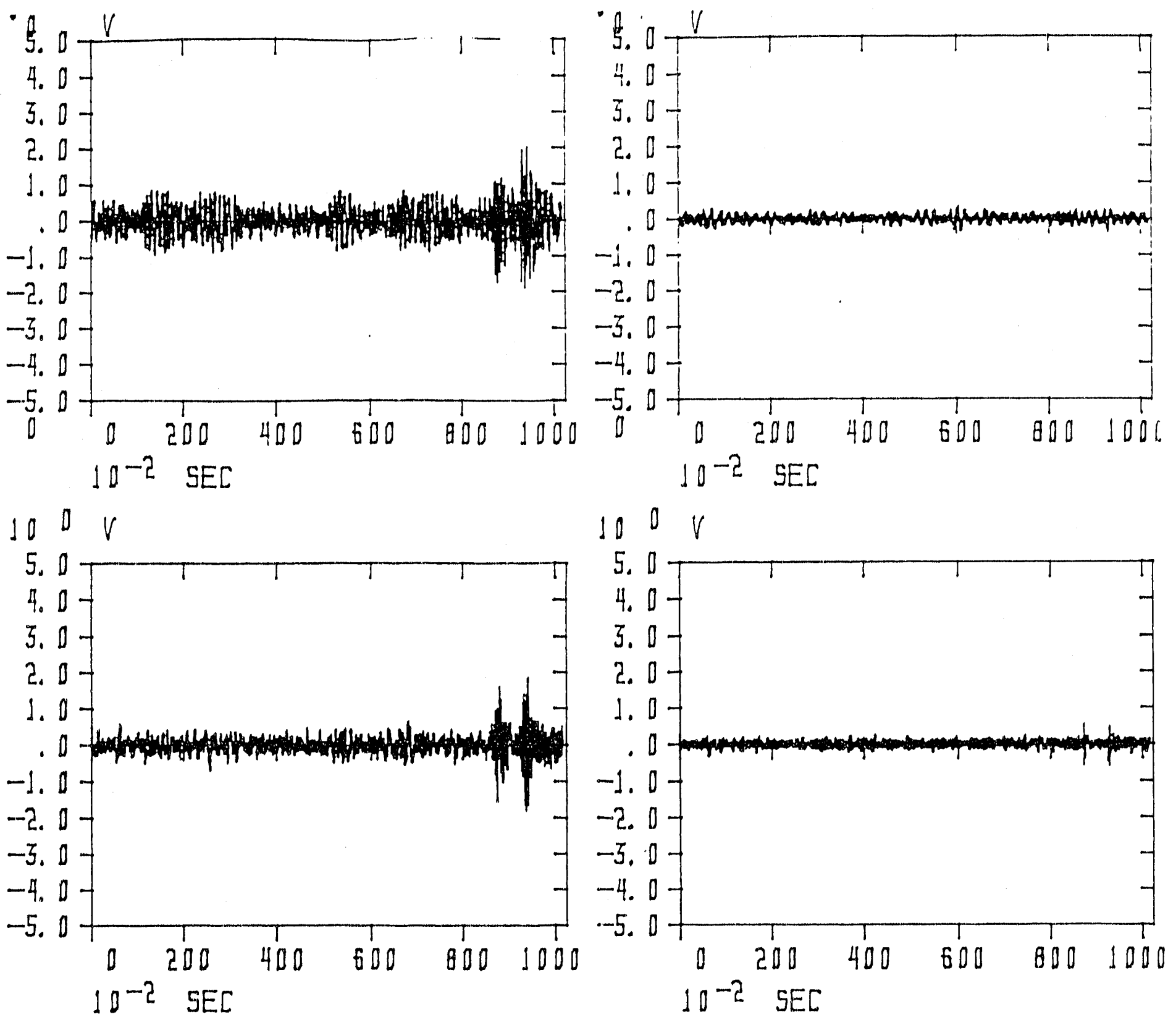

FLOOR

$Y$ Measurement Direction

Primary Resp. Freq. $=9.5 \mathrm{~Hz}$

FLOOR

Z. Measurement Direction

Primary Resp Freq. $=9.5 \mathrm{~Hz}$
VACUUM CHAMBER

$Y$ Measurement Direction

Primary Resp. Freq. $=6.1 \mathrm{~Hz}$

VACUUM CHAMBER

$Z$ Direction Measurement

Primary Resp. Freq. $=11.5 \mathrm{~Hz}$ 

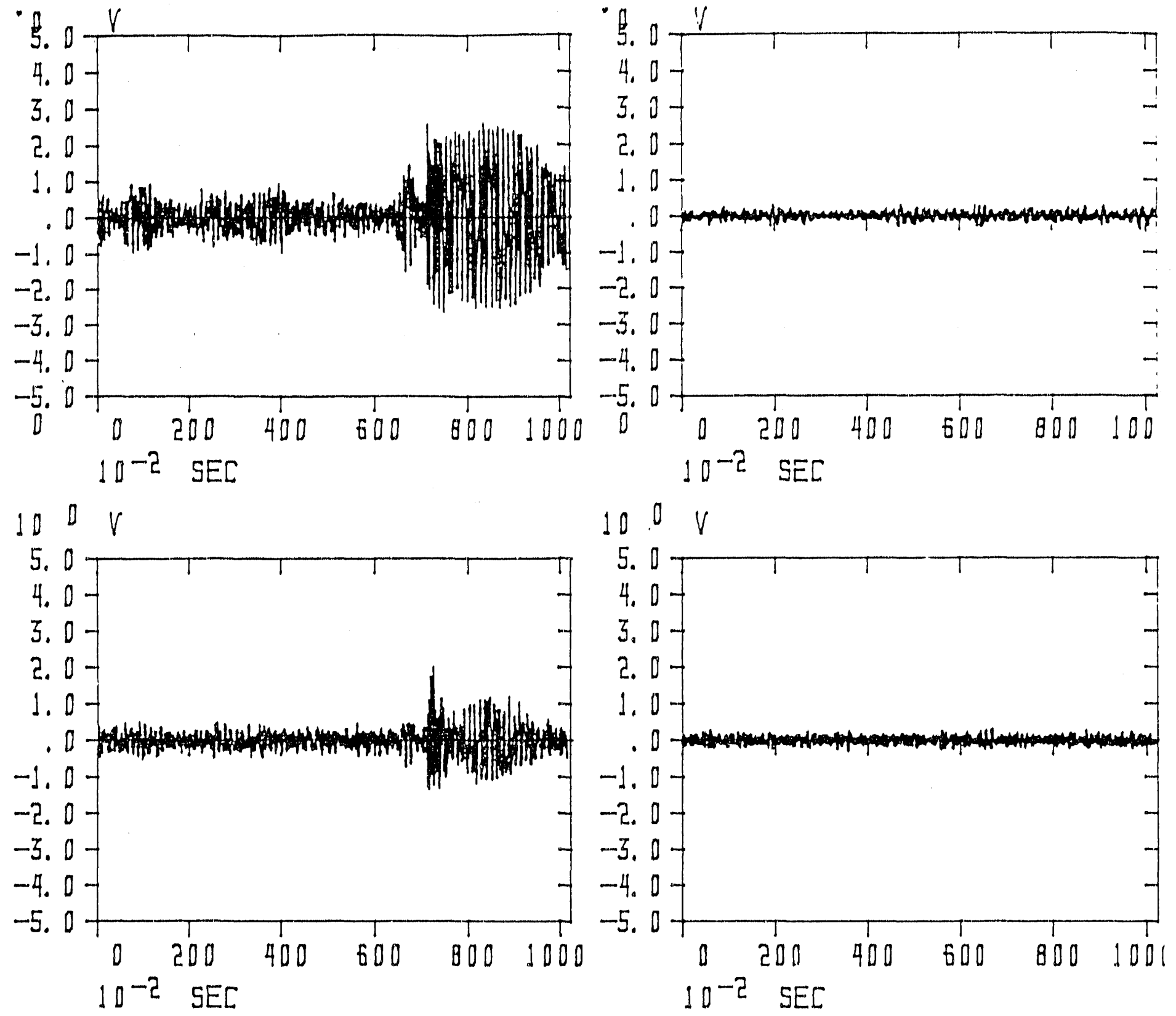

FLOOR

$Y$ Measurement Direction

Primary Resp. Freq. $=9.5 \mathrm{~Hz}$

FLOOR

$Z$ Measurement Direction

Primary Resp Freq. $=9.5 \mathrm{~Hz}$
VACUUM CHAMBER

$Y$ Measurement Direction Primary Resp. Freq.=none

VACUUM CHAMBER

Z Direction Measurement Primary Resp. Freq. $=11.5 \mathrm{~Hz}$ 

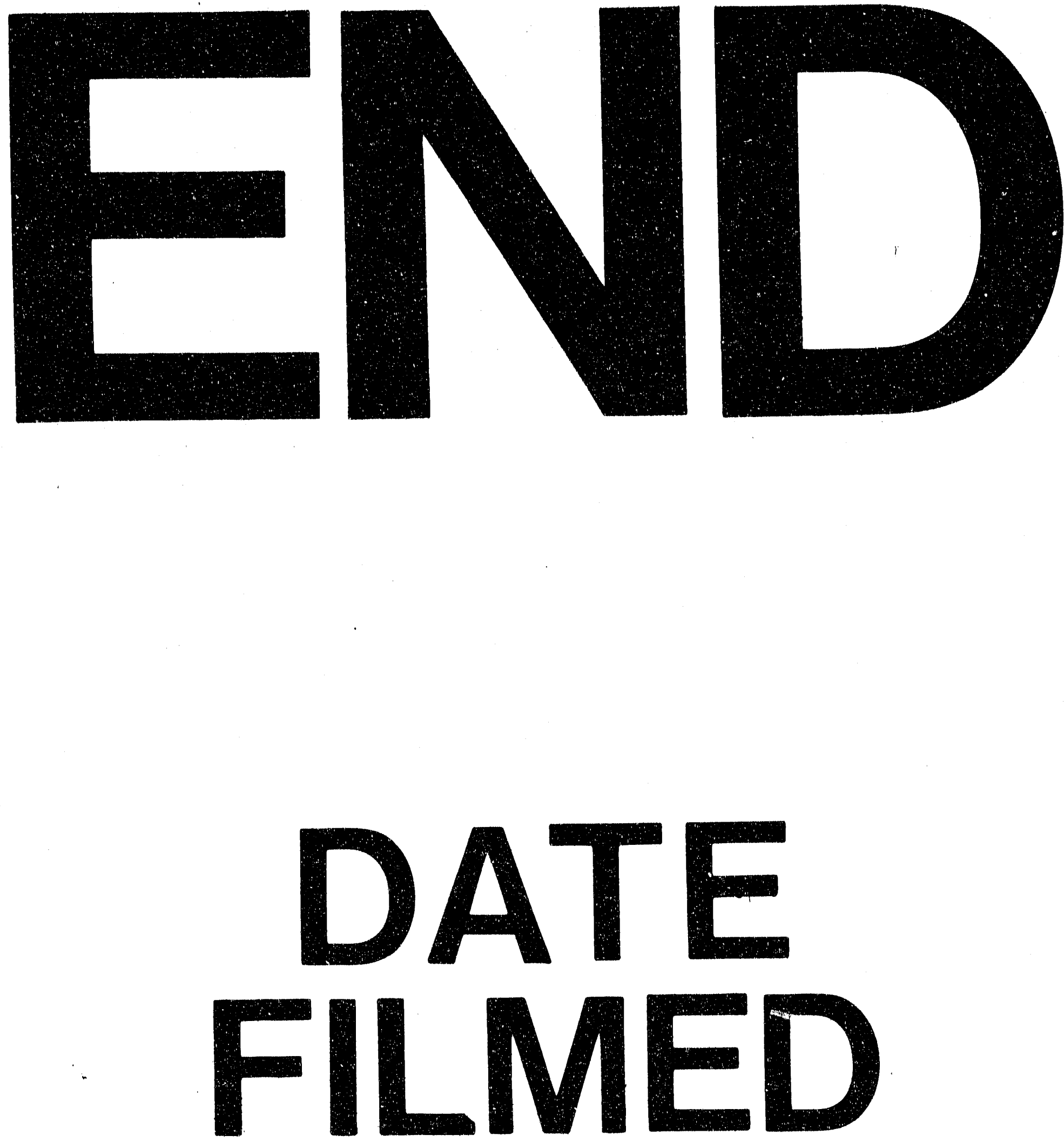

I

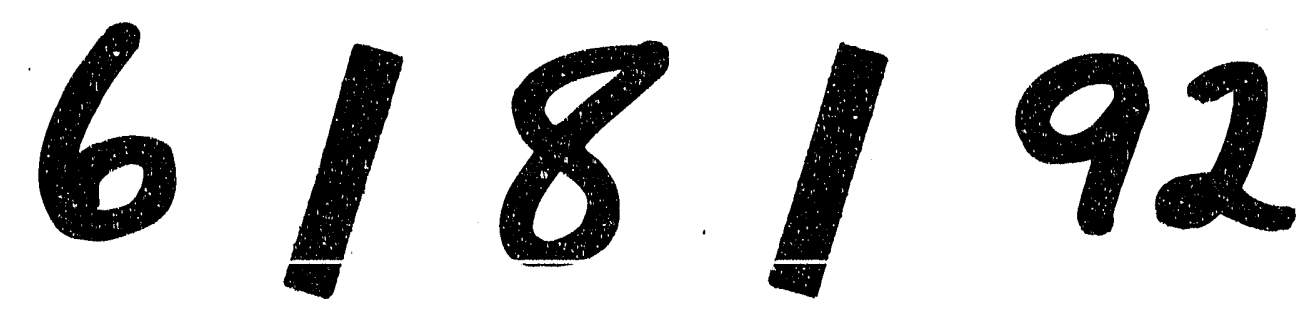


